\author{
UNIVERSIDADE DE SÃO PAULO \\ FACULDADE DE ECONOMIA, ADMINISTRAÇÃO E CONTABILIDADE \\ DEPARTAMENTO DE ADMINISTRAÇÃO \\ PROGRAMA DE PÓS-GRADUAÇÃO EM ADMINISTRAÇÃO
}

\title{
GREEN BONDS E O DESENVOLVIMENTO SUSTENTÁVEL
}

SANDRO TEIXEIRA MARÓSTICA

Orientador

Prof. Dr. Jacques Marcovitch

São Paulo

2019 
UNIVERSIDADE DE SÃo PAULO

Reitor Vahan Agopyan

Vice-reitor Antonio Carlos Hernandes

Pró-reitor de Pós-Graduação Carlos Gilberto Carlotti Júnior

FACUldade de EConomia, Administração e Contabilidade

Diretor Fabio Frezatti

Vice-diretor José Afonso Mazzon

Departamento de Administração

Chefe Moacir de Miranda Oliveira Júnior

Vice-chefe Eduardo Kazuo Kayo

Programa de Pós-Graduação em Administração

Coordenador Eduardo Kazuo Kayo

Vice-coordenador Cesar Alexandre de Souza 
SANDRO TEIXEIRA MARÓSTICA

\title{
GREEN BONDS E O DESENVOLVIMENTO SUSTENTÁVEL
}

\begin{abstract}
Dissertação apresentada à Faculdade de Economia, Administração e Contabilidade da Universidade de São Paulo como requisito para a obtenção do título de Mestre em Administração.
\end{abstract}

Área de Concentração: Administração Geral

Orientador: Prof. Dr. Jacques Marcovitch

Versão Corrigida

São Paulo

2019 


\section{Ficha Catalográfica}

Elaborada pela Seção de Processamento Técnico do SBD/FEA com os dados inseridos pelo(a) autor(a)

\section{Maróstica, Sandro.}

Green Bonds e o Desenvolvimento Sustentável / Sandro Maróstica. - São Paulo, 2019.

$117 \mathrm{p}$.

Dissertação (Mestrado) - Universidade de São Paulo, 2019. Orientador: Jacques Marcovitch.

1. Desenvolvimento econômico - Aspectos ambientais. 2. Mudança Climática. 3. Mercado de Capitais. 4. Economia ambiental. 5. Finanças internacionais. I. Universidade de São Paulo. Faculdade de Economia, Administração e Contabilidade. II. Título. 


\section{Resumo}

Este estudo visa a analisar o papel dos Green Bonds no financiamento da transição para atividades econômicas sustentáveis. O estudo inclui uma comparação entre os Green Bonds e outros bonds já emitidos no mercado pelos mesmos emissores. O rendimento e o preço dos Green Bonds e dos demais bonds são comparados e usados como proxies para se avaliar a importância que a sociedade tem atribuído ao tema das mudanças climáticas e da deterioração do meio ambiente, e para avaliar se os Green Bonds são uma alternativa de financiamento mais atrativa para uma transição para economias sustentáveis do que os bonds tradicionais e demais mecanismos econômicos. Os resultados das comparações mostram que a maioria dos Green Bonds obtêm um prêmio de preço em seus lançamentos, mas tal prêmio tende a se reduzir no mercado secundário. A disponibilização periódica de informações e a padronização do relatório da performance ambiental das atividades financiadas pelos Green Bonds podem ajudar a diferenciá-los no mercado secundário. Outras medidas sugeridas neste estudo contribuiriam para consolidar os Green Bonds como uma classe diferenciada de ativos e para o desenvolvimento de seus mercados. A pesquisa inclui uma abordagem mista qualitativa e quantitativa, cuja técnica é a análise documental.

Palavras-chave: externalidades; mecanismos de mercado; gases de efeito estufa; mudanças climáticas; Green Bonds. 


\begin{abstract}
This study analyses the role of Green Bonds in financing to transition to sustainable development. The study draws a comparison between Green Bonds and other types of bonds already issued by the same issuers. The yields and prices of Green Bonds and other bonds are compared and are adopted as proxies to evaluate the importance that society has been attributing to the subject of climate change and environmental degradation, and to assess whether Green Bonds are an attractive financing alternative to a transition to sustainable economic activities compared to other economic mechanisms. The results of such comparisons indicate that the majority of Green Bonds does obtain a price premium upon issuance, but such premium tend to be reduced in the secondary market. The provision of periodic information and standardized reporting of the environmental performance of the activities financed by Green Bonds could help differentiating them in the secondary bond market. Other measures suggested in the study could help consolidating Green Bonds as a differentiated asset class, contributing to the development of their markets. The research encompasses a qualitative and quantitative mixed approach, whose technique is documental analysis.
\end{abstract}

Keywords: externalities; market mechanisms; greenhouse gases; climate change; Green Bonds. 


\section{SUMÁRIO}

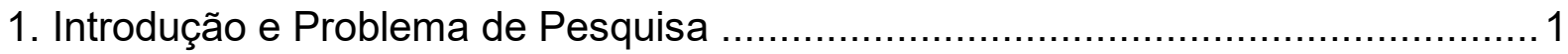

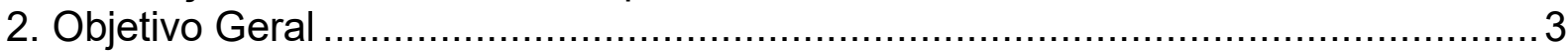

3. Proposições e Estrutura da Dissertação …………..................................... 4

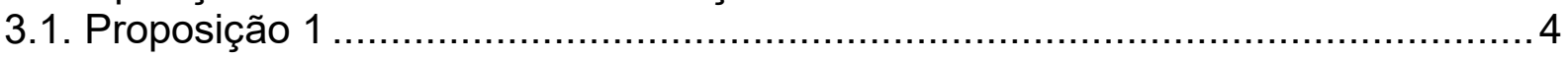

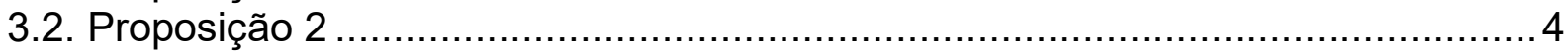

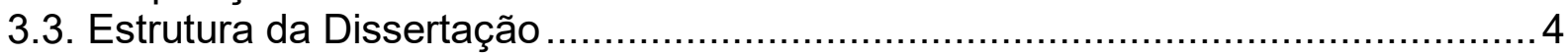

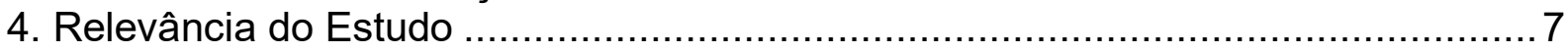

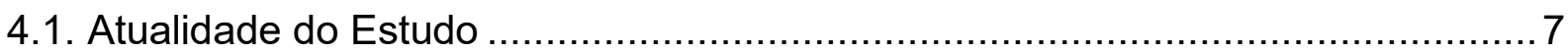

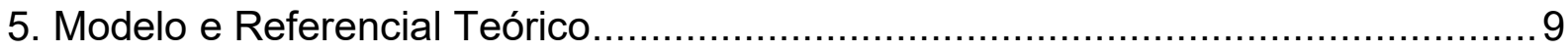

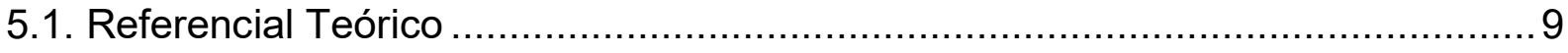

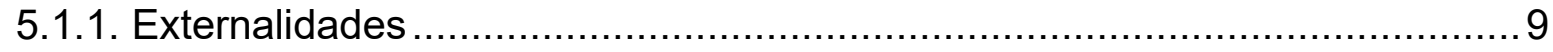

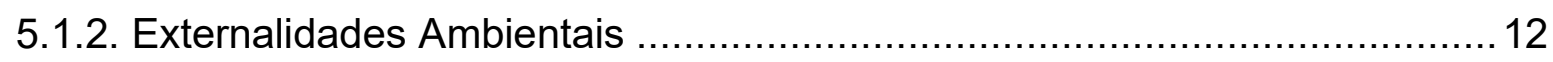

5.1.3. Instrumentos para a Política Ambiental................................................ 15

5.1.4. A Natureza da Incerteza sob Diferentes Instrumentos .............................17

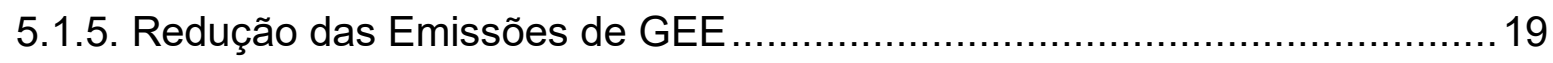

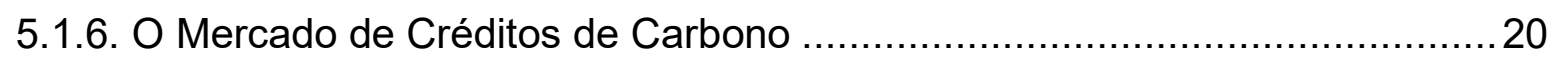

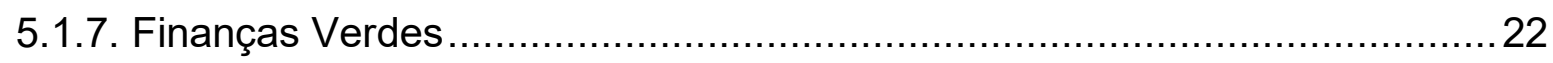

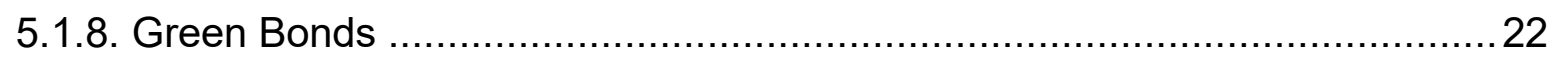

5.1.9. Green Bonds como Instrumento Intergeracional de Financiamento de uma

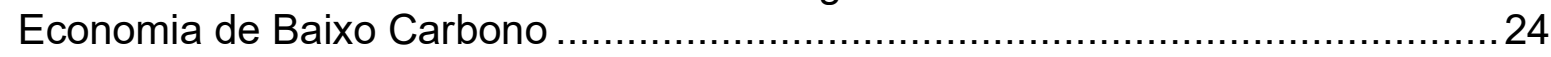

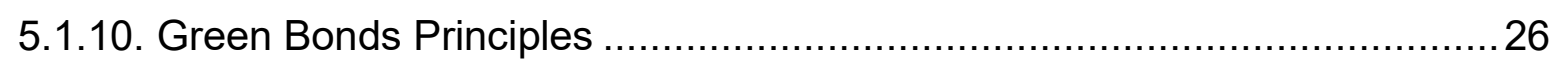

5.1.11. Revisão Externa para Emissão de Green Bonds ....................................26

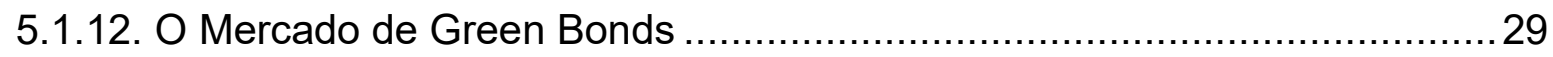

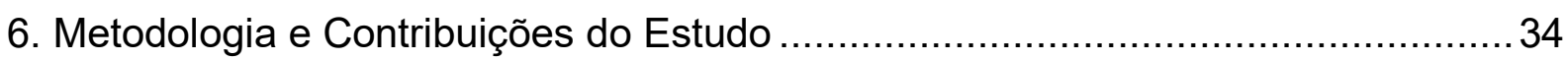

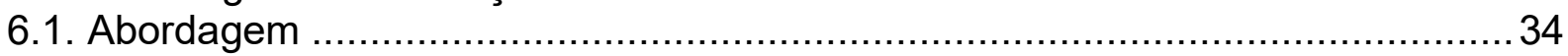

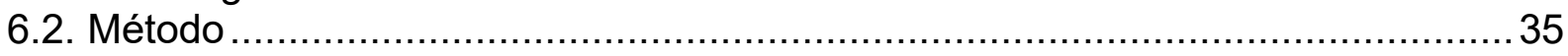

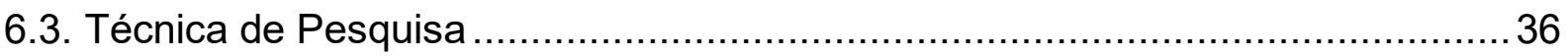

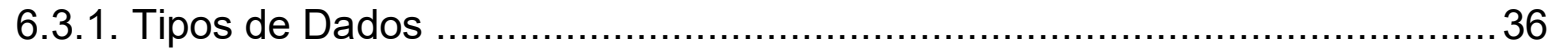

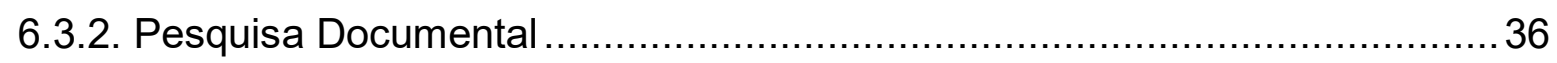

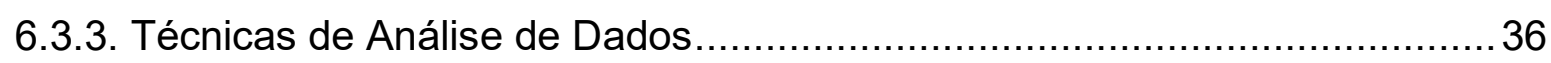

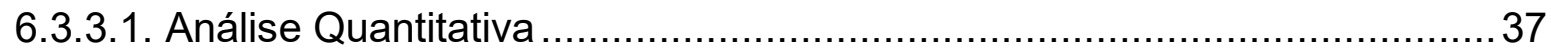

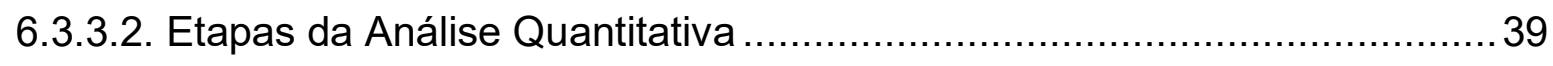

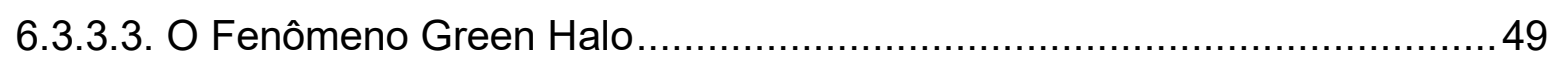

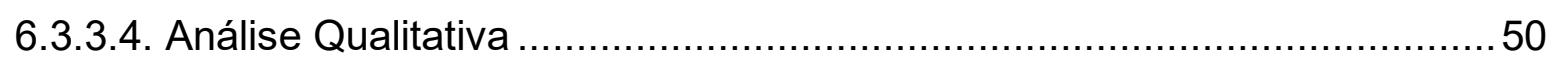

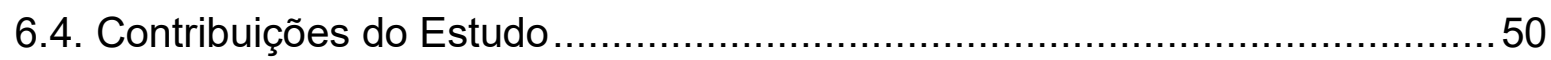

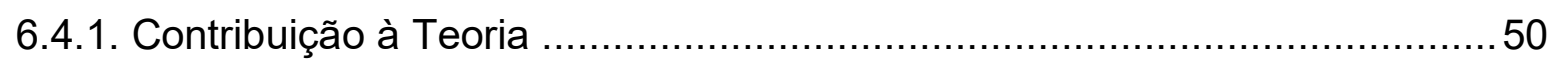

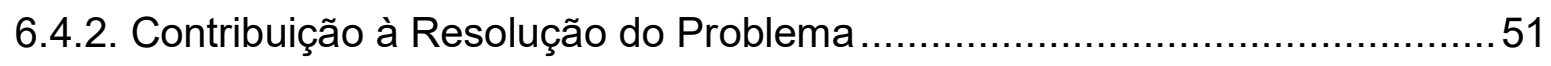

6.4.3. Contribuição para a governança ambiental ............................................51 


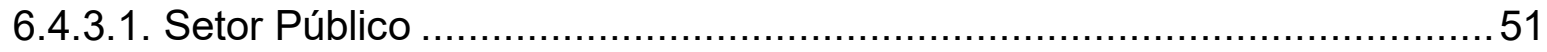

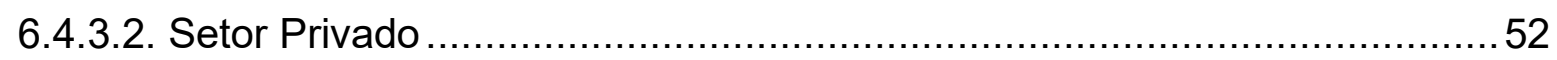

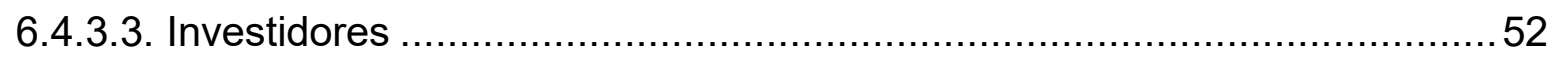

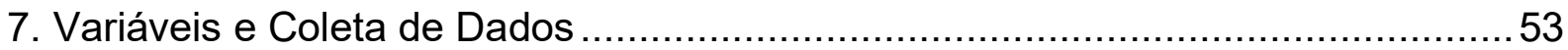

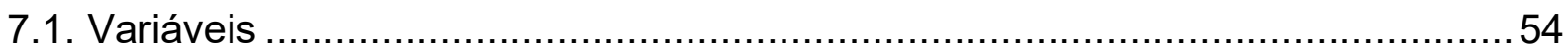

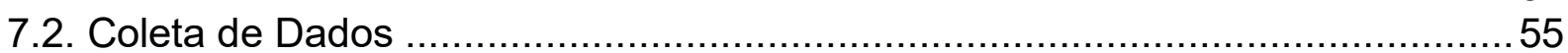

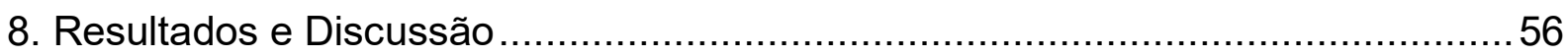

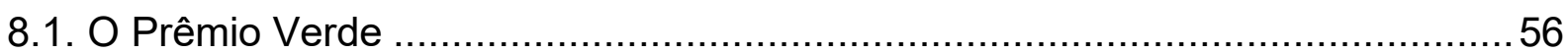

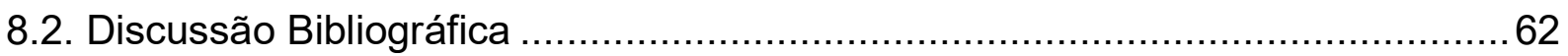

8.2.1. Outros estudos que estimaram o Prêmio Verde dos Green Bonds .............62

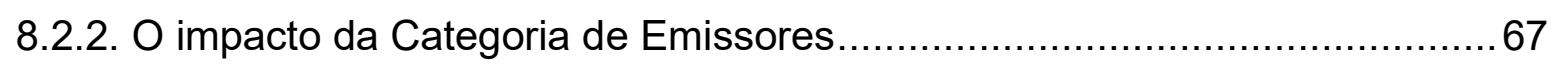

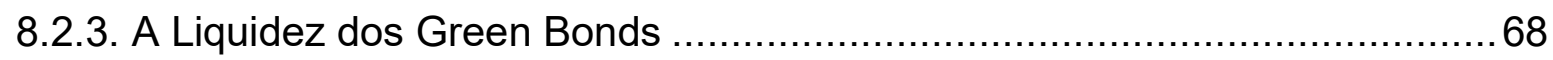

8.2.4. Resultados das Análises de Formação do Green Halo .............................. 71

9. Conclusões e Recomendações ................................................................77

9.1. Recomendações às Partes Interessadas no Desenvolvimento do Mercado de

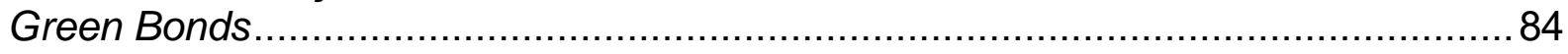

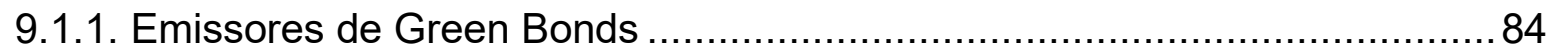

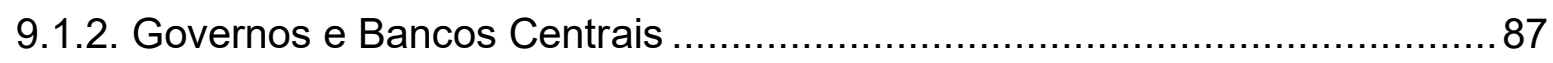

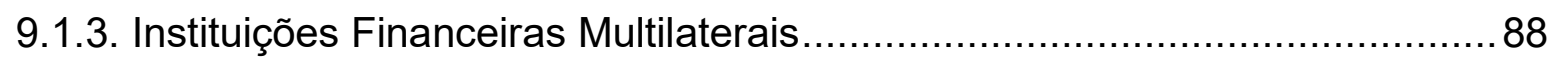

9.1.4. Organizações e Programas de Padronização ............................................ 89

9.1.5. Provedores de Informações Financeiras .................................................. 90

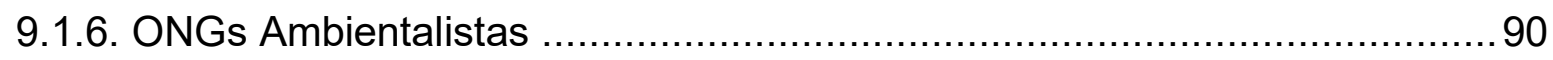

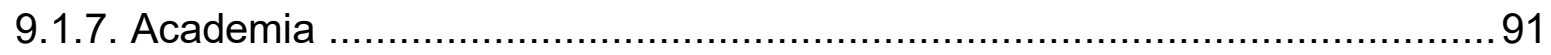

9.1.8. Agências Reguladoras e Supervisoras do Mercado Financeiro ..................91

10. Limitações e Sugestões para Estudos Futuros .............................................93

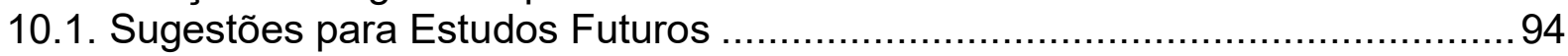

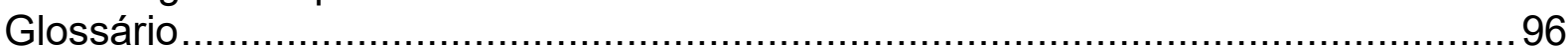

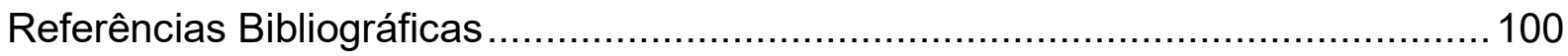




\section{LISTA DE FIGURAS}

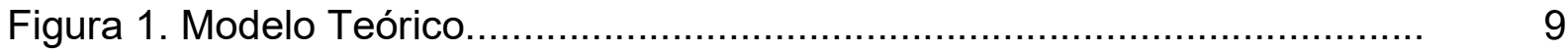

Figura 2. Crescimento do Mercado de Green Bonds.................................... 29

Figura 3. Exemplo de Curva de Rendimentos Green Bond: Apple 2023........... 42

Figura 4. Evolução dos Preços dos Bonds Soberanos e Corporativos em EUR 48

Figura 5. Evolução dos Preços dos Bonds Soberanos e Corporativos em USD 49

Figura 6. Prêmio dos Green Bonds no Lançamento..................................... 58

Figura 7. YTM dos Green Bonds x Curva Teórica, fim do período.................... 58

Figura 8. Porcentagem dos Green Bonds com Prêmio Verde no lançamento e

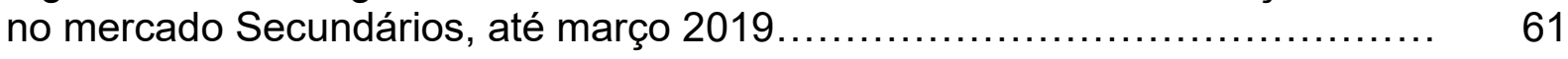

Figura 9. Alteração Spreads x Benchmark Bonds............................... 72 


\section{LISTA DE QUADROS}

Quadro 1. Instrumentos de dívida que podem ser certificados como Green Bond - CBS

Quadro 2. Comparação entre Valores de Mercado de Instrumentos de Precificação de Carbono (valores em USD bilhões) 30

Quadro 3. Green Bonds Emitidos em USD e EUR 53

Quadro 4. Prêmio Verde dos Green Bonds no Período Analisado. 57

Quadro 5. Prêmio dos Green Bonds na Data de Precificação........................... 59

Quadro 6. Green Bonds com Prêmio Verde, Moeda e Tipo de Emissor........... 61

Quadro 7. Outros Estudos que Analisaram a Performance dos Green Bonds... 64

Quadro 8. Liquidez dos Green Bonds................................................. 69

Quadro 9. Green Halo e a Direção do Mercado (EUR)................................. 73

Quadro 10. Green Halo e a Direção do Mercado (USD)................................ 75 


\section{INTRODUÇÃO E PROBLEMA DE PESQUISA}

Em economia, uma externalidade é o custo ou benefício que afeta uma parte que não escolheu incorrer em tal custo ou benefício (BUCHANAN \& STUBBLEBINE, 1962). A emissão de gases de efeito estufa (GEE) é um exemplo de externalidade uma vez que pode ter por origem diversos atores individualmente e causa mudanças climáticas e o aquecimento global, impactando a sociedade humana e os ecossistemas naturais (MILLENNIUM ECOSYSTEM ASSESSMENT, 2005; WORLD BANK GROUP, 2017).

As principais teorias sobre incorporação de externalidades na economia foram desenvolvidas por Pigou (1932) e Coase (1937; 1960), que propunham mecanismos de mercado ou de governo para tratar as externalidades no âmbito econômico. Por um lado, os mecanismos de mercado para incorporação de externalidades, conforme preconizados pelas teorias de Coase (1937; 1960), Wunder (2005) e Wunder, Engel e Pagiola (2008), permitem controlar com mais precisão o volume de redução de GEE, mas não permitem estabelecer os custos (valores de mercado) para tais reduções. Por outro lado, as teorias de Pigou (1932) e Muradian et al. (2010), que preconizam a intervenção de governos no estabelecimento de leis, impostos, incentivos etc., permitem a fixação do custo para a redução dos GEE, mas não permitem um bom controle do volume destes ou de outras externalidades.

As metas de redução de emissões de GEE propostas pelos governos no âmbito do Acordo de Paris e dos Objetivos do Desenvolvimento Sustentável da ONU envolvem recursos significativos para que sejam operacionalizadas (ANDERSON \&, PARKER, 2013).

Segundo a OECD (2017), US\$ 6,7 trilhões de investimento em infraestrutura seriam necessários para se respeitar o limite de aquecimento global de $2^{\circ}$ Celsius. Esta pesquisa busca, portanto, entender o papel dos Green Bonds como novo mecanismo de mercado para financiar a transição para economias sustentáveis, aplicando teorias de incorporação de externalidades. 
Os rendimentos (yield to maturity, ou YTM) dos Green Bonds e dos demais bonds (vanilla bonds) já emitidos nos mercados de capitais, no âmbito deste estudo, serão considerados como proxies para uma avaliação do interesse e preocupação da sociedade com temas ambientais e ações de mitigação das mudanças climáticas.

Para cada emissor de Green Bonds, uma comparação entre os rendimentos de seus bonds tradicionais e os rendimentos de seus respectivos Green Bonds poderá apontar o quanto a sociedade, por meio de seus investimentos, diferencia estes dois instrumentos financeiros e, portanto, a importância que atribui aos temas ambientais, possivelmente aceitando um maior preço na compra de Green Bonds.

Os Green Bonds são o objeto deste estudo devido à crescente adoção desse tipo de instrumento financeiro para projetos e programas na redução de gases de efeito estufa e para a adaptação às mudanças climáticas.

Em 2017 o total de novas emissões de Green Bonds foi de US\$155,5 bilhões (CBI, 2018), equivale a cerca de três vezes todo o montante financeiro envolvido em todos os sistemas de precificação de carbono no mundo no mesmo ano, segundo o relatório do Banco Mundial State and Trends of Carbon Princing 2017 (WORLD BANK GROUP, 2017).

Nota-se, entretanto, que essa comparação não é perfeita uma vez que os recursos provenientes da emissão de Green Bonds não são alocados unicamente para projetos ou atividades que reduzem a emissão de GEE. Estes recursos são também aplicados em projetos que tratam de temas como adaptação, sustentabilidade da água e reciclagem de resíduos, segundo o relatório "Climate Bonds Standard \& Certification Scheme" (CBI, 2017).

Ao final da análise comparativa dos Green Bonds, foi possível concluir o quanto a sociedade, via investimentos, tem valorizado os temas ambientais e sociais. Em outros termos, quanto esse tipo de instrumento financeiro poderia ser adotado ou aperfeiçoado para financiar a transição para economias sustentáveis de forma mais atrativa. 


\section{OBJETIVO GERAL}

O presente trabalho propõe uma análise do papel dos Green Bonds como novo instrumento de mercado para o financiamento de projetos e programas para redução de GEE, adaptação às mudanças climáticas, e para uma transição a atividades econômicas sustentáveis.

Deste modo, a análise atenderá aos objetivos específicos seguintes:

1. Avaliar se a sociedade, por meio de seus investimentos, tem atribuído importância ao tema das mudanças climáticas e da deterioração ambiental, adotando como proxy os rendimentos (YTM) dos Green Bonds e comparando-os com os rendimentos dos demais bonds, numa mesma base de emissores e com as demais características semelhantes.

2. Comparar os Green Bonds com outros mecanismos de mercado e com as prescrições da teoria que trata das externalidades ambientais, além de apresentar recomendações para aperfeiçoar o desempenho dos Green Bonds e desenvolver o mercado. 


\section{PROPOSIÇÕES E ESTRUTURA DA DISSERTAÇÃO}

O estudo define as proposições a seguir, que serão validadas com os estudos e análises das abordagens quantitativa e qualitativa.

\subsection{Proposição 1}

A sociedade, por meio de seus investimentos, já começa a expressar sensibilidade aos temas de mudanças climáticas e deterioração ambiental, e tal sensibilidade está refletida na aceitação de um menor rendimento (YTM) ou maior preço dos Green Bonds em relação aos demais bonds, para a mesma base de emissores e com as demais características semelhantes.

\subsection{Proposição 2}

Comparando-se os Green Bonds com outros mecanismos de mercado e com aquilo que postulam as teorias sobre externalidades, pode-se identificar mecanismos regulatórios, de padronização e/ou para mitigação de riscos ou outros, que poderiam aumentar a viabilidade e atratividade de Green Bonds, permitindo que estes sejam alternativas eficientes para financiar a transição para atividades econômicas sustentáveis.

\subsection{Estrutura da Dissertação}

Após a introdução, que trata da definição do problema, dos objetivos, das proposições e da estrutura da dissertação, a Seção 4 descreve como o estudo é atual e contribuirá para o entendimento do papel dos Green Bonds como uma nova alternativa para financiar essa transição.

O modelo teórico proposto pelo autor é então apresentado na Seção 5, onde os Green Bonds são introduzidos como um novo mecanismo de mercado para a incorporação econômica de externalidades. Em seguida, o texto traz um aprofundamento da temática de externalidades ambientais, a qual aborda as 
principais teorias econômicas sobre incorporação de externalidades por meio da ação dos governos ou de mecanismos de mercado.

A Seção 5 ainda descreve os principais instrumentos econômicos a serem empregados quando mecanismos de mercado ou de governo são adotados - a seção seguinte discorre a respeito das emissões de gases de efeito estufa (GEE) e do mercado de créditos de carbono.

Ainda nessa seção, também é realizada uma revisão bibliográfica sobre os Green Bonds como instrumentos econômicos de mercado que vêm se destacando nos últimos anos para financiar a transição para atividades econômicas sustentáveis, inseridos no contexto de Finanças Verdes.

Na Seção 6 é apresentada a metodologia adotada: o estudo do caso dos Green Bonds como um mecanismo de mercado até então pouco estudado, com uma abordagem qualitativa, feita a partir de uma revisão da bibliografia, e uma abordagem quantitativa, comparando o rendimento e a liquidez dos Green Bonds e dos demais bonds.

A mesma seção também descreve a contribuição do estudo para a teoria e para a resolução do problema de incorporação de externalidades ambientais, adotando os Green Bonds como novos mecanismos de mercado.

Em seguida é oferecida a contribuição gerencial do estudo para atores dos setores público e privado, que buscam migrar para o desenvolvimento econômico sustentável.

A Seção 7 apresenta como foram definidas as amostras e as variáveis das análises e como os dados foram coletados e tratados.

A Seção 8 demonstra os resultados das análises sobre os prêmios dos Green Bonds, a evolução dos prêmios ao longo do tempo, a possível influência da arbitragem das diferenças de rendimentos e dos ganhos reputacionais dos emissores de Green Bonds que resultariam na diminuição do prêmio com o passar do tempo. 
A Seção 9 expõe as conclusões deste trabalho e as recomendações pensadas a partir dos resultados da pesquisa, endereçando especificamente as proposições inicialmente colocadas e os objetivos da pesquisa.

A Seção 10 mostra as limitações do estudo, dado que se trata de um tema ainda pouco estudado, e realiza-se algumas análises que não foram ainda testadas por outros autores.

Ao final são incluídas sugestões para estudos futuros, as Referências Bibliográficas e um Glossário de termos utilizados neste documento. 


\section{RELEVÂNCIA DO ESTUDO}

Do ponto de vista teórico, este estudo contribuirá para o entendimento do papel dos Green Bonds como um mecanismo de mercado inovador para incorporar externalidades ambientais na economia e financiar a transição para atividades econômicas sustentáveis. Até então, as teorias sobre incorporação de externalidades foram aplicadas principalmente na análise de instrumentos como impostos sobre a emissão de GEE, sistemas de cap and trade para emissões de GEE e outros poluentes, mercados de créditos de carbono, incentivos e subsídios governamentais.

\subsection{Atualidade do Estudo}

A realização desse estudo é atual, pois globalmente se discute a necessidade de uma transição para atividades econômicas sustentáveis a mitigar e adaptar-se às mudanças climáticas já em curso. Acordos como o Acordo de Paris (2015) e os Objetivos do Desenvolvimento Sustentável da ONU refletem esses esforços.

A pesquisa bibliográfica incluída neste estudo revelou apenas outros sete trabalhos acadêmicos bastante recentes comparando a performance dos Green Bonds com outros bonds, sendo que todos foram feitos nos últimos dois anos. Os outros sete estudos adotaram uma abordagem puramente quantitativa, enquanto esta pesquisa adotou o método do estudo de caso, com objetivos também exploratórios em que os resultados são inseridos em um contexto teórico e prático mais amplo sobre a incorporação de externalidades ambientais e as experiências com outros instrumentos.

Uma outra característica que diferencia o presente trabalho dos demais já realizados é que se trata do primeiro a analisar a evolução da performance dos Green Bonds (preços e rendimentos) ao longo do tempo, iniciando com seus lançamentos no mercado primário até as negociações subsequentes no mercado secundário, além de testar algumas hipóteses sobre a redução do Prêmio Verde. 
Tais hipóteses não foram formuladas em estudos anteriores e levaram às seguintes análises para testá-las, as quais também são inéditas na literatura acadêmica sobre Green Bonds:

1. A influência da arbitragem agnóstica das diferenças de rendimentos entre Green Bonds e os bonds semelhantes do mesmo emissor no mercado secundário;

2. O ganho reputacional dos emissores de Green Bonds, que neste trabalho foi também referido como o aparecimento do Green Halo, resultando no deslocamento de toda a curva de rendimentos dos bonds para níveis mais baixos. 


\section{MODELO E REFERENCIAL TEÓRICO}

Figura 1. Modelo Teórico

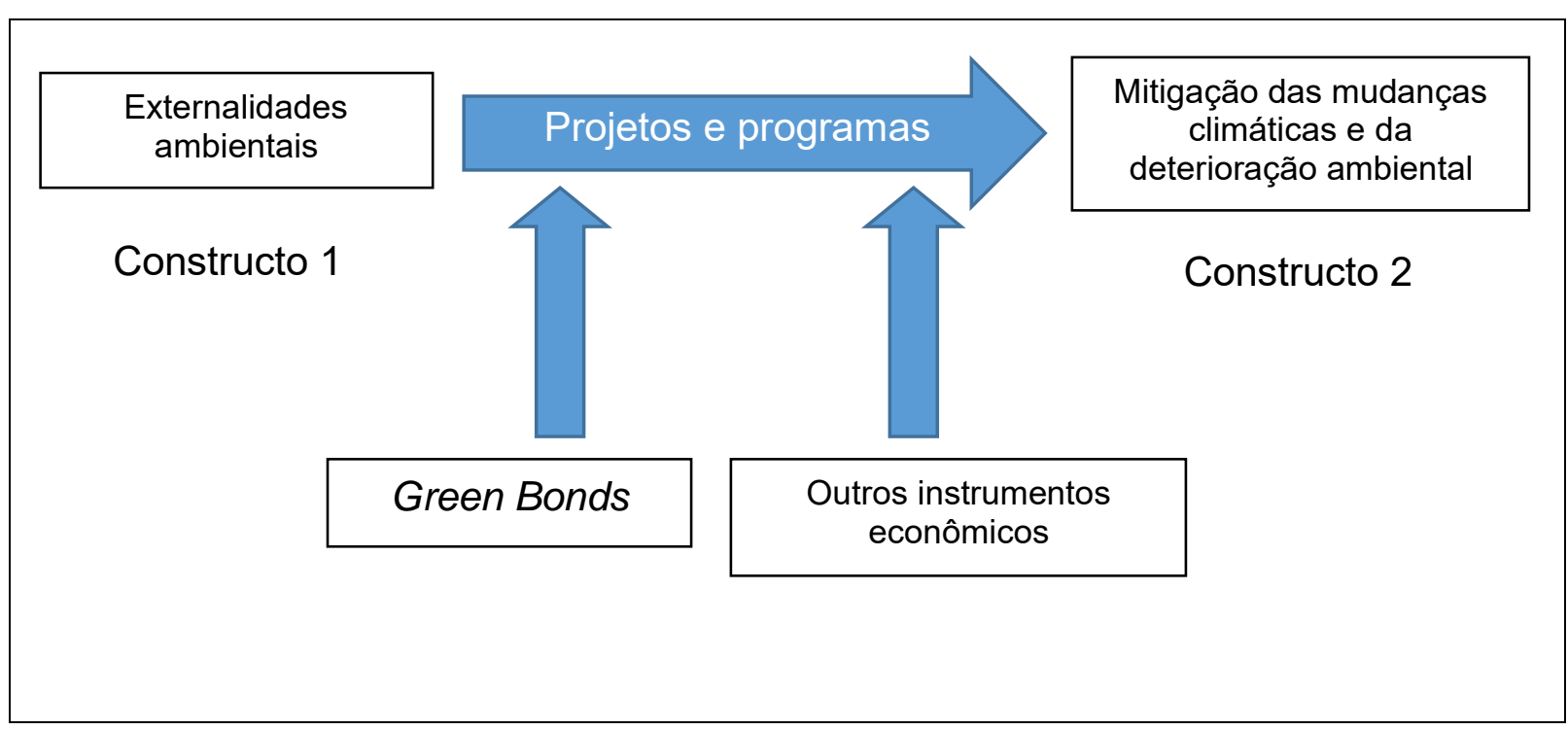

Fonte: elaboração própria do autor.

\subsection{Referencial Teórico}

\subsubsection{Externalidades}

Os recursos naturais e o meio ambiente são de particular interesse aos economistas devido ao potencial que os mercados têm de gerar resultados ineficientes. No caso de recursos naturais, a questão é se o uso dos recursos é otimizado (BUCHANAN \& STUBBLEBINE, 1962; COASE, 1937 e 1960).

A provisão ótima de bens ambientais e o uso de recursos naturais dependem da seguinte condição: se os atores privados atuando no mercado contabilizam custos e benefícios de forma abrangente. Contanto que a produção ou o uso ocorram no ponto em que o benefício social marginal é igual ao custo social marginal, os mercados são eficientes (BUCHANAN \& STUBBLEBINE, 1962).

Entretanto, se os benefícios privados marginais são menores que os benefícios sociais marginais, os mercados vão prover pouca qualidade ambiental, e se custos privados marginais são menores que os custos sociais marginais, os mercados vão usar em excesso os recursos naturais (idem). 
De acordo com Anderson e Parker (2013), os textos de Pigou (1932) são o ponto de partida para qualquer análise de alocação subótima de recursos, seja do lado dos benefícios seja dos custos. Do lado dos benefícios, Pigou afirma que o problema de subprodução de bens e serviços ocorre porque é tecnicamente difícil obter com exatidão o valor do pagamento daqueles que se beneficiam. Do lado dos custos, Pigou argumenta que a divergência entre o custo privado marginal e o custo social marginal decorre da dificuldade técnica de atribuir compensação para desserviços incidentais.

Em artigo de 1960 intitulado "O Problema do Custo Social", Coase (1960) desafia algumas conclusões derivadas da análise de Pigou, em particular a indicação de sempre considerar os poluidores culpados por danos; mas similaridades entre Coase e Pigou são muitas vezes ignoradas.

Coase afirma que sem custos de transação, o uso ótimo de recursos irá emergir a partir de acordos de mútuo benefício, e não há nada nos escritos de Pigou que sugerem sua discordância. Além do mais, o foco de Coase nos custos de transação é, na verdade, parecido com o foco de Pigou nas dificuldades técnicas.

Para Coase, custos de transação são os que incorrem em descobrir os autores interessados na negociação e na realização de uma inspeção necessária para se ter certeza de que os termos do contrato são observados etc.

O autor explica que se a transação de mercado não tem custos, tal rearranjo de direitos acontecerá se este levar a um aumento no valor de produção. Esse argumento tem sido chamado de Teorema de Coase, embora ele próprio não o tenha denominado dessa forma.

Ainda de acordo com Anderson e Parker (2013), o Teorema de Coase implica que a alocação de recursos depende de direitos de propriedade bem definidos e custos de transação zero. Então, é fácil inferir que transações voluntárias de mercado não serão eficientes porque os custos de transação são sempre positivos. Não importando se os custos de transação são os de definir ou reforçar direitos de propriedade ou os custos de negociar direitos de propriedade bem definidos, eles vão levar a uma cunha no processo de alocação que leva a resultados inferiores àqueles que resultariam de um mundo com custos de transação zero. 
A suboferta de bens públicos é fundamentalmente um problema de custos de transação porque pode ser tecnicamente difícil de extrair pagamento exato daqueles que, de outra forma, obteriam o serviço de graça. Entretanto, fazer aqueles que se beneficiam sem custo pagar pelos serviços também requer descobrir quem quer negociar e conduzir negociações que levem a uma barganha (COASE, 1960).

Esses custos de transação seriam enormes em algumas situações, mas é importante enfatizar que uma oferta eficiente não requer pagamento de todos os consumidores. A oferta privada de bens públicos não é sempre ótima, fazendo-se necessário extrair pagamento dos que potencialmente obteriam os bens de graça.

Se os custos para se extrair tais pagamentos são altos, intervenções governamentais podem levar a um nível ótimo de provisão do bem público. Essa intervenção pode se realizar de várias formas, como pela posse direta do recurso pelo governo, e neste caso ele determina a oferta, as técnicas de produção e o preço.

De forma alternativa, a intervenção governamental pode regulamentar decisões privadas, como acontece com os padrões de água sob o Clean Water Act norte-americano e a restrição do uso da terra sob o Endangered Species Act (ANDERSON \& PARKER, 2013); ou estabelecendo limites de exploração, tais como períodos definidos para pesca ou restrições para evitar o excesso de atividade pesqueira.

Finalmente, a intervenção governamental pode ocorrer por meio de subsídios usados para aumentar o benefício privado da provisão de bens públicos. Nem Pigou nem Coase ofereceram uma resposta definitiva sobre se os mercados são preferíveis a intervenções governamentais (idem).

Pigou (1932) afirmou que a extensão em que alternativas governamentais melhoram mercados depende da competência intelectual das pessoas que atuam em nome dos governos, da eficácia da organização por meio da qual as decisões são executadas, a integridade do servidor público perante questões éticas e corrupção, a liberdade de dominação por uma classe privilegiada e a habilidade a resistir à pressão de interesses de poder ou da opinião não estruturada. 
Pigou também reconheceu que todo agente público representa uma oportunidade potencial para alguma forma de interesse próprio contra o interesse público comum. Portanto, não seria suficiente contrastar os ajustes imperfeitos da empresa privada com os ajustes perfeitos que os economistas imaginam em seus modelos. Não podemos esperar que alguma autoridade pública alcance o ideal.

Do mesmo modo, Coase (1960) reconheceu as vantagens e desvantagens dos custos de transação no uso de mercados para alocar recursos, bem como os problemas de ação coletiva no processo de escolha entre arranjos sociais no contexto em que decisões individuais são feitas, temos que ter em mente que a mudança em um sistema existente pode levar a melhoras para algumas decisões, mas pioras para outras. Além disso, temos que levar em consideração os custos envolvidos em operar os diversos arranjos sociais, assim como os custos envolvidos para mudar de sistema.

Em suma, segundo Anderson e Parker (2013), Pigou e Coase entenderam que determinar se intervenção governamental melhora a alocação de mercado requer uma análise comparativa institucional dos custos e incentivos transacionais sob cada sistema de governo ou de mercado. Isso sugere que expressões como "falhas de mercado" ou "falhas de governo" não têm significado a menos que sistemas de mercados e governos sejam comparáveis uns com outros.

\subsubsection{Externalidades Ambientais}

De acordo com Pattanayak, Wunder e Ferraro (2010), a rápida degradação dos ecossistemas pode ser parcialmente explicada pelo fato de que muitos serviços ambientais fornecidos pela natureza são externalidades e que a sociedade falha em criar instituições que internalizem os valores públicos de ecossistemas intactos. Voltando pelo menos até Pigou (1932) e Coase (1960), a teoria econômica sugere que algum tipo de subsídio dos beneficiários (compradores) de serviços ambientais aos provedores (vendedores) de tais serviços poderia resultar em uma oferta ótima.

Recentemente, um novo paradigma para internalizar diretamente as externalidades tem sido chamado de Pagamento por Serviços Ambientais (PSA), 
representando contratos entre provedores e beneficiários (ou agentes governamentais agindo em seu nome).

Enquanto a teoria sobre o PSA é relativamente simples, a prática é muito mais difícil, particularmente em países em desenvolvimento, que enfrentam uma gama de desafios institucionais e de governança.

Ainda segundo Pattanayak et al. (2010), governos podem não estar devidamente posicionados para identificar e oferecer serviços ambientais. A princípio, pagamentos diretos dos usuários contornam muitas ineficiências por meio da geração de novos recursos de usuários informados, que devem ter um incentivo forte para se ter certeza de que os recursos são usados eficientemente.

Entretanto, em adição aos problemas já levantados na discussão da teoria de PSA, questões críticas permanecem sem resposta. As primeiras questões são associadas aos processos que envolvem criar uma transação do tipo de mercado, num cenário de instituições fracas e ausência de mercados. Muitos dos problemas do mundo dependem dos papéis complementares de regulação, normas e sinais de mercado para reduzir a diferença entre comportamento social privado e ótimo.

De acordo com Tol (2018), tem sido amplamente aceito que as mudanças climáticas são uma externalidade negativa e que as emissões de GEE deveriam ser precificadas, preferencialmente por meio de impostos. Embora haja um contínuo debate sobre metas climáticas de longo prazo, muitos economistas acreditam que uma política climática deve começar modesta e depois acelerar.

Apesar do consenso de que há a necessidade de reduzir os GEE, o debate entre economistas sobre mudanças climáticas tem sido tenso, talvez um reflexo da ampla polarização entre os objetivos de crescimento econômico de curto, médio e longo prazos. Em particular, estimativas do impacto marginal das mudanças climáticas variam tanto que o preço inicial do carbono parece ser mais uma questão de política do que de economia.

Para Buchanan e Stubblebine (1962), de uma perspectiva econômica, as emissões de GEE resultam em externalidades que impactam a sociedade. Evidências tais como o aquecimento global (UNFCCC, 2018a; TEEB, 2010) mostram 
que nossas sociedades têm falhado em estabelecer instituições que internalizem o valor dos serviços ambientais e as causas de sua degradação.

O PSA e as negociações de reduções de emissões de GEE são discutidos como novos instrumentos para a conservação da natureza, bem como para deter as mudanças climáticas e superar o problema das externalidades ambientais até então ignorados pelos agentes econômicos.

Mudanças climáticas e degradação ambiental podem, portanto, ser atribuídas à falha crônica dos mercados em internalizar externalidades ambientais. Agentes privados poderiam lançar mão do Teorema de Coase (1937 e 1960), ou seja, beneficiários de boas práticas ambientais deveriam pagar os provedores de serviços ambientais, assumindo que estes últimos vão prover os serviços contratados. Os pagamentos deveriam motivar os provedores a manter boas práticas e serviços ambientais.

O termo Pagamento por Serviços Ambientais se tornou multifacetado, com diversas definições coexistentes. Uma definição importante de PSA é atribuída a Wunder (2005), idem, Engel e Pagiola (2008), focada em transações de mercado e baseada em transações voluntárias, em que um serviço ambiental, que é comprado por no mínimo um comprador e fornecido por no mínimo um fornecedor, é bem definido se, e somente se, o fornecedor do serviço ambiental assegura a provisão desse serviço (condicionalidade).

Essa definição tem sido criticada por ser muito limitada e, portanto, excluir vários sistemas de PSA que não atendem aos seus critérios.

Em particular, o aspecto voluntário (pelo menos do lado do comprador) das transações de PSA, segundo Wunder, tem sido questionado. Muitos PSAs envolvem intervenção governamental e esquemas de pagamento público por PSAs.

A definição de Wunder de PSA, baseando-se no conceito de mercado de Coase, leva à classificação de PSAs genuínos e quase genuínos. Em consequência das limitações da definição de Wunder para PSA, Muradian et al. (2010) elaboraram uma definição baseada no caráter de bem público da maioria dos PSAs e das respectivas externalidades que devem ser internalizadas nos mesmos. Segundo Muradian: 
[...] PSAs deveriam ser a criação de incentivos para a provisão de tais bens, de tal forma mudando o comportamento individual ou coletivo que leva à deterioração dos ecossistemas e dos recursos naturais. Portanto, pode ser mais conveniente definir PSA como uma transferência de recursos entre atores sociais, com o objetivo de criar incentivos que alinham decisões individuais ou coletivas do uso da terra com a gestão de recursos naturais. ${ }^{1}$

A definição de Muradian não exclui esquemas de PSA financiadas por governos, que são comumente tipificados sob o conceito pigouviano de PSA (VATN, 2010).

Vários tipos de PSA têm sido relatados e discutidos nas últimas décadas, entretanto, as duas tipologias mais predominantes nas experiências encontradas mundo afora são as de Wunder-Coase e Muradian-Pigou.

\subsubsection{Instrumentos para a Política Ambiental}

Segundo Goulder e Parry (2008), o conjunto de mecanismos para incorporação ou redução de externalidades ambientais é amplo, incluindo impostos sobre emissões, cap and trade (EUROPEAN COMMISSION, 2018), subsídios, padrões de performance, mandatos para a adoção de tecnologias e subsídios para pesquisa de tecnologias limpas.

A escolha é inerentemente difícil, pois diferentes critérios de avaliação se aplicam. Economistas tendem a focar no critério de eficiência econômica (o agregado dos benefícios de uma política) e sua efetividade de custos.

Outros critérios importantes são a distribuição de benefícios ou custos por meio de grupos econômicos, étnicos, regionais, de geração etc. e a habilidade de avaliar as incertezas. Alguns analistas incluiriam também a viabilidade política como critério. Avaliar o impacto ao longo de qualquer uma dessas dimensões já é difícil o suficiente.

Um princípio elementar dos livros-texto é que o princípio pigouviano, em que a poluição deveria ser precificada ao custo marginal externo. Esse princípio usualmente sugere que impostos sobre emissões são superiores aos instrumentos alternativos.

\footnotetext{
1 Tradução livre do autor.
} 
Enquanto as ideias de Pigou permanecem altamente válidas, as pesquisas conduzidas nas últimas décadas nem sempre se mostram suficientes ou confiáveis devido a problemas de informação, limitações institucionais e tecnológicas, além de interações fiscais (HORSH \& RICHTER, 2017).

Minimizar os custos de redução da poluição a uma dada quantia requer equalizar custos de abatimento marginal por meio de todas as opções potenciais e de agentes, incluindo:

- Os vários canais de abatimento disponíveis para uma dada firma ou instalação, por exemplo para combustíveis mais limpos;

- Firmas ou instalações de um dado setor produtivo que podem enfrentar custos de abatimento diferentes;

- Setores produtivos, como manufatura e geração de energia;

- Residências e firmas.

Em teoria, essas condições são satisfeitas quando todos os atores sociais encaram um preço comum, na margem, para suas contribuições em relação a emissões de GEE. Nestas circunstâncias, cada firma em cada setor produtivo emissor tem um incentivo para explorar as oportunidades de abatimento até que o custo marginal de redução das emissões se iguala ao preço da emissão.

Além disso, o controle do custo das emissões e o preço pago para as emissões que permanecem serão passados adiante aos preços finais das mercadorias e serviços. Consequentemente, os consumidores encontrarão preços que refletem as emissões associadas à produção das mercadorias que eles compram ou dos serviços que utilizam.

Portanto, mantendo a condição acima, as escolhas de consumo vão contribuir para as emissões de GEE. Considerando que a todos os agentes serão cobrados a mesma unidade de preço para suas contribuições diretas ou indiretas de emissões de GEE, os custos marginais das reduções de emissões de todos os agentes serão iguais.

Maximizar a eficiência de custo requer que todos os agentes enfrentem 0 mesmo preço das emissões. A condição mais forte para maximizar os ganhos de 
eficiência de uma política de intervenção implica um nível específico para esse preço, fora os benefícios marginais e custos das reduções de emissões para todos os setores econômicos e agentes.

De acordo com Keohane (2009), uma firma buscando minimizar seus custos para cumprir um programa vai abater sua poluição até que o custo marginal se iguale ao preço de mercado de uma alocação (ou crédito de carbono). Como resultado, em teoria, programas de cap and trade como o europeu (EUROPEAN COMMISSION, 2018) são efetivos, pois eles atingem a quantidade requerida de redução de emissões ao custo de abatimento mais baixo possível.

A flexibilidade intertemporal equalizará os custos de abatimento ao longo do tempo. Essa característica é crucial pois os danos das mudanças climáticas são causados por emissões cumulativas de GEE ao longo do tempo.

As alocações podem ser livremente distribuídas, vendidas em leilões ou alguma combinação dos dois. Não importa como elas são inicialmente distribuídas, sob premissas padrão, negociações levarão a um preço de equilíbrio igual ao imposto sobre emissões que alcançaria o mesmo abatimento. De fato, na ausência de custos de transação, a alocação de equilíbrio será igual sob um sistema cap and trade e um imposto sobre o carbono (COASE, 1937 e 1960).

O Esquema de Negociação de Emissões da União Europeia, ou European Trading Scheme (ETS), experimentou vários modelos de alocação de emissões às instalações poluentes para que estas participem do mecanismo de mercado criado no continente. Várias lições puderam ser aprendidas com esse esquema pioneiro.

\subsubsection{A Natureza da Incerteza sob Diferentes Instrumentos}

Sob um sistema de impostos sobre emissões, o preço destas (a taxa de imposto) é pré-estabelecida. O que é incerto é o agregado da quantidade de emissões que resultarão depois que as firmas respondam ao imposto. Em contraste, num sistema de alocação de emissões, o agregado da quantidade de emissões é conhecido dada a quantidade de alocações colocadas no mercado, mas o preço será determinado por este. 
Consideremos agora três questões que dificultam a escolha do instrumento: múltiplas externalidades de um só produto ou serviço, as interações entre diferentes instrumentos e a possibilidade de conectar instrumentos por meio de jurisdições.

Uma questão importante são os vazamentos de emissões, em que o aumento delas fora de uma determinada jurisdição anula as reduções promovidas na jurisdição. Um vazamento pode ocorrer pelo menos de duas formas. Novas regulamentações em uma jurisdição podem aumentar os custos de produção, causando a realocação das firmas para outra jurisdição. Além disso, uma nova regulamentação imposta por uma jurisdição pode mudar a demanda de consumo, reduzindo a compra de produtos mais caros produzidos na jurisdição regulamentada, o que leva a um aumento de demanda e emissões em outro lugar (KEOHANE, 2009).

Para Keohane (2009), embora o uso de qualquer instrumento que eleve custos possa causar vazamentos, alguns instrumentos podem causar mais vazamento que outros. Neste aspecto, alguns instrumentos regulatórios, como padrões de portfólio de energia renovável, poderiam ser superiores ao cap and trade na prevenção de vazamento acompanhado de uma mudança na demanda.

Isso acontece porque instrumentos regulatórios diretos não precificam as emissões inframarginais e, portanto, têm um impacto mais fraco nos preços de eletricidade dentro da jurisdição, implicando em menos vazamento. Essa vantagem pode ser contrabalanceada pelas desvantagens em termos de custo.

Bushnell, Peterman e Wolfram (2008) argumentam que os vazamentos são mais pronunciados em regulamentações que impõem um custo adicional às firmas do que em subsídios destinados a premiar produção com fontes não poluentes. Argumenta-se que as firmas podem mudar para outras jurisdições em que não há tais custos extras. Firmas podem também mudar para jurisdições em que há subsídios para novas tecnologias.

Ainda segundo Keohane (2009), apesar de sua proposição de que nenhum instrumento é superior a outro em todas as situações, a análise da literatura de escolha de instrumentos aponta fortemente para o uso de instrumentos flexíveis, baseados em políticas de incentivo. 
Com base nessa conclusão, esta pesquisa busca entender mais adiante o papel de um mecanismo flexível e baseado em incentivos: os Green Bonds (CBI, 2008 e 2018; LINDENGERG, 2014).

\subsubsection{Redução das Emissões de GEE}

Keohane (2009) compara impostos sobre as emissões de GEE em relação a um sistema de mercado com créditos de carbono. Independentemente, se as emissões são taxadas ou limitadas (cap), elas precisam ser medidas. Se as emissões são difíceis ou custosas para serem medidas, o "ponto de regulação" pode ser estabelecido mais acima na cadeia produtiva, tanto para impostos como para um programa de cap and trade. Por exemplo, emissões de carros e caminhões poderiam ser medidas na refinaria, e não nos postos de abastecimento veicular.

A maior vantagem de um sistema de cap and trade é a flexibilidade: ele não requer que legisladores aloquem as emissões de graça, mas oferece uma forma direta de se fazer isso. Afinal, um leilão de alocações pode levantar recursos tão bem como impostos (MCINERNEY \& JOHANNSDOTTIR, 2016).

A distinção de preço versus quantidade leva a diferentes debates sobre os objetivos dessas políticas. A proposta para taxar emissões de GEE foca o debate no tamanho do imposto e no potencial custo para a economia. Em contraste, a proposta de limitar as emissões direciona a discussão em termos dos limites a serem estabelecidos e as consequências para as mudanças climáticas.

Portanto, a escolha do instrumento provavelmente vai gerar diferentes resultados, com o sistema cap and trade, mais apto a suportar reduções de emissões mais ambiciosas, e os impostos promoveriam uma política menos restringente.

No contexto internacional, o cap and trade tem clara vantagem sobre impostos, uma vez que permite que políticas domésticas sejam alinhadas sem coordenação explícita em relação aos alvos das políticas entre países. Essa característica é crucial, porque reduzir as emissões de GEE com o mínimo custo possivel requer equalizar os custos marginais de abatimento a partir dos países. 
Dadas as amplas variações em oportunidades de abatimento entre países industrializados e em desenvolvimento, os ganhos potenciais de negociações em um ambiente de mercado são enormes.

As fontes de menor custo de abatimento estão localizadas em países em desenvolvimento, o que cria um desencontro entre as oportunidades de reduzir emissões e a capacidade para pagar por elas.

Portanto, não é somente eficiente, mas também justo que nações mais ricas transfiram recursos para países em desenvolvimento de forma a ajudar o abate das emissões de GEE (idem).

\subsubsection{O Mercado de Créditos de Carbono}

A Convenção-Quadro das Nações Unidas para Mudanças Climáticas $(\text { UNFCCC })^{2}$ foi adotada em 1992 e entrou em vigor em 1995, com adesão quase universal.

O Protocolo de Kyoto, adotado em 1997 na COP3, incluía compromissos vinculantes: um regime de cortes e relatórios para os países desenvolvidos, baseado na opinião predominante da Convenção de que estes deveriam tomar a liderança no processo.

O Protocolo também incluía mecanismos de mercado inovadores que forneceriam ferramentas para a redução de emissões a custo eficiente. Dentre eles, destaca-se o Mecanismo de Desenvolvimento Limpo (MDL), ou Clean Development Mechanism (UNFCCC, 2018b; MURADIAN et al., 2010), criado para catalisar a transferência de tecnologia para países em desenvolvimento, via unidades de redução de emissões comercializáveis (créditos de carbono), utilizadas pelas partes do Protocolo de Kyoto.

O princípio básico do Mecanismo de Desenvolvimento Limpo é simples: projetos que geram reduções certificadas de emissões (RCEs) em países em desenvolvimento poderão gerar créditos de carbono, negociáveis entre os países desenvolvidos.

\footnotetext{
${ }^{2}$ Cf. o portal da UNFCCC em: www.unfccc.int.
} 
O objetivo é incentivar investimentos em oportunidades de redução de baixo custo em países em desenvolvimento, com o aporte de recursos dos países desenvolvidos, ao mesmo tempo em que aumentam a eficiência econômica para alcançar as metas iniciais de redução de emissões de gases de efeito estufa. A lógica de funcionamento do MDL é baseada no princípio de beneficiar projetos em que haja a ocorrência de melhorias em termos de emissões de gases de efeito estufa, mas não premia atividades "limpas" já estabelecidas.

O Acordo ficou restrito ao período de 2008 a 2012, e a COP (Conferência das Partes da UNFCCC) de Durban, em 2011, selou o compromisso de um acordo global pós-2020, que foi estabelecido em 2015 em Paris.

O Mecanismo de Desenvolvimento Limpo (artigo 12 do Protocolo de Kyoto) (UNFCCC, 2018b) inclui vários escopos setoriais para desenvolvimento de projetos, tais como metano evitado, energia renovável, troca de combustível fóssil por renovável etc.

A União Europeia se comprometeu a reduzir as emissões de GEE de setores relevantes e criou um mercado regulado para alocações de carbono, as EUAs (European Union Allowances), e denominou o sistema de European Union Emissions Trading System (EU ETS) (SCHMALENSEE \& STAVINS, 2017; UNFCCC, 2018a).

A União Europeia tem sido a maior compradora de créditos de carbono do MDL, os quais podem ser utilizados para o cumprimento de parte das metas de redução de GEE na Europa, de acordo com dados a respeito dos países do Anexo I do Protocolo de Kyoto, disponíveis no website da UNFCCC.

De acordo com a European Commission (2018), o valor total das transações de alocações sob o sistema EU ETS em 2012 foi de EUR 56 bilhões (ou aproximadamente US\$69,2 bilhões, segundo o câmbio à época).

Os países onde mais projetos MDL foram registrados no período entre 2005 e 2012 foram China, Índia e Brasil, segundo o banco de dados de projetos da UNFCCC, e, portanto, nesses países estão localizados os mais importantes fornecedores das Reduções Certificadas de Emissões (RCEs), ou Certified Emission Reductions (CERs), para a União Europeia. 
O Protocolo de Kyoto e seus mercados conectados EU ETS e MDL operaram globalmente de 2005 a 2012. Durante a 21a Conferência das Partes (COP21), seu sucessor foi criado, o Acordo de Paris.

\subsubsection{Finanças Verdes}

De acordo com Lindenberg (2014), as Finanças Verdes se referem ao financiamento de investimentos públicos e privados verdes (incluindo custos preparatórios e de bens de capitais) nas seguintes áreas:

- Bens e serviços ambientais (tais como gestão da água ou proteção da biodiversidade e paisagens);

- Prevenção, minimização e compensação de danos ao meio ambiente e ao clima (como eficiência energética ou reservatórios de hidroelétricas);

- Financiamento de políticas públicas (incluindo custos operacionais) que encorajem a implementação de projetos e iniciativas de mitigação de danos ambientais ou adaptação (como tarifas diferenciadas para energia renovável);

- Componentes do sistema financeiro que lidam especificamente com investimentos verdes, tais como o Fundo Verde do Clima, ou Green Climate Fund, e instrumentos financeiros para investimentos verdes (por exemplo, Green Bonds e fundos verdes estruturados), incluindo suas condições legais, econômicas e institucionais.

\subsubsection{Green Bonds}

De acordo com a International Capital Market Association (ICMA, 2018), Green Bonds são qualquer tipo de título de dívida cujos recursos serão exclusivamente aplicados para financiar ou refinanciar em parte ou a totalidade de projetos verdes (ou com propósitos ambientais) elegíveis, novos ou existentes.

Em seu artigo, Flaherty et al. (2017) explicam que as necessidades de investimento para uma transição a uma economia de baixo carbono são grandes, porém atingíveis. Mclnerney e Johannsdottir (2016) estimam que é necessário 
investir US\$ 10 trilhões em tecnologias verdes em 2030 para se atingir 450 partes por milhão de $\mathrm{CO}_{2}$, nível que é considerado ainda moderadamente seguro.

Segundo as mesmas autoras, a riqueza que poderia ser usada para financiar tais projetos existe. Trata-se de incentivar os investimentos adequadamente. As autoras mencionam uma inserção no mercado de US\$ 80 trilhões de títulos de dívida (bonds) para financiar novas estradas, aeroportos, construções, sistemas de suprimento de água e energia que poderiam reduzir os efeitos das mudanças climáticas.

Existem várias estimativas do volume de investimentos verdes necessários, mas é amplamente aceito que os níveis atuais estão muito abaixo do necessário.

Segundo $\mathrm{Ng}$ e Tao (2016), atualmente $50 \%$ dos ativos de investidores institucionais ocorrem na forma de bonds. Em termos de custo de capital, os custos de financiamento via bonds provavelmente são menores do que via ações ou outros tipos de financiamento, como empréstimos bancários.

A teoria de finanças corporativas indica que produtos de renda fixa provavelmente são mais baratos que empréstimos bancários devido aos menores custos de monitoramento e dispersão de propriedade e riscos, que por sua vez contribuem para um risco de prêmio menor e, consequentemente, custos de financiamento mais baixos.

Ainda segundo $\mathrm{Ng}$ e Tao, os Green Bonds são tipicamente bem equipados para lidar com altos custos de transação e falta de padronização. Primeiramente os emissores, normalmente bancos e agências do setor público, são bem capitalizados e têm capacidade para internalizar os custos de transação. Em adição, o monitoramento do uso dos recursos poderia ser muito mais fácil para instituições financeiras.

Segundo Mclnerney e Johannsdottir (2016), existe um apetite significativo por investimentos em setores de baixo carbono, o que pode ser demonstrado pelo crescimento do mercado de Green Bonds.

Um dos temas chave que surgiram da COP21 e da Conferência Global de Produção Limpa (Espanha, 2015) foi o papel-chave que as finanças precisam 
desempenhar para uma transição eficiente a economias de baixo carbono. É amplamente reconhecido que um dos maiores desafios é a falta de capital.

O crescimento do mercado de Green Bonds tem sido facilitado pelo processo de padronização (CBI, 2008) em desenvolvimento e que facilitará a transparência e monitoramento de recursos para evitar greenwashing.

Papel importante para o desenvolvimento do mercado de Green Bonds poderia ser desempenhado por iniciativas público-privadas como o Fundo Mundial para o Ambiente, ou Global Environmental Facility (GEF), estabelecido em 1991 para ajudar a proteger o meio ambiente e promover o desenvolvimento sustentável.

O GEF oferece recursos a projetos relacionados a biodiversidade, mudanças do clima, águas internacionais, degradação da terra e da camada de ozônio e poluentes orgânicos. O Fundo Verde para o Clima, ou Green Climate Fund (GCF), para o qual países desenvolvidos concordaram em mobilizar US\$ 100 bilhões por ano de recursos novos e adicionais, até 2020, foi criado ajudar países em desenvolvimento responder às mudanças climáticas.

A importância que os Green Bonds podem ter no financiamento da transição para uma economia de baixo carbono pode ser ainda mais relevante dado que, segundo Cui e Huang (2018), entidades multilaterais como o GCF se confrontam com problemas de fundos insuficientes e com a falta de regras claras para que os países desenvolvidos aumentem suas contribuições.

\subsubsection{Green Bonds como Instrumento Intergeracional de Financiamento de uma Economia de Baixo Carbono}

De acordo com Cui e Huang (2018), vários autores indicam a emissão de Green Bonds para aumentar as finanças climáticas, em que as gerações futuras repagariam os bonds enquanto aproveitassem os benefícios de políticas de mitigação das mudanças climáticas implementadas.

A possibilidade de os Green Bonds serem um instrumento intergeracional também foi descrita por autores como Flaherty et al. (2017), os quais afirmam que, nos modelos atuais, o ônus de se implementar políticas de mitigação e adaptação incide sobre a geração atual. 
No artigo "Climate Change and Intergenerational Well-being", Sachs (2015) propõe um compartilhamento intergeracional do ônus, sugerindo que a implementação de políticas climáticas representaria uma estratégia para uma melhoria de Pareto para gerações atuais e futuras.

A emissão de Green Bonds poderia financiar investimentos imediatos para a mitigação climática de forma que parte do débito seja pago por gerações futuras, os que se beneficiarão mais da redução dos danos ambientais.

A maior parte das medidas atuais para mitigação climática aparecem como custos para a geração atual. Sachs sugere o uso de bonds de longo prazo que reembolsam os custos das gerações atuais para os esforços de adaptação e que são pagos por gerações futuras por meio de impostos. Essa estratégia, segundo o autor, pode melhor o bem-estar geral (melhoria de Pareto).

Flaherty et al. (2017) propõem um modelo em três estágios. O primeiro representa os negócios atuais ou usuais, com danos ambientais como um subproduto do processo de produção. No segundo estágio, políticas climáticas são implementadas por meio de agentes privados em uma economia de mercado, porém, tais agentes são reembolsados por seus esforços via emissão de Green Bonds.

A dívida soberana poderia aumentar conforme os efeitos ambientais e climáticos são reduzidos a níveis sustentáveis. Finalmente, no terceiro estágio, futuras gerações pagariam de volta os bonds por meio de impostos. As gerações futuras não experimentariam danos ambientais, e o bem-estar geral melhoraria. Depois desse período, uma vez que os bonds são pagos e os GEE estabilizados a um nível baixo, o imposto poderia ser reduzido.

Desta forma, a geração atual permaneceria tão bem quanto sem os esforços de mitigação, enquanto melhoraria o bem-estar das gerações futuras. A política intergeracional de imposto e transferência tornaria a mitigação e adaptação às mudanças climáticas em uma estratégia de melhoria de Pareto para ambas as gerações. 


\subsubsection{Green Bonds Principles}

Os Green Bond Principles (GBP) (ICMA, 2018) são diretrizes voluntárias que recomendam transparência e promovem integridade no desenvolvimento do mercado de Green Bonds, esclarecendo o processo para emissão destes.

Os GBP são de amplo uso para o mercado, pois oferecem aos emissores orientações sobre componentes-chave envolvidos no lançamento de Green Bonds com credibilidade, ajudam investidores disponibilizando informação necessária para avaliar o impacto ambiental de Green Bonds etc.

Os GBP possuem quatro componentes principais:

1. Uso dos recursos;

2. Processo para avaliação de projeto e seleção;

3. Gestão dos recursos;

4. Relatórios.

\subsubsection{Revisão Externa para Emissão de Green Bonds}

É recomendado que emissores de Green Bonds adotem uma revisão externa para confirmar o alinhamento de seus Green Bonds em relação às características definidas pelos GBP. Existe uma variedade de formas para que os emissores obtenham opinião externa para a formulação de seus Green Bonds, e há vários níveis e tipos de revisão que podem oferecer ao mercado. Tais orientações e revisões externas podem incluir:

1. Revisão de consultores: um emissor pode buscar aconselhamento de consultores ou instituições com expertise reconhecida em sustentabilidade ambiental ou em outros aspectos da emissão de Green Bonds, como por exemplo para uma segunda opinião.

2. Verificação: o emissor pode ter seu Green Bond verificado independentemente por partes qualificadas, como por exemplo auditores. Em contraste com a certificação, a verificação pode focar no alinhamento em relação a padrões internos ou afirmações feitas pelo emissor. 
3. Certificação: um emissor pode ter seu Green Bond certificado para padrões externos, os quais definem critérios, e o alinhamento a tais critérios é testado por uma terceira parte certificada.

4. Rating: um emissor de Green Bond pode obter uma nota (rating) de uma terceira parte qualificada, como as agências de rating tradicionais. $\mathrm{O}$ rating de Green Bonds seria separado da nota de ESG (Environment, Social and Governance) do emissor, pois a nota ESG se refere ao emissor e não a um bond específico.

O Climate Bonds Standard (CBI, 2008) e o sistema de certificação são um esquema de rotulagem parecido com o que existe para Comércio Justo (Fairtrade), mas neste caso para bonds. Critérios científicos rigorosos asseguram consistência no limite de $2^{\circ} \mathrm{C}$ de aquecimento estabelecido no Acordo de Paris. O esquema é usado globalmente por emissores de bonds, governos, investidores e mercados financeiros para priorizar investimentos que genuinamente contribuem para enfrentar as mudanças climáticas.

De acordo com o CBS, os instrumentos de dívida podem ser certificados sob o CBS versão 2.1 (ldem), como se pode observar no Quadro 1.

Quadro 1. Instrumentos de dívida que podem ser certificados com Green Bond - CBS

\begin{tabular}{|l|l|}
\hline $\begin{array}{l}\text { Instrumento } \\
\text { de dívida }\end{array}$ & Definição \\
\hline $\begin{array}{l}\text { Bond para uso } \\
\text { dos recursos }\end{array}$ & $\begin{array}{l}\text { Uma obrigação de dívida-padrão. Os recursos devem ser alocados a uma subconta, } \\
\text { movimentados a um subportfólio ou acompanhados pelo emissor e atestados por um } \\
\text { processo formal interno que conecta às operações de empréstimo e investimento do } \\
\text { emissor para projetos e ativos elegíveis. }\end{array}$ \\
\hline $\begin{array}{l}\text { Bond para uso } \\
\text { de receitas }\end{array}$ & $\begin{array}{l}\text { Uma dívida para a qual não cabe recurso. A exposição de crédito em bonds é contra } \\
\text { fluxos de caixa de vendas, honorários, impostos etc., e o uso dos recursos pode ser } \\
\text { direcionado para projetos e ativos relacionados a tal fluxo ou não. }\end{array}$ \\
\hline $\begin{array}{l}\text { Bond de } \\
\text { projeto }\end{array}$ & $\begin{array}{l}\text { Um bond de projeto para um único ou múltiplos projetos ou ativos. O investidor tem } \\
\text { exposição direta ao risco do projeto, com ou sem recurso ao emissor. }\end{array}$ \\
\hline $\begin{array}{l}\text { Bond de } \\
\text { securitização }\end{array}$ & $\begin{array}{l}\text { Um bond colateralizado por um ou mais projetos ou ativos elegíveis. Inclui valores } \\
\text { mobiliários atrelados a ativos, a hipotecas e a outras estruturas de securitização. A } \\
\text { única fonte de repagamento é o fluxo de caixa dos ativos. }\end{array}$ \\
\hline Bond coberto & $\begin{array}{l}\text { Um bond de duplo recurso que se baseia primariamente no repagamento pelo emissor, } \\
\text { mas também acessa um conjunto de ativos. O conjunto coberto, o qual geralmente } \\
\text { inclui hipotecas e outros ativos, podem ser utilizados como colaterais. }\end{array}$ \\
\hline $\begin{array}{l}\text { Bonds ou notas } \\
\text { conversíveis }\end{array}$ & $\begin{array}{l}\text { São aqueles que têm o direito, mas não a obrigação, de conversão a um número } \\
\text { específico de ações ordinárias, sob termos e condiçóes específicos. }\end{array}$ \\
\hline $\begin{array}{l}\text { Papéis } \\
\text { comerciais }\end{array}$ & $\begin{array}{l}\text { Dívida de curto prazo. Notas promissórias não asseguradas emitidas por fortes } \\
\text { entidades, como instituições financeiras e corporações. Geralmente têm uma } \\
\text { maturidade de 270 dias ou menos. }\end{array}$ \\
\hline
\end{tabular}




\begin{tabular}{|l|l|}
\hline Nota & $\begin{array}{l}\text { Um instrumento de dívida tradicional alemão, com taxa fixa ou variável. Tem } \\
\text { Schuldschein } \\
\text { maturidade de 2 a } 10 \text { anos e um volume típico de EUR } 10 \text { a } 500 \text { milhões. Legalmente, } \\
\text { é um certificado de bom pagador. Algumas características são parecidas com as de } \\
\text { empréstimo, outras com as de bonds. }\end{array}$ \\
\hline Sukuk & $\begin{array}{l}\text { "Sukuk" é um termo que se refere a instrumentos quase-dívida que foram } \\
\text { desenvolvidos para atender às restrições das finanças islâmicas. Um dos princípios é } \\
\text { evitar o pagamento ou a cobrança de juros. }\end{array}$ \\
\hline \multirow{5}{*}{$\begin{array}{l}\text { Uma linha de crédito disponível para financiar projetos ou outros propósitos. } \\
\text { Empréstimos podem ser garantidos ou não. Exemplos típicos de empréstimos } \\
\text { empréstimos } \\
\text { segurados são Project Finance e hipotecas. } \\
\text { Pode incluir empréstimos sindicalizados, clube de investidores, seguradoras, fundos de } \\
\text { dívida, fundos Hedge, private equity, finanças estruturadas (porções com diferentes } \\
\text { riscos e preços), crédito para exportação etc. } \\
\text { A Associação do Mercado de empréstimos publicou os Princípios dos Empréstimos } \\
\text { Verdes em 2018, que fornecem um guia semelhante aos Princípios para Green Bonds. }\end{array}$} \\
\hline
\end{tabular}

Fonte: CBS (CBI, 2008).

As etapas para a obtenção de recursos via Green Bonds são as seguintes (CBI, 2018):

1. Selecionar projeto ou ativo que qualifica como green segundo o CBS;

2. Contratar revisores independentes (lista em CBS) e obter endosso do Climate Bonds Standard Board;

3. Definir o montante financeiro a ser obtido no mercado de capitais com base no valor dos ativos ou projetos selecionados;

4. As etapas seguintes são as mesmas das emissões de bonds tradicionais (seleção de entidades financeiras distribuidoras, obtenção de rating, road show, bookbuilding, lançamento etc.);

5. Monitorar e reportar as atividades do projeto ou ativo green aos investidores anualmente.

Horsch e Richter (2017) apresentam outra forma de classificar Green Bonds, a qual leva em consideração se o bond é explicitamente denominado como green:

- Bonds denominados pelo mercado como green;

- Bonds denominados como green por provedor de dados;

- Bonds não denominados como green.

Quando se refere a Green Bonds, é importante diferenciar entre bonds denominados ou não denominados green. Os denominados se referem a bonds 
negociados como green, enquanto os não denominados se referem aos que são usados para projetos ambientais, porém não são negociados como Green Bonds.

É importante notar que qualquer organização é elegível para emitir um Green Bond. A credencial green não é atribuída ao emissor, mas sim ao projeto para onde os recursos serão direcionados.

Ainda segundo Horsch e Richter, embora agências supranacionais e bancos multilaterais sejam mais ativos, o desenvolvimento do mercado mostra que bancos comerciais, corporações e agências locais têm também emitido Green Bonds.

As emissões que são apoiadas por governos ou instituições multilaterais possuem melhor classificação de risco e pagam um cupom menor. Os Green Bonds emitidos por corporações são os que têm pagado maior cupom.

\subsubsection{O Mercado de Green Bonds}

Conforme mostra o gráfico abaixo, extraído do site da Climate Bonds Initiative (2018), as emissões de Green Bonds têm crescido expressivamente.

Figura 2. Crescimento do Mercado de Green Bonds

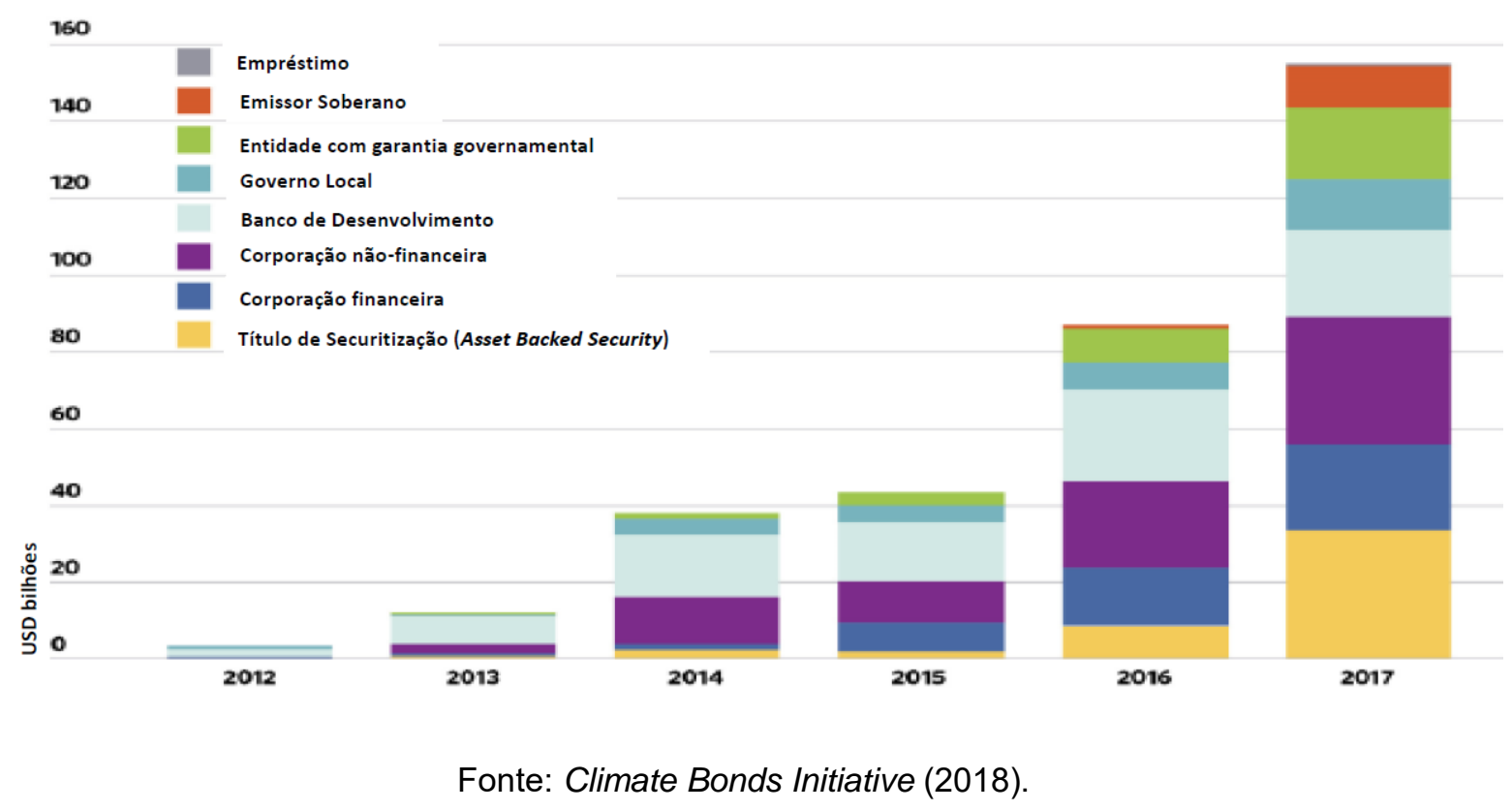

Os valores apresentados no gráfico são significativos quando comparados ao valor total do mercado de alocações do EU ETS. Enquanto cerca de US\$ 45 bilhões 
foram emitidos em denominados Green Bonds em 2015 (ICMA, 2018), em 2012 no EU ETS foram negociados US\$ 69,22 bilhões em créditos de carbono (alocações ou allowances), conforme mostra o website da European Commission (2018) (observase que, em 2012, o preço por tonelada era de US\$8,7 e, em 2017, foi entre US\$ 5 e $6)$.

US\$ 52 bilhões é o valor global das iniciativas de precificação de carbono em 2017, incluindo o carbono efetivamente negociado no mercado (a um preço menor do que em 2012), os impostos recolhidos pelos governos mundo afora e as receitas dos países participantes do EU ETS provenientes de leilões de permissões para emissão de GEE (WORLD BANK GROUP, 2017).

Segundo dados compilados pela Climate Bonds Initiative (2018), somente em 2017 foram emitidos cerca de US\$ 162 bilhões de novos Green Bonds, o que representa mais de três vezes todas as demais iniciativas globais de precificação de carbono em 2017, conforme mencionado acima. Segundo a mesma fonte, em 2018 foram emitidos US\$ 168 bilhões, e há uma estimativa de emissões de US\$250 bilhões em 2019.

Ainda de acordo com Horsch e Richter (2017), até agora os Green Bonds têm apresentado desvios padrão mais baixos do que os das ações negociadas em bolsa, mas não oferecem retornos condizentes com seus riscos. De acordo com suas posições de risco/retorno, eles não representam um investimento eficiente durante o período de observação.

Quadro 2. Comparação entre Valores de Mercado de Instrumentos de Precificação de Carbono (valores em USD bilhões)

\begin{tabular}{|c|c|c|c|}
\hline Ano & $\begin{array}{c}\text { Créditos de carbono } \\
\text { EU ETS }\end{array}$ & Green Bonds & $\begin{array}{c}\text { Todas iniciativas precificação Carbono } \\
\text { (excluindo Green Bonds) }\end{array}$ \\
\hline $\mathbf{2 0 1 2}$ & 69 & 5 & 52 \\
\hline $\mathbf{2 0 1 5}$ & & 45 & \\
\hline $\mathbf{2 0 1 7}$ & 16 & 156 & \\
\hline
\end{tabular}

Fonte: Relatório World Bank Group (2017) e CBI (2018).

Apesar da ineficiência numa base isolada, os Green Bonds poderiam representar um componente valioso a um portfólio se as correlações e os riscos deste forem considerados. 
De acordo com Mathews e Kidney (2012), em áreas novas como energia renovável, os instrumentos de dívida precisam ser modelados o mais próximo possível de bonds simples. Inovações específicas como pagamentos variados de juros precisam ser minimizados, visando atrair uma gama mais ampla possível de investidores institucionais.

Para esses autores parece ser contra produtivo fazer um link entre Green Bonds como veículos de investimentos e créditos de carbono, de modo a serem negociados em mercados de carbono. Os créditos de carbono atraem participantes que desejam compensar suas emissões de carbono. Isso é bem diferente da clientela de investidores institucionais que são atraídos por Green Bonds emitidos em grandes denominações.

No caso de Green Bonds emitidos por bancos de desenvolvimento de países em desenvolvimento, provavelmente em associação a um banco de investimento de um país desenvolvido, também teriam que ser estruturados de forma a endereçar algumas preocupações, como por exemplo o prêmio de risco atrelado a investimentos em países em desenvolvimento.

Nessas circunstâncias, os países em desenvolvimento de fato têm algo a oferecer que não está disponível no mundo desenvolvido. Brasil ou África do Sul, por exemplo, possuem abundância de luz solar, chuvas, terra onde os biocombustíveis podem ser produzidos, energia renovável gerada e abundância de proprietários rurais dispostos a dispor suas terras à geração de energia.

Esse encontro entre a demanda por investimento seguro vinda dos países desenvolvidos e as opções de fornecimento de energia renovável no mundo em desenvolvimento fornecem as bases racionais para os Green Bonds.

Além disso, os Green Bonds emitidos até hoje poderiam ajudar a agregar pequenos projetos a grandes projetos. Sabe-se que isso pode ser realizado visto que instituições privadas já emitiram bonds designados a agregar e padronizar atividades econômicas, tais como provisão de infraestrutura sustentável.

Uma comparação interessante entre a emissão de Green Bonds e impostos para uma transição à economia verde é feita por Monasterolo e Raberto (2018), na qual eles concluem que, sob as premissas do modelo usado, políticas públicas 
verdes implementadas por meio da emissão de Green Bonds soberanos representam uma solução "ganha-ganha" para uma transição a uma economia verde e para a performance do mercado de crédito, graças aos novos investimentos verdes que contribuem com a redução de importação de matérias-primas.

Em contraste, os negócios usuais, baseados em investimentos e produção "sujos", obtêm resultados inferiores em termos de acumulação de capital, emprego, reservas bancárias e depósitos, devido à alta importação de matérias-primas.

Entretanto, as políticas públicas verdes se diferem em termos de seus efeitos distributivos. Essa diferença poderia ser explicada pela forma e condições (características fiscais, orçamento e juros da dívida soberana) pelas quais ela é implementada e financiada.

As políticas públicas influenciam o poder de compra do cidadão e a concentração de riqueza no setor de crédito, com efeitos cascata na economia real e no mercado de crédito. Restringir ou relaxar o orçamento governamental é crucial para explicar a diferença entre efeitos distributivos das políticas fiscal e monetária verdes, em uma economia caracterizada por limitações orçamentárias, tais como as medidas de austeridade fiscal aplicadas na União Europeia.

No cenário de incentivos, em que o governo não está sujeito a um orçamento equilibrado, a dívida pública cresce como uma consequência da emissão de Green Bonds soberanos, os quais, por sua vez, têm um efeito positivo no crescimento verde e nos postos de trabalho. Entretanto, a dívida pública adicional pode afetar negativamente os trabalhadores no longo prazo, implicando em questões de equidade intergeracional.

Em contraste, no cenário de incentivos ou impostos verdes, o governo aumenta a taxação para endereçar os custos da política verde e respeitar os limites de orçamento, afetando em particular o poder de compra dos trabalhadores já no curto prazo. Isso, por sua vez, aumenta o desemprego e diminui o acúmulo de capital, enquanto bancos comerciais fornecem menos empréstimos e abrem menos contas como consequência de uma economia real que performa menos.

O governo brasileiro, por exemplo, por meio do BNDES, emitiu um Green Bond no mercado internacional em 2017 no valor de US\$ 1 bilhão para financiar 
projetos de geração de energia solar e eólica (BNDES, 2018), em um esforço para aumentar a participação desse tipo de energia renovável na matriz energética do país.

Esse Green Bond vence em 2024, paga um cupom de 4,75\% ao ano e os recursos serão alocados para financiar $1.323 \mathrm{MW}$ de energia renovável gerada por oito projetos de energia eólica já selecionados.

Baseado nos Green Bonds Principles (GBP) e observando as melhores práticas de governança, gestão e prestação de contas da alocação dos recursos e performance dos projetos, o BNDES busca com essa emissão criar também um precedente de boas práticas e encorajar outros emissores brasileiros a acessar o mercado de Green Bonds. 


\section{METODOLOGIA E CONTRIBUIÇÕES DO ESTUDO}

\subsection{Abordagem}

Neste estudo, a metodologia utilizada é o estudo de caso focado em Green Bonds como mecanismo de mercado para a incorporação de externalidades ambientais, com uma abordagem mista qualitativa e quantitativa, por se tratar de um tema com maturidade intermediária (teorias existem, porém, serão testadas em situação específica).

A abordagem quantitativa analisa o rendimento (YTM) nos mercados primário e secundário de diversos Green Bonds emitidos nos mercados de capitais e o compara ao rendimento dos outros bonds de mesmo rating, mesma senioridade (DebtRank) e de um mesmo emissor para diferentes durations modificadas que formam a curva de rendimentos dos bonds do emissor.

Os rendimentos dos bonds serão, portanto, proxies para avaliar se a sociedade diferencia as duas categorias de bonds e a importância que ela tem atribuído aos temas ambientais. Tal comparação é executada observando, para um mesmo emissor, o posicionamento do rendimento dos Green Bonds em relação à curva de rendimentos, que será obtida por meio de regressões polinomiais dos pontos representando os rendimentos dos demais bonds de mesmo rating, mesma senioridade (DebtRank), para um mesmo emissor, versus a duration modificada de cada bond.

A abordagem qualitativa estuda a adoção de mecanismos econômicos em diversos setores e apontará como os Green Bonds se comparam a esses outros mecanismos e como podem ser mais amplamente adotados visando financiar a transição para atividades econômicas sustentáveis.

Tal abordagem também inclui uma análise de outros sete estudos que compararam os rendimentos dos Green Bonds e a proposição de mecanismos que otimizem a performance dos Green Bonds e que removam obstáculos ao investimento nesse tipo de instrumento. 


\subsection{Método}

Para o estudo de caso dos Green Bonds, múltiplas fontes de informação são levadas em conta: banco de publicações (Web of Science), internet, banco de dados financeiros como o Bloomberg.

O método do estudo de caso foi selecionado por ser, segundo os autores mencionados abaixo, indicado para:

- Responder à questão "por que" ou "como";

- Analisar múltiplas fontes de informação de cada caso: internet, relatórios de empresas e governo, artigos científicos;

- Explicar o sucesso ou o fracasso de organizações ou projetos;

- Permitir abordagens múltiplas, qualitativa e quantitativa;

- Circunscrever-se a poucas unidades de análise;

- Apresentar caráter de profundidade e detalhamento;

- Investigar empiricamente um fenômeno contemporâneo dentro de seu contexto de vida real, especialmente quando os limites entre o fenômeno e o contexto não estão claramente definidos;

- Enfrentar uma situação única com mais variáveis de interesse que dados, a qual será baseada em diversas fontes de evidências, procurando a convergência de dados e informações;

- Apresentar transversalidade pela ligação entre características e resultados das unidades estudadas.

Os principais autores que embasam teoricamente o estudo de caso são: Einsenhardt (1989), Einsenhardt e Graebner (2007), Serra, Costa e Ferreira (2007) e Yin (2003). 


\subsection{Técnica de Pesquisa}

A técnica de pesquisa é a análise documental, incluindo textos teóricos e artigos científicos sobre o tema, assim como o banco de dados financeiros utilizados pelo mercado de capitais.

\subsubsection{Tipos de Dados}

A análise dos dados será realizada por meio de uma pesquisa qualitativa e quantitativa, as quais podem ser definidas da seguinte forma:

- Pesquisa qualitativa: trata-se da análise de textos teóricos, artigos científicos e outras publicações sobre o tema.

- Pesquisa quantitativa: análise de dados quantitativos do rendimento (YTM) de Green Bonds (classificados como green pelos emissores) e outros bonds, assim como a duration modificada e volumes negociados dos dois tipos de bonds.

\subsubsection{Pesquisa Documental}

$\mathrm{Na}$ análise, serão relevadas as tipologias e bases documentais seguintes:

- Tipos de documentos: artigos científicos, estudos sobre o tema, documentos e banco de dados financeiros;

- Fontes de acesso dos documentos: internet, Web of Science, terminais Bloomberg;

- Categorias pesquisadas: teorias sobre externalidades, mecanismos de mercado, tratados climáticos internacionais, Protocolo de Kyoto, Mecanismo de Desenvolvimento Limpo, Acordo de Paris, Green Bonds.

\subsubsection{Técnicas de Análise de Dados}

Para a análise de dados e informações da pesquisa são necessárias análises quantitativa e qualitativa. 


\subsubsection{Análise Quantitativa}

Na comparação entre o rendimento (YTM) de Green Bonds (classificados como green pelos emissores) que possuam um relatório de terceiros para comprovar os atributos ambientais (second opinion), de acordo com os Green Bonds Principles e o rendimento dos outros bonds, utiliza-se a técnica estatística de regressão para a obtenção das curvas polinomiais de segunda ordem dos rendimentos de diversos bonds e Green Bonds de um mesmo emissor, versus a duration modificada de cada bond.

Para um mesmo emissor são apenas comparados Green Bonds e outros bonds de mesmo rating, prioridade de pagamento (seniority), mesma moeda (EUR ou USD) e mesmas opções de resgate antecipado. Espera-se que o rating dos bonds reflita a existência de garantias e colaterais envolvendo cada emissão.

Para a análise comparativa dos YTM foi feita uma adaptação da metodologia adotada pela IFC (International Finance Corporation) juntamente com a CBI (Climate Bonds Initiative $)^{3}$, para elaboração dos relatórios da série Green Bond Pricing in the Primary Market (CBI, 2019).

Também foram comparados os volumes financeiros médios negociados (seis meses precedentes a cada data de coleta dos dados) dos Green Bonds e demais bonds dos mesmos emissores, com o objetivo de avaliar se existem diferenças de liquidez.

Uma outra análise comparou o diferencial de rendimentos entre os demais bonds de cada curva de cada emissor de Green Bonds e seus respectivos bonds de referência (benchmark bonds) seis meses antes da emissão de cada Green Bond e em março de 2019. Essa análise serve para avaliar se as emissões dos Green Bonds geraram impacto reputacional e deslocaram toda a curva de rendimentos dos bonds de cada emissor em alguma direção.

Embora existam índices como o Bloomberg Barclays MSCl Global Green Bonds Select e Fundos Negociados em Bolsa (Exchange Traded Funds, ETFs) como o iShares Global Green Bond e o UC MSCl European Green Bond, que acompanham a performance dos Green Bonds, estes não foram usados na análise

\footnotetext{
${ }^{3}$ Disponível em: www.climatebonds.net.
} 
quantitativa para comparar a performance dos Green Bonds versus os demais bonds, pois não seria possível controlar algumas variáveis que impactariam os resultados, tais como diferentes emissores, diferentes maturidades, ratings etc., e os resultados seriam menos precisos. Um estudo não acadêmico deste tipo foi apresentado pela Climate Bonds Initiative (2019).

Outras formas de se desenhar análises quantitativas para se avaliar a performance dos Green Bonds foram adotadas pelos autores de outros sete estudos mencionados na parte dedicada às discussões dos resultados.

Segundo Zerbib (2019), por exemplo, o método empírico usado na literatura CSR (corporate social responsibility) para analisar rendimentos de bonds consiste em performar regressões de um certo parâmetro. Este passo requer que se determine variáveis financeiras e extra financeiras independentes que possam explicar o valor intrínseco do rendimento dos bonds da forma mais exaustiva possível, enquanto assegura a robustez dos parâmetros selecionados.

A análise do rendimento de Green Bonds realizada no presente estudo não necessita das regressões feitas por Zerbib porque são comparados os bonds do mesmo emissor de Green Bonds, para o qual quase todos os fatores que explicam os rendimentos são semelhantes, exceto o fator green.

Zerbib utiliza, portanto, o que chama de método de matching, também conhecido como método livre de modelo ou direto, que é uma técnica útil para analisar o valor intrínseco de um instrumento financeiro especializado. $O$ método de matching consiste em comparar um par de instrumentos financeiros com as mesmas propriedades, exceto aquela cujos efeitos interessa. Esse método tem sido usado por outros autores para avaliar o retorno adicional de fundos éticos e o custo de liquidez comparando pares de bonds emitidos pela mesma firma.

Zerbib compara os Green Bonds com apenas dois outros bonds adjacentes do mesmo emissor, um com maturidade menor e outro com maturidade maior do que a do Green Bond analisado.

A metodologia adotada pela IFC (International Finance Corporation) e pela Climate Bonds Initiative (2019) foi adaptada para este trabalho. Ela compara os Green Bonds com no mínimo outros quatro bonds do mesmo emissor para que seja 
possível obter as curvas polinomiais por meio de regressões, conforme detalhado a seguir.

A comparação conforme realizada por Zerbib tem a vantagem de qualificar uma amostragem maior, pois bastam dois outros bonds do mesmo emissor para que a comparação seja feita. A análise da IFC e da CBI adaptada para este estudo tem a desvantagem de qualificar uma amostragem menor (apenas Green Bonds com outros quatro bonds do mesmo emissor); porém, apresenta a vantagem de permitir extrapolações das curvas polinomiais e também possibilitar uma comparação entre as diferenças de rendimentos quando a distribuição dos bonds não é graficamente linear.

\subsubsection{Etapas da Análise Quantitativa}

As etapas dos estudos da série de publicações Green Bond Pricing in the Primary Market, preparados pela IFC juntamente com a CBI, foram adaptadas para que a metodologia pudesse ser utilizada de modo a avaliar a performance dos Green Bonds na data do lançamento destes e durante as negociações no mercado secundário. As etapas 2, 13, 14, 15 e 16 abaixo foram adicionadas no presente estudo.

1. Identificação, por meio do site da Climate Bonds Initiative (2018) dos Green Bonds já emitidos, classificados como green pelo emissor (green labelled) e que aderem aos Green Bonds Principles.

2. Confirmação da classificação green na página descritiva dos bonds nos terminais Bloomberg (menu "Description" > "Additional Information").

3. Seleção dos Green Bonds emitidos em dólares americanos ou euros, para buscar a porção mais líquida do mercado, que permite análises mais precisas.

4. Seleção dos Green Bonds em EUR e USD cujo tamanho na emissão tenha sido acima de USD 300 milhões, buscando também maior liquidez e mais precisão nos resultados. 
5. Seleção dos Green Bonds em EUR e USD que tenham relatório de terceiros (second opinion) ou auditoria de terceira parte, atestando os atributos ambientais do uso dos recursos segundo os Green Bonds Principles.

6. Eliminação dos Green Bonds que não tenham pelo menos mais de três anos até o vencimento, para eliminar eventual liquidez reduzida.

7. Identificação dos emissores de cada Green Bond selecionados até as etapas acima.

8. Identificação dos demais bonds emitidos em mesma moeda respectivamente pelos emissores de Green Bonds que tenham, pelo menos, mais de três anos até o vencimento e valor mínimo na emissão de USD 300 milhões.

9. Compilação dos Green Bonds e outros bonds de cada emissor de Green Bonds, selecionados até a etapa anterior, identificando para cada emissor os bonds de mesma moeda, mesmo rating e prioridade de pagamento (senioridade ou DebtRank) dos Green Bonds por ele emitidos.

10. Seleção dos emissores de Green Bonds que possuem pelo menos mais quatro outros bonds comparáveis (cf. item 9 acima) na primeira coleta de dados, em maio de 2018 (ainda que o número de bonds comparáveis diminua devido à passagem do tempo compreendido entre as coletas mensais), para que seja possível a regressão dos dados a uma curva polinomial minimamente precisa.

11. Tabulação do rendimento (YTM) e duration modificada dos bonds selecionados na etapa anterior.

12. Para cada emissor de Green Bonds, realização de uma regressão estatística dos rendimentos (YTM) versus durations modificadas para obtenção das respectivas curvas polinomiais (curvas de rendimentos ou yield curves) somente dos outros bonds, conforme a etapa 4 acima. 
13. Cálculo da diferença entre o valor real do YTM de cada bond e o valor teórico obtido a partir da curva de regressão polinomial. Cálculo do desvio padrão das diferenças.

14. Para cada curva de rendimentos de diferentes emissores de Green Bonds, avaliação de onde os rendimentos (YTM) dos Green Bonds se posicionam em relação à curva de rendimentos de seu emissor e às curvas que representam os desvios padrão.

15. Classificação do rendimento (YTM) de cada Green Bond de acordo com os seguintes critérios:

a) Abaixo da curva de rendimentos do emissor e com uma distância da curva maior do que o desvio padrão calculado na etapa 12: o mercado atribui um prêmio ao Green Bond.

b) Sobre a curva de rendimentos do emissor ou a uma distância desta que seja menor ou igual ao desvio padrão calculado na etapa 12: o mercado não diferencia entre o Green Bond e demais bonds de um mesmo emissor.

c) Acima da curva de rendimentos do emissor e a uma diferença maior que o desvio padrão calculado na etapa 12: o mercado desconta/desvaloriza o Green Bond.

Para o emissor Apple Inc., observa-se na Figura 3 um exemplo de curva de rendimentos obtida por meio das etapas acima, bem como o posicionamento do Green Bond 2023. 
Figura 3. Exemplo de Curva de Rendimentos Green Bond: Apple 2023, Classificação (b)

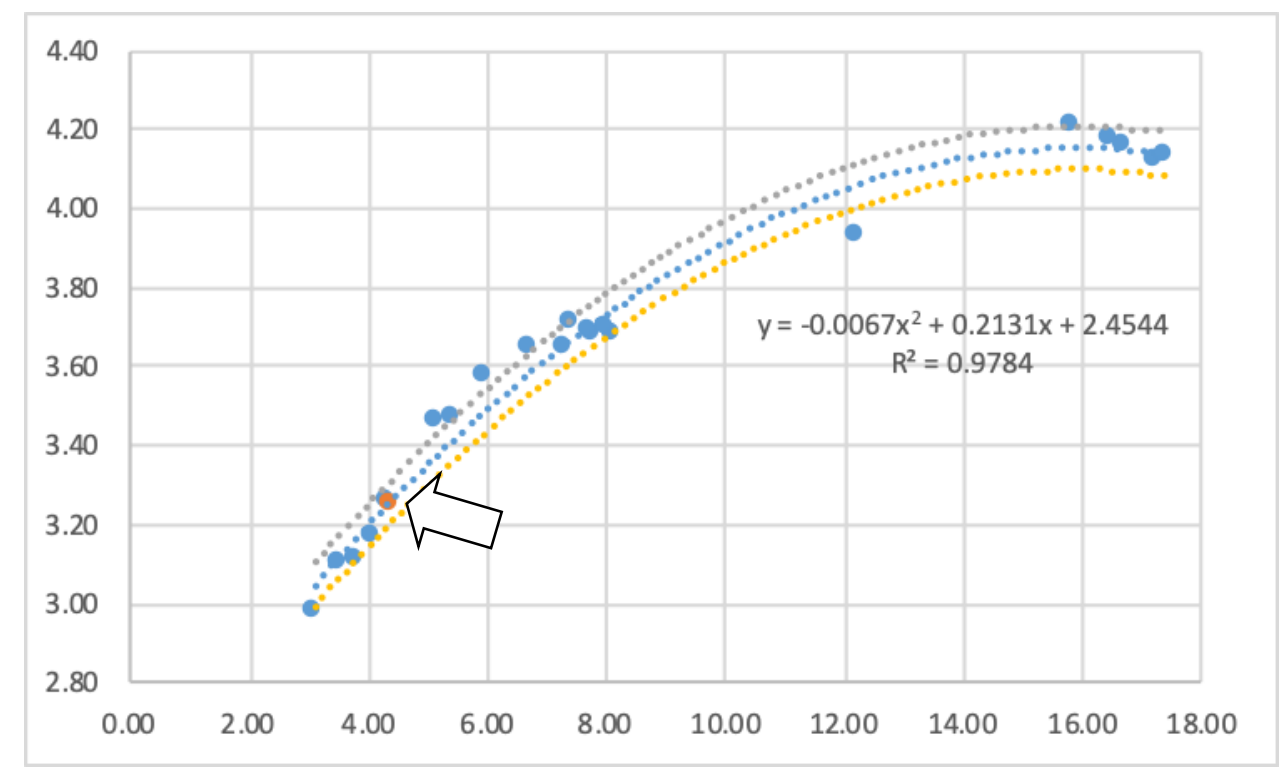

Fonte: elaboração própria do autor (Maróstica, 2019), baseado em dados obtidos junto a Bloomberg.

16. Comparação dos resultados da classificação acima para cada Green Bond no momento da precificação deste e ao final do período de análise e busca de variáveis que possam impactar nos resultados, tais como a Arbitragem de taxas de Rendimento e a formação do Green Halo.

Para checar a influência da arbitragem das diferenças de rendimentos entre os Green Bonds e outros bonds semelhantes do mesmo emissor, checou-se a liquidez no mercado secundário, conforme dados compilados nos terminais Bloomberg.

Fama e French (2007) demonstraram que, quando um grupo de investidores tem apreço por certo tipo de ativo, os preços de equilíbrio mudam e o Modelo tradicional de Precificação de Preço de Ativos (Capital Asset Pricing Model, CAPM) falha em explicar os retornos de tais ativos. Uma parte do universo de investidores parece ter um certo apreço pelas características não pecuniárias dos Green Bonds, outros são agnósticos ou indiferentes a elas.

Uma possível explicação para a queda do prêmio de rendimentos dos Green Bonds no mercado secundário poderia ser a ação de negociadores indiferentes aos 
seus atributos ambientais, que arbitrariam um possível prêmio ou desconto dos Green Bonds com o rendimento dos demais bonds na curva de seu emissor.

Neste caso, o negociador indiferente aos atributos ambientais venderia o Green Bond com menor rendimentos e compraria outro bond com modified duration semelhante na curva do mesmo emissor (ou outro semelhante), lucrando com a diferença das taxas de rendimentos entre os dois. O inverso aconteceria para Green Bonds com desconto. Tal arbitragem também poderia ser feita a partir de derivativos como swaps, que simplificariam a operação e reduziriam os custos.

De acordo com Fama e French et al., os negociadores indiferentes aos atributos ambientais estariam restabelecendo o equilíbrio de preços segundo o CAPM, por não terem nenhum apreço às características não pecuniárias dos Green Bonds, fazendo com que o rendimento destes retorne ao que seria esperado segundo o CAPM, ou seja, sobre a curva de rendimentos do emissor.

No caso de tal arbitragem de taxas de rendimento realmente acontecer, a liquidez dos Green Bonds teria que ser semelhante à dos demais bonds na curva de seu emissor. Uma eventual liquidez reduzida dos Green Bonds excluiria a possibilidade de desaparecimento do prêmio verde por meio da arbitragem.

O parâmetro de seleção da amostragem para este estudo, que estabelece um valor mínimo de emissão de USD 300 milhões para os Green Bonds e bonds a serem comparados, busca a priori a propriedade de que todos os bonds sejam líquidos. Entretanto, as diferenças de liquidez puderam ser avaliadas empiricamente graças à maior disponibilidade de informações sobre volumes negociados a partir de 2018, o que será explicado a seguir.

Bonds são em sua maioria negociados via balcão (over the counter, OTC), e dados confiáveis não são facilmente obtidos, segundo Duffee (1998) e Warga (1991).

No presente estudo, as análises foram feitas por meio da média dos últimos seis meses dos volumes financeiros negociados e registrados em bolsas de negociação ou em balcão, de acordo com a fonte de dados da Bloomberg, que para cada emissor apresentou maiores volumes reportados. 
Em alguns casos de bonds emitidos em dólares e negociados nos Estados Unidos, a fonte de dados Bloomberg que apresentou mais informações (maiores volumes negociados) foi a Trace. Segundo Friewald et al. (2012), as bases de dados da Trace têm sido bastante completas desde sua implementação final.

$\mathrm{Na}$ maioria dos outros casos, as fontes de dados Bloomberg que apresentaram mais informações sobre volumes negociados foram a MFTD e a MiFID. Nestas, são disponibilizadas informações sobre negociações de bonds, em atendimento à nova resolução financeira da European Securities and Markets Authority (ESMA) para o mercado europeu. A resolução MiFID II passou a valer a partir de 2018 na Europa e busca promover maior transparência e proteção aos investidores em bonds.

A introdução das regulamentações sob a MiFID II significa que se faz necessário reportar negociações de bonds que acontecem em ambientes de balcão (OTC) na Europa.

É possível que, nos estudos anteriores, os dados recentes sobre volumes negociados e que são resultado da implementação da MiFID II não estivessem ainda disponíveis, e por isso proxies foram adotadas pelos outros autores.

Para checar a Influência da melhora na reputação dos emissores de Green Bonds devido à percepção de melhora na qualidade da governança, da gestão, dos riscos etc., analisou-se o deslocamento de toda a curva de rendimentos em relação à curva dos respectivos bonds de referência.

O sistema Bloomberg seleciona e disponibiliza automaticamente os bonds de referência (benchmark bonds) para cada bond emitido, incluindo para os Green Bonds. A informação sobre o rendimento dos bonds de referência pode ser obtida a partir da função "BNCHMRK_BOND_YLD" nos terminais Bloomberg. Os bonds de referência são normalmente soberanos ou supranacionais, com maturidade ou duration semelhante à dos bonds analisados.

As diferenças dos bonds analisados e seus respectivos bonds de referência foram utilizadas neste estudo para checar se houve o aparecimento do efeito Green Halo, ou impacto reputacional positivo, detalhado na seção seguinte. 
Com a emissão de Green Bonds pode haver uma mudança na percepção do mercado com relação ao emissor nos seguintes aspectos:

- Melhora da qualidade de risco do emissor, pois o processo de emissão, alocação dos recursos e gestão dos projetos ambientais demandam o aprimoramento da governança e a integração de equipes de diferentes áreas, como ambiental, financeira, operacional etc. (KARPF \& MANDEL, 2018; ZERBIB, 2019; HACHENBERG \& SHIERECK et al., 2018).

- O portfólio de negócios dos emissores terá riscos ambientais e regulatórios reduzidos devido ao carácter ambiental das atividades adicionadas para as quais os recursos dos Green Bonds serão alocados. Entretanto, este ponto pode ser controverso, pois alguns autores argumentam o contrário, dizendo que novas tecnologias financiadas pelos Green Bonds ainda são pouco conhecidas e regulamentadas (DASZŃSKA-ŻYGADŁO, 2018).

- Redução do custo médio do capital, melhor gestão e mitigação de riscos ZERBIB, 2019).

- O emissor passa a acessar novos nichos de investidores dedicados a investimentos de impacto ou sustentáveis, e o aumento da base de investidores, por sua vez, aumentaria a demanda e colocaria pressão sobre os preços dos demais bonds do emissor (idem).

A análise do efeito Green Halo envolveu as seguintes etapas:

1. Identificação da data de precificação de cada Green Bond.

2. Obtenção dos $Y_{T M}{ }^{b}$ para cada bond que faz parte de uma curva de rendimentos de emissores de Green Bonds, assim como de seus bonds de referência $\left(\mathrm{YTMBK}^{\mathrm{b}}\right)$, seis meses antes da data de precificação dos Green Bonds. Essa seria a linha de base para eliminar os efeitos da emissão dos Green Bonds nos demais bonds.

3. Cálculo das diferenças de cada $Y_{T M}{ }^{b}$ e seus respectivos $Y_{T M B K}{ }^{b}$, para obtenção do spread $\left(\mathrm{S}^{\mathrm{b}}\right)$ na data de referência (ou linha de base):

$$
S^{b}: Y^{\prime} M^{b}-Y^{\prime} M B K^{b}
$$


4. Cálculo das diferenças ou spreads $\left(\mathrm{S}^{p}\right)$ entre os $\mathrm{YTM}^{\mathrm{p}}$ dos bonds que compõem cada curva de rendimentos de emissores de Green Bonds e os respectivos $\mathrm{YTMBK}^{\mathrm{p}}$ dos bonds de referência, na data da última coleta de dados, no início de março de 2019.

$$
S^{p}: Y^{p} M^{p}-Y_{T M B K}^{p}
$$

5. Cálculo da diferença entre $S^{p}$ e $S^{b}$.

6. Nos casos em que $S^{b}-S^{p}>0$, mostrando que os spreads diminuíram e após a emissão dos Green Bonds a curva de rendimentos se deslocou para valores mais baixos, foi feita uma comparação com o comportamento geral do mercado de renda fixa e com mudanças de Rating dos Green Bonds.

As diferenças entre os spreads podem revelar alterações em consequência da emissão de Green Bonds. Esse fenômeno se assemelharia ao Green Halo (ver detalhes na seção seguinte), ou efeito reputacional positivo.

As variações de Rating foram levadas em consideração na análise devido ao fato de que os especialistas das agências de Rating podem ter uma a perspectiva própria, e podem ter opiniões que diferem da percepção de risco/retorno e outros interesses não pecuniários de parte dos negociadores do mercado de renda fixa.

Como as alterações de Rating também influenciam as decisões de parte dos negociadores do mercado, esta variável deve ser levada em conta na análise da formação do Green Halo.

Em alguns casos a mudança de Rating antecipa as mudanças de percepção de risco/retorno de investidores em relação aos ativos avaliados pelas agências. Em outros casos tal mudança de Rating acontece em consequência da mudança da percepção dos investidores, expressada através da variação de preços e rendimentos.

Nesta análise foram levadas em consideração as mudanças de Rating dos Green Bonds para se avaliar se existe correlação entre a formação de Green Halo e alterações de Rating. 
Ainda para a análise da formação de Green Halo, tem-se que levar em consideração que a contração de taxas de rendimentos (spreads) nas curvas analisadas não pode se dar em decorrência da contração de taxas do mercado de renda fixa em geral (diferenças entre os rendimentos de bonds corporativos e soberanos).

Para as análises da evolução dos spreads nos mercados de renda fixa de títulos soberanos e corporativos em USD e EUR, foram considerados os seguintes índices:

- LUATTRUU (Bloomberg Barclays US Treasury Total Return Unhedged USD): índice que mostra o retorno de títulos do Tesouro Americano em USD, sem proteção cambial;

- LUACTRUU (Bloomberg Barclays US Corporate Total Return Unhedged USD): índice que mostra o retorno de títulos de corporações americanas em USD, sem proteção cambial;

- LEATTREU (Bloomberg Barclays EURO Treasury Aggregate Total Return Index Unhedged EUR): índice que mostra o retorno agregado de títulos do tesouro de vários países europeus, emitidos em EUR, sem proteção cambial;

- LECPTREU (Bloomberg Barclays EURO Aggregate CorporateTotal Return Index Unhedged EUR): índice que mostra o retorno agregado de títulos corporativos de empresas de vários países europeus, emitidos em EUR, sem proteção cambial.

Os gráficos apresentados nas Figuras 8 e 9 mostram a evolução das diferenças entre os preços dos bonds soberanos e dos corporativos emitidos em EUR e USD no período analisado, que vai de 2013 (seis meses antes dos bonds com data de emissão mais antiga, 2014, incluídos na amostragem) até março de 2019.

Os gráficos revelam que uma redução das diferenças (spreads) entre os bonds analisados e os benchmark bonds precisariam levar em consideração também as condições gerais do mercado de bonds corporativos e soberanos em 
EUR e USD, para que variações consequentes de fatores externos à emissão dos Green Bonds sejam ponderadas na análise.

Figura 4. Evolução dos Preços dos Bonds Soberanos e Corporativos em EUR

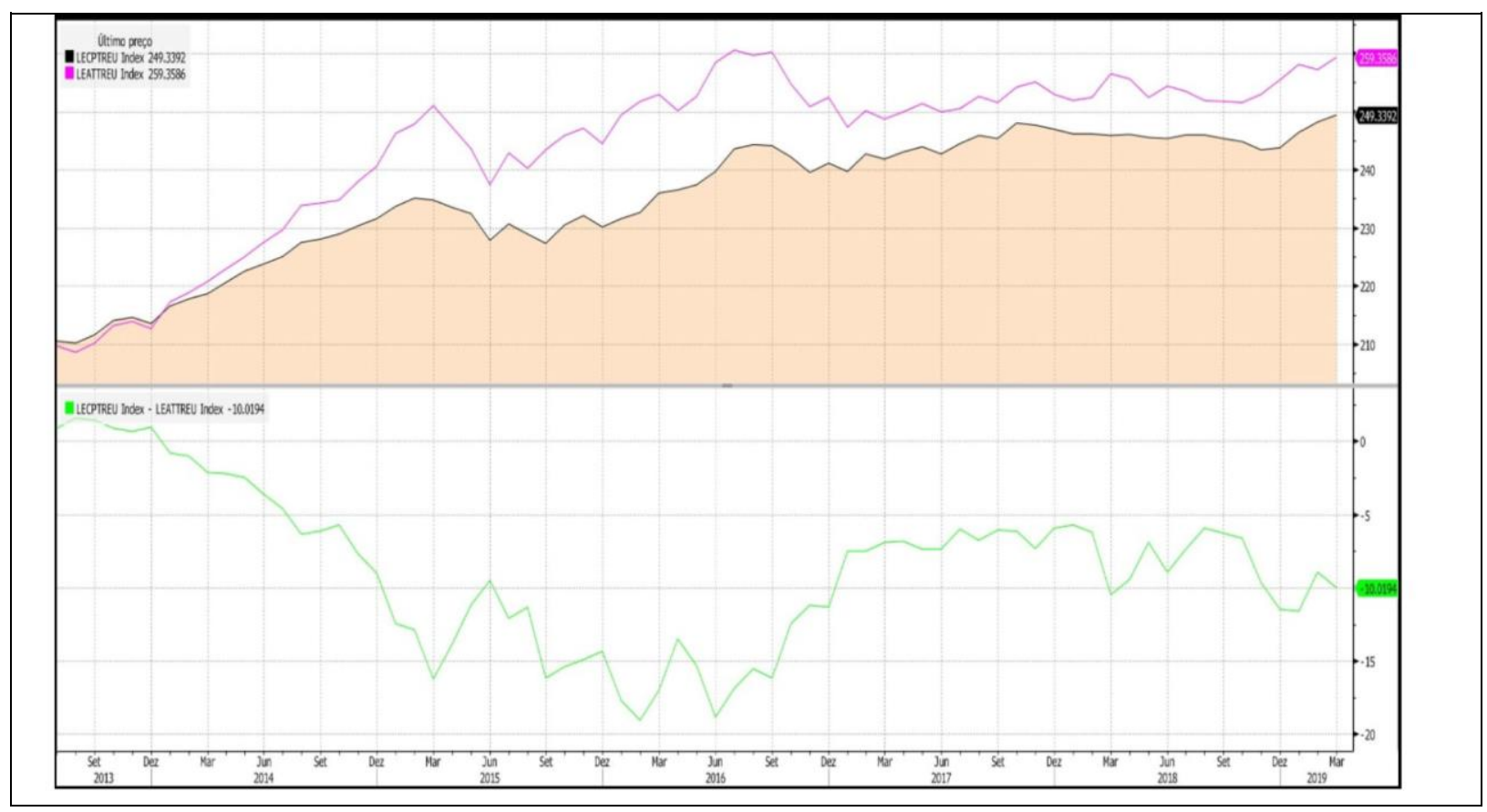

Fonte: Terminal Bloomberg. 
Figura 5. Evolução dos Preços dos Bonds Soberanos e Corporativos em USD

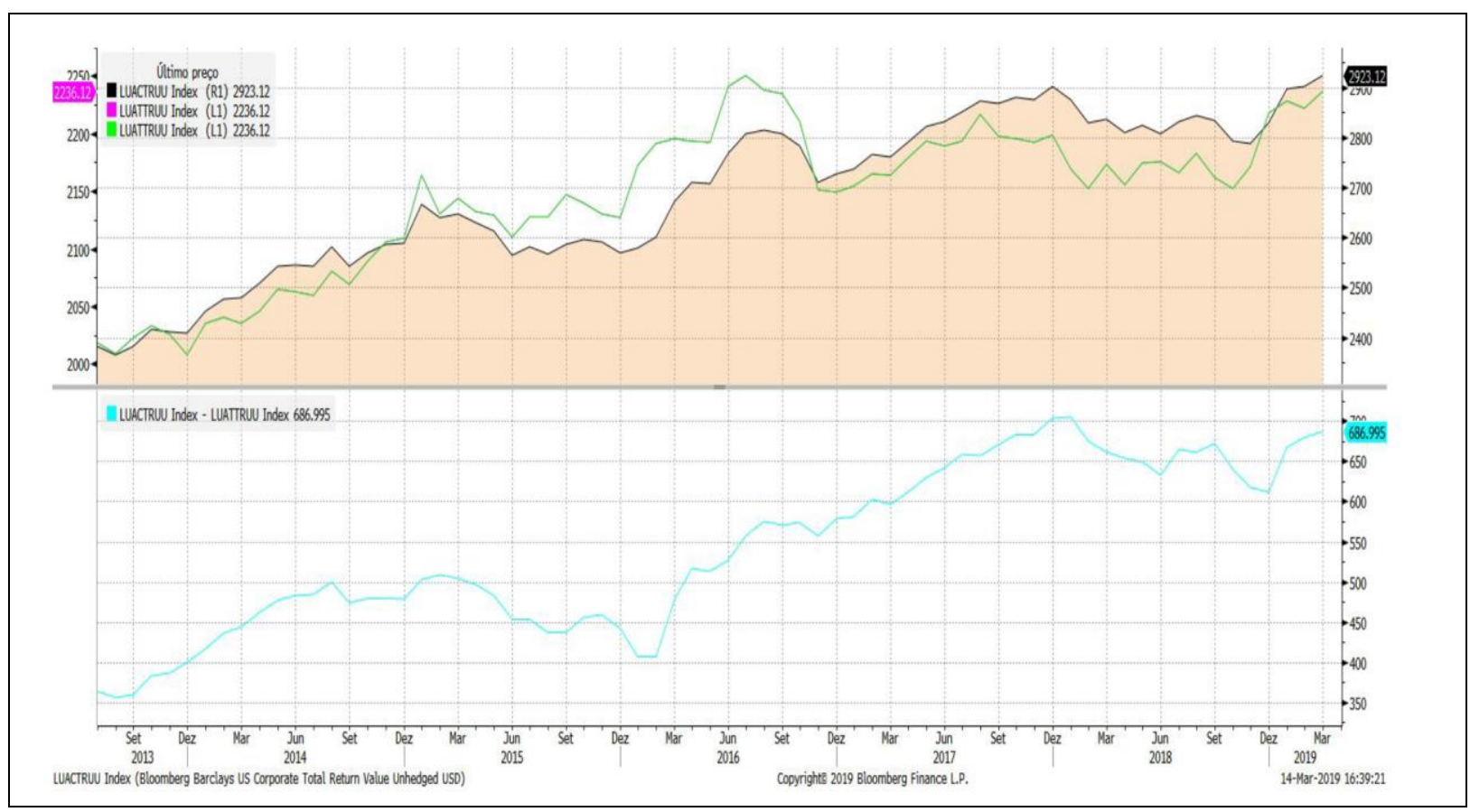

Fonte: Terminal Bloomberg.

\subsubsection{O Fenômeno Green Halo}

O conceito Green Halo foi inicialmente estudado e empregado nas áreas de pesquisa e práticas de responsabilidade social corporativa (corporate social responsibility, CSR). Segundo Chernev e Blair (2015), a CSR tem sido comumente visto somente como uma ferramenta para melhorar a reputação de corporações e obter a cooperação de clientes. Entretanto, suas pesquisas recentes mostram que o impacto de CSR pode ser extendido e pode influenciar a forma como consumidores avaliam os produtos ou serviços de uma empresa.

O estudo de Chernev e Blair mostra que atos de boa vontade social de empresas podem alterar a percepção de seus produtos, e consumidores passam a percebê-los como superiores aos concorrentes.

Tendo surgido inicialmente na área de CSR, o termo Green Halo já tem sido usado no mercado financeiro para se referir ao efeito positivo que a emissão de Green Bonds poderia causar na percepção de risco e qualidade do emissor. 
Uma análise não acadêmica patrocinada por um banco privado em 2018 comparou a curva de rendimentos de sete emissores de Green Bonds com uma curva teórica de outros emissores dos mesmos setores.

A análise concluiu que os bonds das curvas dos emissores de Green Bonds negociavam com rendimentos de dois a treze pontos-base mais baixos que os dos bonds de outros emissores comparáveis. A análise tem sido criticada pois a comparação com um portfólio sintético não é perfeita.

A falha na análise de tal estudo não acadêmico é contornada neste estudo ao comparar os rendimentos dos bonds dos emissores de Green Bonds com seus respectivos benchmark bonds. O período de comparação se inicia seis meses antes da data de precificação dos Green Bonds (linha de base) e termina em março de 2019, conforme já descrito anteriormente neste documento.

\subsubsection{Análise Qualitativa}

Foi realizada uma análise de conteúdo de documentos teóricos, artigos científicos, teorias sobre externalidades, mecanismos de mercado, ações governamentais para redução de GEE, tratados climáticos internacionais, o Protocolo de Kyoto, o Mecanismo de Desenvolvimento Limpo, o Acordo de Paris, Green Bonds, a literatura sobre incorporação de externalidades via mecanismos de mercado e de governo para mitigação das mudanças climáticas, finanças corporativas e finanças comportamentais.

Os autores consultados para fundamentar a análise qualitativa foram: Bardin (2011), Cooper e Schindler (2015), Eisenhardt (1989), Page (2008), Petticrew e Roberts (2006), Serra, Costa e Ferreira (2007), Tranfield, Denyer e Smart (2003) e Yin (2003).

\subsection{Contribuições do Estudo}

\subsubsection{Contribuição à Teoria}

As principais teorias sobre incorporação de externalidades ambientais foram desenvolvidas e aplicadas, até então, propondo impostos (sobre emissões de 
poluentes), sistemas de cap and trade de emissões de GEE, mercados de carbono e de PSA, subsídios, incentivos ou a combinação destes.

Este estudo permite uma melhor compreensão da aplicação de teorias de incorporação de externalidades a um novo mecanismo de mercado, os Green Bonds.

A pesquisa desenvolvida também contribui para a literatura sobre as motivações não pecuniárias dos investimentos éticos ou de impacto (neste caso, socioambientais) e como estes podem modificar os preços de equilíbrio de ativos financeiros (FAMA \& FRENCH, 2007).

\subsubsection{Contribuição à Resolução do Problema}

Este trabalho permite identificar de que maneira os Green Bonds podem ser um novo mecanismo de mercado a ser amplamente adotado por governos e pelo setor privado para financiar a transição para atividades econômicas sustentáveis, de baixo impacto ambiental e impacto social positivo.

A partir de uma revisão bibliográfica, apenas sete artigos acadêmicos foram encontrados nos quais foram analisadas as performances dos Green Bonds e os fatores que as influenciam. Este trabalho, portanto, complementa algumas análises que ainda não foram feitas por tais artigos, tal como a evolução do prêmio verde dos Green Bonds ao longo do tempo, a formulação de hipóteses que justifiquem tal evolução, assim como adiciona propostas para o desenvolvimento do mercado e aperfeiçoamento dos Green Bonds como uma nova classe de ativos.

\subsubsection{Contribuição para a governança ambiental}

\subsubsection{Setor Público}

Outra contribuição deste estudo seria para o melhor entendimento a respeito das características e da possibilidade de obtenção de recursos financeiros de forma diferenciada por meio de Green Bonds, para financiar as ações que visam a transição para atividades econômicas mais sustentáveis e o cumprimento de 
compromissos internacionais como o Acordo de Paris e dos Objetivos de Desenvolvimento Sustentável 2030 da ONU.

\subsubsection{Setor Privado}

Assim como para o setor público, a melhor compreensão das características e da possibilidade de obtenção de recursos financeiros de forma mais eficiente por meio de Green Bonds pode contribuir para que o setor privado busque a melhor forma de estruturar emissões, mitigar riscos envolvidos, acessar o mercado de capitais, validar e monitorar a alocação dos recursos financeiros provenientes das emissões de Green Bonds em projetos ambientais e/ou gerenciar a performance financeira destes no mercado secundário.

\subsubsection{Investidores}

A qualificação transparente e consistente das atividades ou projetos que serão financiados por recursos obtidos por meio de Green Bonds, assim como o monitoramento e verificação da alocação dos recursos e performance das atividades, dos projetos e dos Green Bonds no mercado secundário, podem ajudar no melhor entendimento das características de risco/retorno destes.

A melhor compreensão a respeito das características de risco/retorno dos Green Bonds suportaria, deste modo, as decisões de diversas categorias de investidores, desde aqueles exclusivamente dedicados a investimentos de impacto (impact investors), seguradoras, fundos de pensão e até pessoas físicas. 


\section{VARIÁVEIS E COLETA DE DADOS}

A Climate Bonds Initiative (2018) compila, em sua página Market ${ }^{4}$, todos os Green Bonds emitidos desde 2009 e etiquetados como tal pelo emissor. Uma análise de tal banco de dados apresenta as seguintes informações:

- Quantidade de Green Bonds etiquetados emitidos até abril 2018 em todas as moedas: 2560 ;

- Quantidade de Green Bonds com avaliação de segunda opinião (second opinion) em todas as moedas: 2395 (93,6\%).

- Outras moedas de Green Bonds emitidos e não incluídos no Quadro 3: dólar australiano, real brasileiro, dólar canadense, yuan chinês, peso colombiano, libra esterlina, dólar de Hong Kong, florim húngaro, rupia indiana, yen japonês, dirrã marroquino, peso mexicano, ringgit malaio, coroa norueguesa, dólar neozelandês, novo sol peruano, peso filipino, złoty polonês, rublo russo, coroa sueca, dólar de Singapura, lira turca, dólar de Taiwan e rand sul-africano.

Quadro 3. Green Bonds Emitidos em USD e EUR

\begin{tabular}{|l|l|l|l|}
\cline { 2 - 4 } \multicolumn{1}{c|}{} & Euros & Dólares & Total EUR + USD \\
\hline Valor total em US\$* milhões (valor de face) & 144,327 & 157,500 & 301,827 \\
\hline Quantidade & 212 & 1,702 & 1,914 \\
\hline Valor médio em US\$* milhões na emissão & 663 & 93 & 378 \\
\hline $\begin{array}{l}\text { Quantidade acima de US\$ 300 milhões } \\
\text { (valor de face) - valor mínimo para análise }\end{array}$ & 156 & 154 & 310 \\
\hline $\begin{array}{l}\text { Quantidade acima de US\$ 300 milhões e } \\
\text { com relatório de segunda opinião }\end{array}$ & 123 & 116 & 239 \\
\hline $\begin{array}{l}\text { Bonds selecionados nas etapas acima e } \\
\text { com possibilidade de comparação com } \\
\text { outros 4 bonds do mesmo emissor, com } \\
\text { vencimento acima de 3 anos }\end{array}$ & 45 & 13 & 58 \\
\hline
\end{tabular}

*EUR/USD - Bloomberg, 1 maio 2018

1.2616

Fonte: elaboração própria do autor, baseado em dados da Climate Bonds Initiative (2018).

\footnotetext{
${ }^{4}$ Cf. https://www.climatebonds.net/market.
} 
Os dados mostrados no Quadro 3 indicam que embora exista um conjunto significativo de Green Bonds já emitidos em todas as moedas, apenas 58 destes, representando $3 \%$ do total emitido em USD e EUR, se qualificam para esta análise, conforme critérios definidos anteriormente neste documento.

Existe um conjunto significativo de Green Bonds municipais emitidos em USD que não foram incluídos neste estudo devido à falta de dados disponíveis sobre os demais bonds dos mesmos emissores nos terminais Bloomberg, e devido também aos diferentes impostos que são pagos sobre os rendimentos dependendo da municipalidade emissora. Uma outra dificuldade encontrada é que as emissões de Green Bonds municipais normalmente acontecem simultaneamente à emissão de bonds tradicionais, de modo que pode haver interferência de um sobre o outro.

Embora a Bloomberg compile informações sobre se determinado bond é green ou não, a existência de relatórios de segunda opinião e a auditoria de terceira parte atestando que determinado Green Bond adere aos Green Bonds Principles (GBP) não estão disponíveis (KARPF \& MANDEL, 2018). Assim sendo, a listagem de Green Bonds para se determinar a amostragem neste estudo partiu da compilação de dados da Climate Bonds Initiative (2018).

\subsection{Variáveis}

Para cada Green Bond que faz parte da amostragem desta análise, as seguintes variáveis foram coletadas e analisadas tanto para o Green Bond analisado como para os demais bonds que compõem a curva de rendimentos do mesmo emissor, conforme descrito anteriormente:

- Rendimento até a maturidade (YTM);

- Duration modificada;

- Liquidez, medida a partir da média dos últimos seis meses do volume financeiro negociado no mercado secundário, usando a fonte de dados sobre volumes negociados em bolsa e balcão, registrados e disponíveis na Bloomberg; 
- Rendimento dos bonds de referência (Benchmark YTM) para os Green Bonds e demais bonds que compõe a curva de cada emissor. Os bonds de Referência são selecionados e informados pelo próprio terminal Bloomberg e representam os bonds soberanos de melhor qualidade (rating), com maturidade semelhante ao bond analisado.

\subsection{Coleta de Dados}

A coleta de dados para a análise das variáveis listadas acima teve as seguintes características:

- Fonte de dados: Bloomberg, por meio do terminal disponível na biblioteca da Escola de Administração de Empresas de São Paulo da Fundação Getúlio Vargas (EAESP-FGV) em São Paulo.

- Período da coleta de dados sobre rendimentos dos bonds: de maio de 2018 a março de 2019.

- Frequência da coleta de dados: uma vez ao mês, com exceção de agosto de 2018, devido ao limite do terminal Bloomberg utilizado já ter sido ultrapassado para download de dados para planilhas Excel na data da coleta. Nesses casos, é necessário aguardar a virada do mês para que o limite seja novamente zerado e os dados possam ser transferidos para uma planilha Excel.

- Ferramenta de coleta e análise de dados e cálculos: planilha Excel. 


\section{RESULTADOS E DISCUSSÃO}

\subsection{O Prêmio Verde}

Conforme descrito anteriormente, para cada Green Bond selecionado nesta análise, foi traçada a curva de rendimentos de seu emissor. O rendimento (YTM) dos Green Bonds foi então classificado em:

- Acima da curva de rendimentos (Green Premium): quando o rendimento do Green Bond está a pelo menos um desvio padrão acima da curva de rendimentos de seu emissor;

- Sobre a curva de rendimentos: quando o rendimento do Green Bond está a uma distância menor do que um desvio padrão da curva de rendimentos;

- Abaixo da curva de rendimentos: quando o rendimento do Green Bond está a pelo menos um desvio padrão abaixo da curva de rendimentos de seu emissor. Nesse caso, ou o Green Bond está sendo penalizado pelo mercado ou sua classificação é resultado de características que não dizem respeito ao fato de ser green.

Os resultados obtidos podem ser observados a seguir.

Nota-se que durante o período de coleta de dados do mercado secundário, que durou onze meses, houve flutuações nas performances dos Green Bonds, os quais serão discutidos a seguir. Ao final do período de análise a maioria dos rendimentos dos Green Bonds no mercado secundário está dentro da faixa normal prevista da curva de regressão polinomial dos rendimentos de cada emissor, adicionada a um desvio padrão acima e abaixo da curva, com uma tendência de queda no prêmio verde no decorrer do período analisado.

Os dados mostram uma queda significativa do prêmio verde a partir do lançamento (precificação) dos Green Bonds no mercado. No lançamento o número de Green Bonds com prêmio é de $58,6 \%$, com um prêmio médio para toda a amostragem de -22 pontos-base. Ao final do período analisado, somente $25,7 \%$ dos Green Bonds apresentam prêmio verde, com um valor médio de -2 pontos-base. 


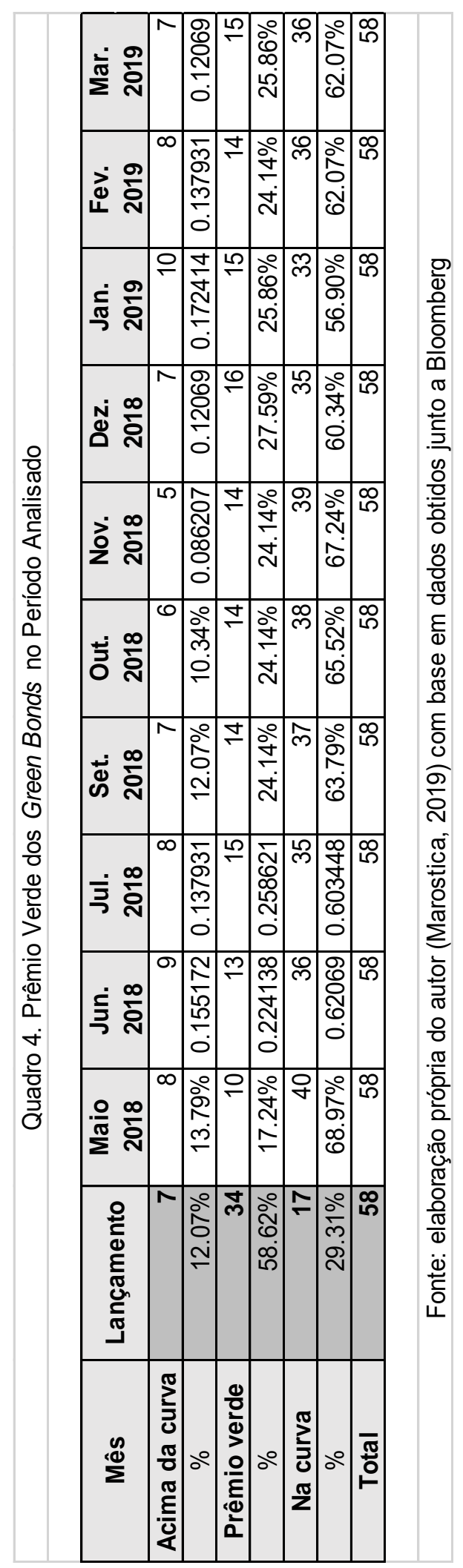


Figura 6. Prêmio dos Green Bonds no Lançamento

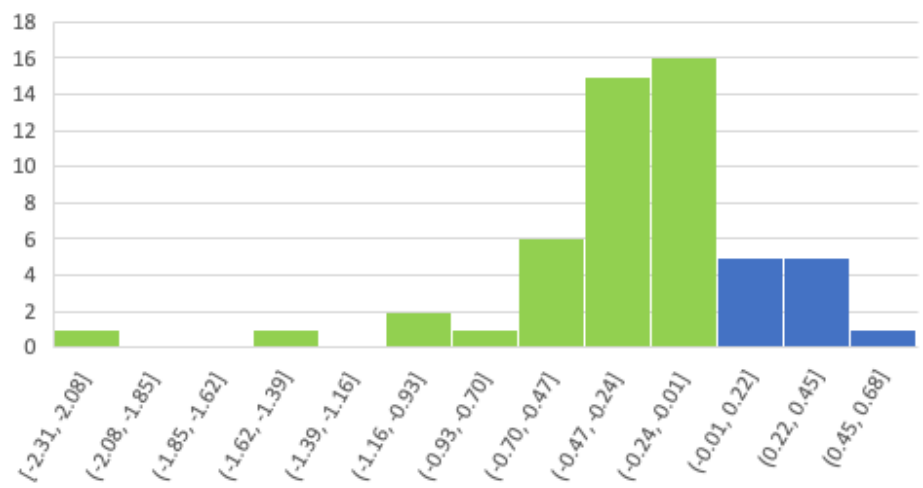

Fonte: elaboração própria do autor (Maróstica, 2019), baseado em dados obtidos junto a Bloomberg.

Figura 7. YTM dos Green Bonds x Curva Teórica, Fim do Período

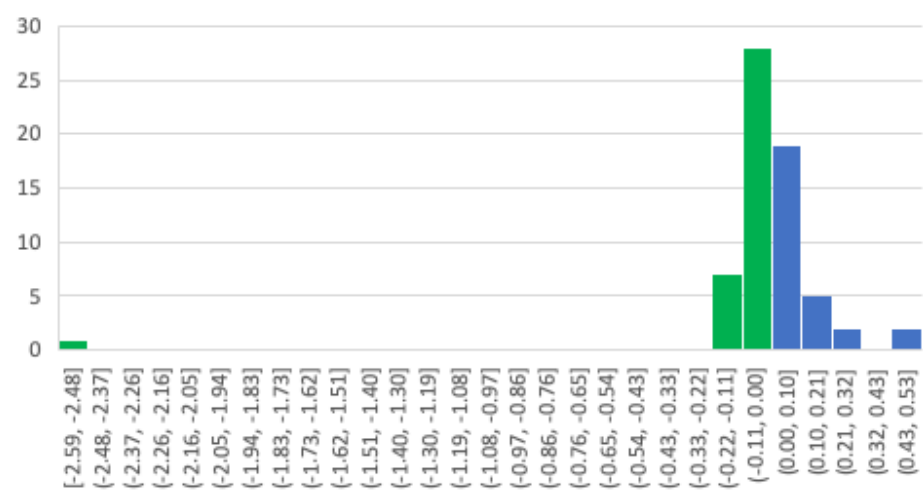

Fonte: elaboração própria do autor (Maróstica, 2019), baseado em dados obtidos junto a Bloomberg.

No mercado de renda fixa, observa-se a prática de um prêmio de lançamento, que seria um melhor rendimento ou um menor preço em relação ao teoricamente esperado, aos investidores que fizerem parte do processo de lançamento (bookbuilding) de um novo bond para que os emissores possam atrair novos investidores.

Segundo Akhigbe et al. (1997), o surgimento de tal prêmio aos investidores depende das motivações do emissor para se emitir um novo bond, e o prêmio ao investidor (menor preço do bond ou maior YTM) somente surge quando o emissor emite novo bond para endereçar desafios relacionados ao fluxo de caixa.

Quando a emissão do bond se dá por outras motivações, como gastos com bens de capital ou investimentos, o impacto da nova emissão nos bonds previamente emitidos é positivo, porém pequeno. 
A emissão de Green Bonds não tem motivações relacionadas ao fluxo de caixa do emissor, pois o uso dos recursos ocorre para investimentos e operacionalização de projetos sustentáveis.

Segundo Akhigbe et al., os demais bonds deveriam se valorizar com uma nova emissão. Pode-se concluir, portanto, que o diferencial positivo de preço (e YTM mais baixo) oriundo no lançamento da maioria dos Green Bonds pode ser exclusivamente atribuído ao fato de se tratar de Green Bonds.

Quadro 5. Prêmio dos Green Bonds na Data de Precificação

\begin{tabular}{|c|c|c|c|c|}
\hline & Prêmio & & NA & \\
\hline Green Bond & Lançamento & GREEN & CURVA & ACIMA \\
\hline IFC 26 & 0.38 & & & 1 \\
\hline APPLE 23 & -0.34 & 1 & & \\
\hline MITSUBISHI 23 & -0.13 & & 1 & \\
\hline ASIA 26 & 0.10 & & 1 & \\
\hline ASIA 25 & -0.03 & & 1 & \\
\hline ENGIE 26 & -1.44 & 1 & & \\
\hline KFW 25 & -0.37 & 1 & & \\
\hline ENGIE 28 & 0.25 & & & 1 \\
\hline ENGIE 29 & -0.60 & 1 & & \\
\hline POLAND 26 & -0.57 & 1 & & \\
\hline SPAREBANK 25 & -0.32 & 1 & & \\
\hline SNCF 24 & -0.80 & 1 & & \\
\hline KFW 24 & -0.31 & 1 & & \\
\hline IBERDROLA 26 & -0.19 & 1 & & \\
\hline SNCF 31 & -0.05 & & 1 & \\
\hline AG FRANCE 24 & -0.98 & 1 & & \\
\hline GAS NAT 25 & 0.09 & & 1 & \\
\hline IBERDROLA 27 & -0.14 & 1 & & \\
\hline SNCF 47 & -0.37 & & 1 & \\
\hline POLAND 21 & -0.03 & & 1 & \\
\hline IBERDROLA 22 & -2.31 & 1 & & \\
\hline UNIBAIL 24 & 1.10 & & & 1 \\
\hline IBERDROLA 25 & -0.08 & & 1 & \\
\hline TOYOTA 21 & -0.20 & 1 & & \\
\hline ADIF 23 & -0.45 & 1 & & \\
\hline DEUT. HYPO & -0.07 & 1 & & \\
\hline WESTPAC 24 & -0.25 & 1 & & \\
\hline BERLIN HYPO & -0.52 & 1 & & \\
\hline NRW 27 & -0.21 & 1 & & \\
\hline NORDEA 22 & -0.29 & 1 & & \\
\hline RAPT 27 & -0.61 & 1 & & \\
\hline
\end{tabular}




\begin{tabular}{|lrrrr||}
\hline INTESA 22 & -0.16 & & 1 & \\
TENNE 29 & -0.16 & 1 & & \\
TENNE 25 & -0.14 & 1 & & \\
ABD 27 & 0.05 & & 1 & \\
KFW 22 & 0.36 & & & 1 \\
EDF 25 & -0.03 & & 1 & \\
APPLE 27 & 0.08 & & 1 & \\
BANK OF CHINA & & & & \\
21 & -0.38 & 1 & & \\
MID AM. ENERGY & & & & 1 \\
48 & 0.35 & & & 1 \\
IBRD 25 & 0.24 & & & \\
CHINA 22 & -0.30 & 1 & & \\
NAB 22 & -0.23 & 1 & & \\
BNP 22 & -0.43 & 1 & & \\
NRW 26 & -0.25 & 1 & & \\
TENNE 33 & 0.11 & & 1 & \\
RABOBANK 21 & 0.16 & & 1 & \\
BERLIN HYPO 23 & 0.46 & & & 1 \\
TENNE 26 & -0.29 & 1 & & \\
TENNE 36 & -0.14 & 1 & & \\
ABN 22 & -0.58 & 1 & & \\
NRW 25 & -0.25 & & 1 & \\
BERLIN HYPO 22 & -0.28 & 1 & & \\
UNIBAIL 25 & -0.55 & 1 & & \\
BPCE 22 & -1.08 & 1 & & \\
CITY PARIS 31 & -0.19 & 1 & & \\
FRANCE 39 & 0.56 & & 1 & \\
KFW 21 & 0.15 & & 1 & \\
Média & -0.218 & & & \\
TOTAL & -12.65 & 34 & 17 & \\
\% & & $58.6 \%$ & $29.3 \%$ & $12.1 \%$ \\
\hline
\end{tabular}

Fonte: elaboração própria do autor (Maróstica, 2019), baseado em dados obtidos junto a Bloomberg. 
Figura 8. Porcentagem de Green Bonds com Prêmio Verde no lançamento e no Mercado Secundário até março de 2019

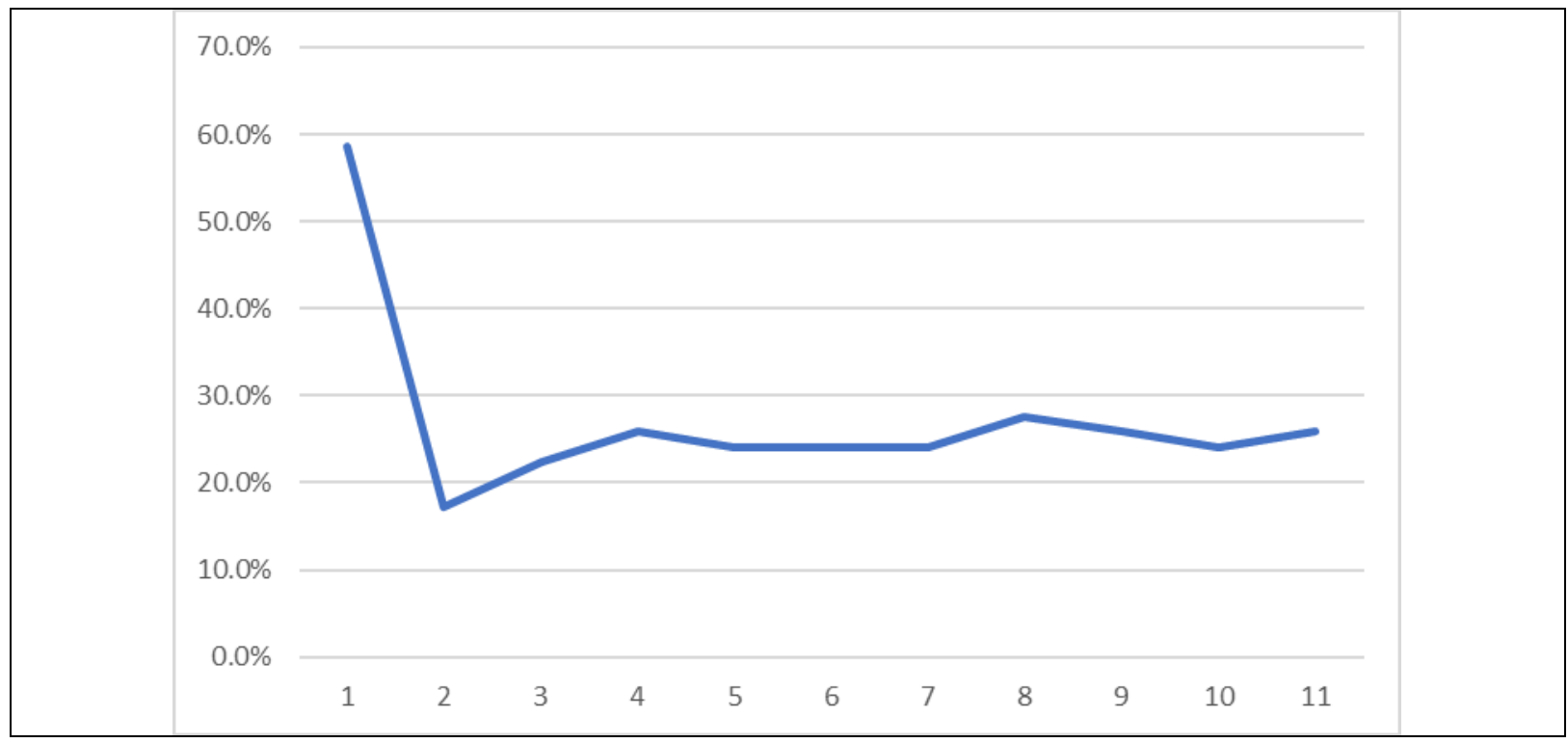

Fonte: elaboração própria do autor (Maróstica, 2019), baseado em dados obtidos junto a Bloomberg.

Os Green Bonds contidos no Quadro 6 apareceram pelo menos três vezes entre aqueles com prêmio ou desconto no período de análise, dessa forma merecendo uma avaliação mais detalhada nas análises a seguir.

Quadro 6. Green Bonds com Prêmio Verde, Moeda e Tipo de Emissor

\begin{tabular}{|l|l|c|}
\hline Green Bond & Moeda & $\begin{array}{l}\text { Soberano } \\
\text { supranacional, } \\
\text { agência de } \\
\text { desenvolvimento }\end{array}$ \\
\hline $\begin{array}{l}\text { Desconto (acima da curva de } \\
\text { rendimentos) }\end{array}$ & USD & sim \\
\hline Bank of China 21 & EUR & \\
\hline Berlin Hypo 23 & EUR & \\
\hline Engie 26 & EUR & \\
\hline Gas Natural 25 & EUR & \\
\hline lberdrola 26 & EUR & \\
\hline Iberdrola 27 & USD & \\
\hline IFC 26 & EUR & \\
\hline Sparebank 25 & EUR & \\
\hline Tenne 25 & EUR & \\
\hline Tenne 36 & EUR & \\
\hline Unibail 24 & & \\
\hline $\begin{array}{l}\text { Prêmio (abaixo da curva de } \\
\text { rendimentos) }\end{array}$ & & \\
\hline ABN 22 & EUR & \\
\hline ADIF 23 & EUR & \\
\hline Berlin Hypo 23 3 sim \\
\hline Berlin Hypo 27 & EUR & \\
\hline China 22 & EUR & \\
\hline
\end{tabular}




\begin{tabular}{|l|l|l|} 
Engie 28 & EUR & \\
\hline Engie 29 & EUR & \\
\hline Iberdrola 22 & EUR & \\
\hline IBRD 25 & USD & sim \\
\hline KFW 24 & EUR & sim \\
\hline KFW 25 & EUR & sim \\
\hline Mitsubishi 23 & USD & \\
\hline Nordea 22 & EUR & \\
\hline NRW 26 & EUR & \\
\hline NRW 27 & EUR & \\
\hline RATP 27 & EUR & \\
\hline Tenne 29 & EUR & \\
\hline Tenne 33 & EUR & \\
\hline Toyota 21 & EUR & \\
\hline
\end{tabular}

Fonte: elaboração própria do autor (Maróstica, 2019), baseado em dados obtidos junto a Bloomberg.

\subsection{Discussão Bibliográfica}

\subsubsection{Outros estudos que estimaram o Prêmio Verde dos Green Bonds}

A revisão bibliografica de artigos acadêmicos que pesquisaram quantitativa e diretamente (não incluindo portanto índices, ETFs ou outras proxies) o prêmio verde dos Green Bonds resultou, até junho de 2019, em sete artigos publicados em revistas cientificas cujas características e resultados estão resumidos no Quadro 7, que inclui também um resumo dos resultados do presente trabalho.

Nota-se que o presente trabalho foi o único, até junho de 2019, que analisou o prêmio verde no mercado primário (emissão) e a evolução deste no mercado secundário, bem como formulou e testou hipóteses para justificá-la.

As hipóteses para justificar a redução do prêmio verde no mercado secundário, testadas somente pelo presente estudo são: o efeito da arbitragem de taxas de rendimentos dos Green Bonds com os demais de suas curvas, e da formação do Green Halo (deslocamento de toda a curva de rendimentos).

Os demais trabalhos avaliaram a influência de variáveis como rating, setor do emissor, existência de relatórios de verificação e outros na formação do prêmio verde. A influência dessas variáveis na formação do prêmio verde não faz parte das análises do presente estudo.

Zerbib (2019) concluiu que os bonds do setor financeiro e os de pior rating são os que obtêm maior prêmio verde. $O$ autor também concluiu que a volatilidade 
(ou o risco) dos Green Bonds e o risco sistêmico não explicam o prêmio verde, e que este ocorre, portanto, devido a interesses não pecuniário dos investidores.

Karpf e Mandel (2018) estudaram também a variação do prêmio verde em relação à maturidade dos Green Bonds municipais americanos e concluíram que quanto mais longo o vencimento maior o prêmio.

Baker et al. (2018) identificaram um maior prêmio verde entre os Green Bonds com certificação $\mathrm{CBI}$ e verificados por terceiros. Quando os bonds municipais analisados eram emitidos juntamente com Green Bonds (mesmo emissor), os autores identificaram que o prêmio verde era menor, e o YTM dos bonds tradicionais era maior. Portanto, ele recomenda não fazer emissões conjuntas. Baker também compara os custos de certificação com o prêmio verde e conclui que a certificação vale a pena do ponto de vista de ganhos econômicos. 


\begin{tabular}{|c|c|c|c|c|c|c|c|c|c|c|c|c|c|}
\hline & 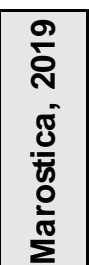 & $\frac{E}{\infty}$ & 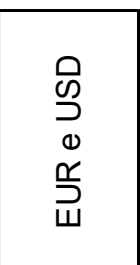 & $\begin{array}{l}\text { \& } \\
\stackrel{0}{\circ} \\
\text { है }\end{array}$ & : & 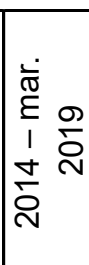 & 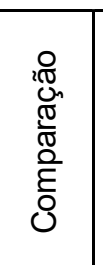 & 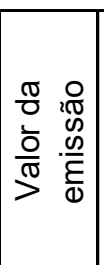 & $\frac{E}{\infty}$ & 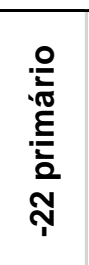 & 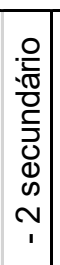 & & \\
\hline \multirow{8}{*}{ 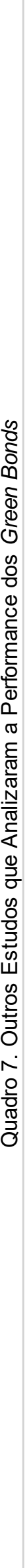 } & 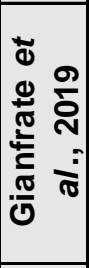 & 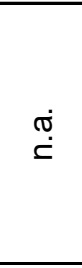 & 号 & $\begin{array}{l}\text { ஜn } \\
\frac{8}{E} \\
\frac{1}{<}\end{array}$ & $\stackrel{\grave{\Upsilon}}{\simeq}$ & 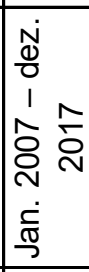 & 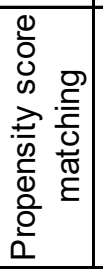 & $\frac{E}{\omega}$ & $\frac{E}{\omega}$ & 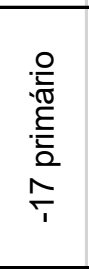 & 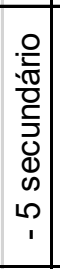 & 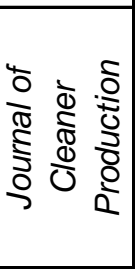 & \\
\hline & 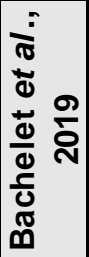 & $\frac{E}{\infty}$ & $\begin{array}{l}\overline{\widetilde{O}} \\
\bar{O} \\
\overline{0}\end{array}$ & 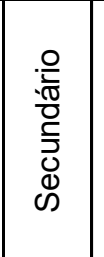 & வ & 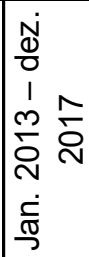 & $\begin{array}{l}\frac{O}{.} \\
\frac{D}{0} \\
\frac{0}{0} \\
\frac{\pi}{2}\end{array}$ & 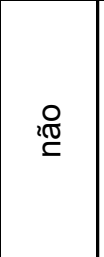 & $\frac{E}{\omega}$ & $\begin{array}{l}8 \\
0 \\
10 \\
0 \\
0 \\
8 \\
\end{array}$ & & 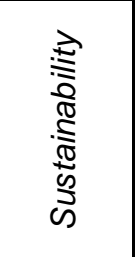 & \\
\hline & $\begin{array}{l}\text { o } \\
\text { ㅇ } \\
\frac{0}{\overline{0}} \\
\frac{2}{2} \\
\text { N }\end{array}$ & $\frac{E}{\infty}$ & $\begin{array}{l}\overline{\mathbb{O}} \\
\bar{O} \\
\overline{0}\end{array}$ & 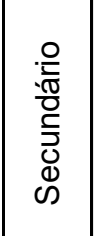 & $\stackrel{ }{ }$ & 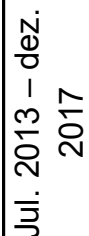 & 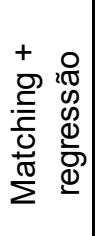 & i̊ & $\frac{E}{n}$ & $\uparrow$ & & 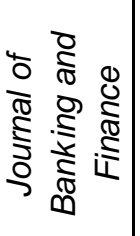 & \\
\hline & 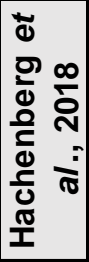 & $\frac{E}{\omega}$ & $\begin{array}{l}\overline{\widetilde{O}} \\
\bar{O} \\
\overline{0}\end{array}$ & 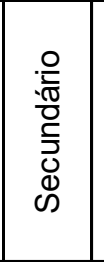 & $\widetilde{\varnothing}$ & 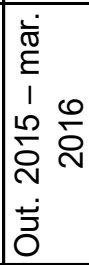 & 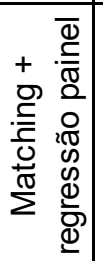 & 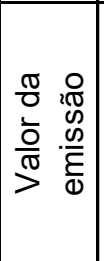 & $\frac{E}{\omega}$ & די & & 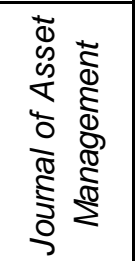 & $\begin{array}{l}\bar{\pi} \\
0 \\
\frac{0}{0} \\
0 \\
\frac{\pi}{0} \\
\frac{\pi}{0} \\
\frac{0}{0} \\
\frac{\pi}{0}\end{array}$ \\
\hline & 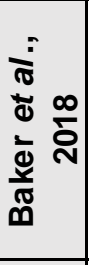 & 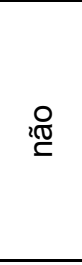 & 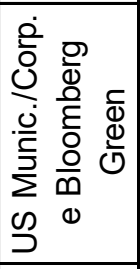 & 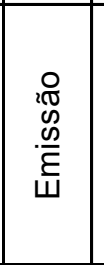 & $\begin{array}{l}\text { జ్ } \\
\text { ర్ }\end{array}$ & 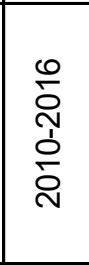 & 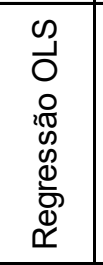 & 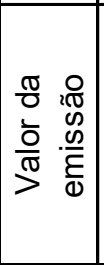 & $\frac{\varepsilon}{\omega}$ & 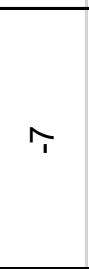 & & 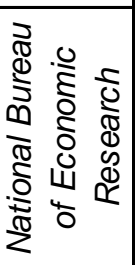 & \\
\hline & 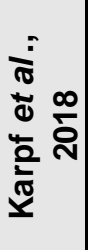 & 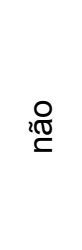 & 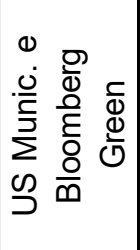 & 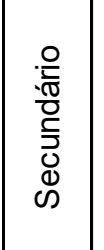 & $\begin{array}{l}\mathbb{\infty} \\
\stackrel{\infty}{\leftarrow}\end{array}$ & 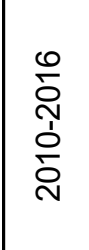 & 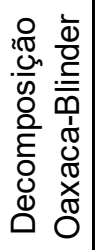 & 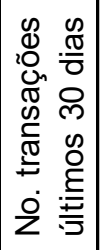 & $\frac{E}{n}$ & $\stackrel{\infty}{\sim}$ & & 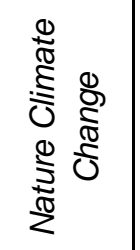 & \\
\hline & 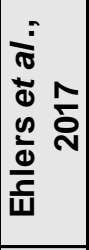 & $\frac{\varepsilon}{\omega}$ & 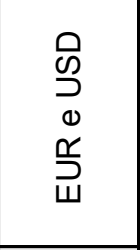 & 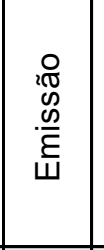 & $\bar{\sim}$ & 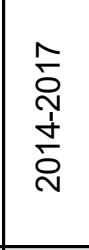 & 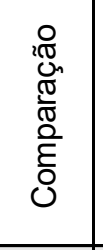 & 20 & $\frac{E}{\omega}$ & $\stackrel{\infty}{\top}$ & & 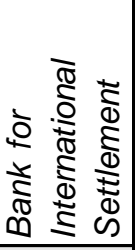 & \\
\hline & & 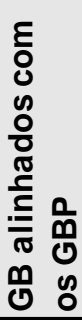 & 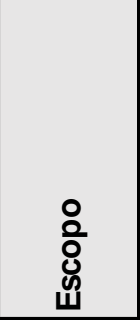 & 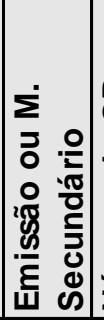 & 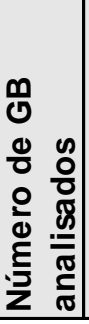 & 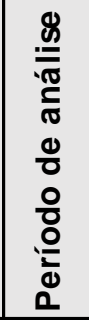 & $\begin{array}{l}\frac{0}{0} \\
\frac{0}{0} \\
\frac{0}{20}\end{array}$ & $\begin{array}{l}N \\
\frac{N}{0} \\
\frac{0}{3} \\
.0 \\
\frac{0}{0} \\
\frac{0}{0} \\
\underline{2} \\
0 \\
0\end{array}$ & 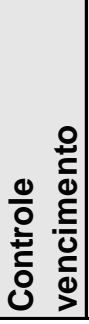 & 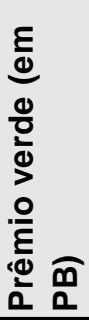 & & 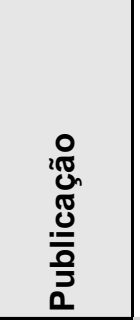 & \\
\hline
\end{tabular}


Ehlers e Packer (2017) argumentaram que o pequeno prêmio verde encontrado se deve ao fato de que os Green Bonds são servidos pelo fluxo de caixa total de seus emissores e não somente dos projetos ambientais que financiam. Os autores também identificaram um impacto importante da flutuação das moedas dos emissores e prescreveram que a proteção cambial é uma caracteristica importante para o desenvolvimento do mercado. Eles também argumentaram que os Green Bonds estão mais expostos a riscos ambientais por serem emitidos por atores de setores mais vulneráveis a tais riscos.

Hachenberg e Shiereck (2018) concluíram que o volume da emissão, a maturidade e a moeda não influenciam o prêmio verde. Este é influenciado pela indústria do emissor, pelo rating e pela existência de um rating ESG (Environment, Social and Governance), sendo menor neste último caso. O rating ESG permite que investidores de impacto tenham liberdade de investir não somente nas limitadas emissões de Green Bonds, mas também nos bonds tradicionais.

Os autores também afirmam que o prêmio verde não é maior possivelmente por receio dos investidores a respeito da possibilidade de greenwashing dos emissores de Green Bonds.

A análise empreendidada por Hachenberge e Shiereck utilizou os i-Spreads fornecidos pela Bloomberg, ao invés do YTM. Este último reflete os riscos de crédito somados ao risco básico da economia, enquanto os $i$-Spreads mostram apenas a diferença em relação às respectivas taxas de referência livres de risco (risk-free benchmarks).

As análises foram feitas comparando-se os prêmios dos Green Bonds com os dos bonds adjascentes (matching) do mesmo emissor e com as demais características, do modo mais semelhante possível em relação ao dos Green Bonds.

As análises de Hachenberge e Shiereck indicaram que o prêmio verde é maior para os Green Bonds com rating A, levando-os a afirmar que o prêmio é maior quanto pior for o rating do emissor, até que este se aproxime dos ratings que não são grau de investimento, como o rating $\mathrm{BBB}$ que está no limite de grau de investimento e apresenta rendimento acima dos bonds com rating $\mathrm{A}$. 
Existem também diferenças de prêmios em função do setor do emissor. Hachenberge e Shiereck descobriram que o maior prêmio verde aparece nos emissores do setor financeiro e o menor prêmio nos emissores soberanos.

Bachelet et al. (2019) concluíram que os Green Bonds de emissores institucionais (soberanos e supranacionais) apresentam prêmio verde no mercado secundário e que, entre os emissores privados, somente aqueles que passaram por processo de verificação por terceira parte apresentaram prêmio verde, destacando, portanto, a importância da verificação ou da reputação dos emissores na redução da assimetria de informações e redução do risco de fraudes (greenwashing).

O trabalho também concluiu que a liquidez dos Green Bonds é maior do que a dos demais bonds comparáveis e que a volatilidade dos Green Bonds é menor.

Gianfrate e Peri (2019) adotaram o método PSM (Propensity Score Matching) para analisar o prêmio verde de Green Bonds nos mercados primário e secundário. Foi o único trabalho, juntamente com o presente estudo, que levou em consideração na análise os mercados primário e secundário para a mesma base de Green Bonds.

Os autores concluíram que o prêmio verde é maior para os emissores corporativos e persiste no mercado secundário (embora reduzido). Apesar de os resultados com a metodologia PSM tenham sido submetidos a testes de robustez, eles não avaliaram a liquidez dos bonds analisados, nem coletaram os prêmios verdes num período de tempo e com a frequência que o fez o presente estudo.

Gianfrate e Peri (2019) consideraram a hipótese de que o prêmio verde tem diminuído porque a oferta de Green Bonds tem aumentado mais do que a demanda. Entretanto, essa hipótese não foi testada e outras hipóteses, como as examinadas pelo presente estudo, não foram consideradas.

O mesmo artigo estima que o custo adicional causado pelas certificações e verificações, de 3 a 5 PB, ainda é menor do que o prêmio verde identificado e que, portanto, justificaria a emissão de Green Bonds certificados ou verificados do ponto de vista econômico.

Comparando-se os resultados encontrados pelos diversos trabalhos, incluindo este, os quais foram executados adotando-se diferentes metodologias, nota-se 
consistência dos valores pequenos dos prêmios verde dos Green Bonds nos mercados primário e secundário.

Na emissão dos Green Bonds o presente trabalho encontrou um prêmio médio de $-22 \mathrm{~PB}$, enquanto que a média dos demais estudos foi de $-14 \mathrm{~PB}$. No mercado secundário a presente análise identificou um prêmio médio de -2 PB, enquanto que os demais estudos identificaram um desconto médio (rendimento acima da curva de rendimentos) de 0,8 PB.

Independentemente da metodologia e das características de cada análise, pode-se concluir que os estudos que buscaram estimar o prêmio verde dos Green Bonds chegaram a maiores prêmios na emissão dos Green Bonds do que no mercado secundário. O presente estudo é o único que busca explicar tal diferença.

\subsubsection{O impacto da Categoria de Emissores}

A presença maior de emissores soberanos ou agências governamentais entre os Green Bonds em USD, representando $57 \%$ do total da amostra em USD neste estudo, conforme Quadro 6 acima, pode ser uma justificativa para a quantidade menor de Green Bonds com prêmio verde nessa moeda. Os bonds governamentais normalmente já possuem melhor rating que os bonds privados, e possíveis melhorias na percepção de qualidade e riscos resultantes da emissão verde seriam, portanto, menos impactantes. Esta característica seria consistente com as conclusões de Zerbib (2019), Gianfrate e Peri (2019).

Além disso, alguns emissores soberanos buscam ativamente promover o crescimento do mercado de Green Bonds e, com isso, buscam reduzir o prêmio verde dos Green Bonds para que este não atrapalhe o crescimento do mercado entre os investidores que não têm mandatos para investimentos de impacto. Emissores como EIB e KfW afirmam, em prospectos de Green Bonds, que nenhum prêmio é cobrado em seus Green Bonds (HACHENBERG \& SHIERECK, 2018).

Os Green Bonds governamentais ou de agências em EUR representam apenas cerca de $16 \%$ do total da amostra de Green Bonds nessa moeda, e talvez por esse motivo identifica-se a maior incidência do prêmio verde entre os Green Bonds em EUR. 
Observa-se que para o Green Bond IFC 2026 não foi possível obter informações sobre a média de volumes negociados nos terminais da Bloomberg.

\subsubsection{A Liquidez dos Green Bonds}

Outros autores, como Hachenberg e Shiereck (2018), Karpf e Mandel (2018) e Zerbib (2019), também buscaram analisar ou controlar o parâmetro liquidez de Green Bonds por meio de ajustes e pela adoção de proxies, pois todos se depararam com a dificuldade da falta de dados.

Zerbib (2019) compilou oito estudos de outros autores e mostrou que, em quatro deles, não foi feito nenhum controle de liquidez. Em dois deles, a liquidez foi controlada por meio de seleção de emissões com grandes volumes e limites acima e abaixo do volume de emissão dos Green Bonds analisados; em outro, a liquidez foi controlada por meio da data de emissão; e, em outro, a liquidez foi avaliada por meio do número de transações nos trinta dias precedentes.

No estudo de Zerbib, foi usada a diferença entre os valores de oferta de compra e de venda (bid/ask spread) dos Green Bonds e dos demais bonds analisados como medida das diferenças de liquidez.

A coleta de dados sobre volumes de negócios dos Green Bonds que apresentam rendimento anormal (acima ou abaixo da curva) neste estudo está reportada abaixo, sendo que foi adotada a seguinte classificação:

- Liquidez maior: número de vezes em que, na coleta de dados, surgiu volume maior de negócios em relação aos demais bonds da curva de rendimentos, ou aos bonds na curva com vencimento até dois anos antes ou depois do vencimento de cada Green Bond - método matching com bonds adjacentes, adaptado de Hachenberg e Shiereck (2018);

- Liquidez igual: número de vezes em que, na coleta de dados, surgiu volume de negócios que está dentro do intervalo de volumes dos demais bonds da curva de rendimentos;

- Liquidez menor: número de vezes em que, na coleta de dados, surgiu volume menor de negócios em relação a todos os demais bonds da curva 
de rendimentos, ou aos bonds na curva com vencimento até dois anos antes ou depois do vencimento do Green Bond.

Quadro 8. Liquidez dos Green Bonds

\begin{tabular}{|c|c|c|c|}
\hline \multirow{2}{*}{ Green Bond } & \multicolumn{3}{|c|}{ Liquidez } \\
\hline & Maior & Igual & Menor \\
\hline \multicolumn{4}{|c|}{$\begin{array}{l}\text { Desconto (acima da curva de } \\
\text { rendimentos) }\end{array}$} \\
\hline Bank of China 21 & 1 & 11 & 0 \\
\hline Berlin Hypo 23 & 1 & 11 & 0 \\
\hline Engie 26 & 1 & 11 & 0 \\
\hline Gas Natural 25 & 1 & 11 & 0 \\
\hline Iberdrola 26 & 1 & 11 & 0 \\
\hline Iberdrola 27 & 0 & 11 & 0 \\
\hline IFC 26 & - & - & - \\
\hline KBN 28 & - & - & - \\
\hline Sparebank 25 & 0 & 12 & 0 \\
\hline Tenne 25 & 0 & 12 & 0 \\
\hline Tenne 27 & 0 & 12 & 0 \\
\hline Tenne 36 & 0 & 12 & 0 \\
\hline Unibail 24 & 0 & 12 & 0 \\
\hline Subtotal 1 & 5 & 126 & 0 \\
\hline \multicolumn{4}{|c|}{$\begin{array}{l}\text { Prêmio (abaixo da curva de } \\
\text { rendimentos) }\end{array}$} \\
\hline ABN 22 & 1 & 11 & 0 \\
\hline ADIF 23 & 1 & 10 & 1 \\
\hline Berlin Hypo 23 & 0 & 12 & 0 \\
\hline Berlin Hypo 27 & 1 & 11 & 0 \\
\hline China 22 & 1 & 11 & 0 \\
\hline Engie 28 & 0 & 12 & 0 \\
\hline Engie 29 & 0 & 12 & 0 \\
\hline Iberdrola 22 & 0 & 12 & 0 \\
\hline IBRD 25 & 0 & 12 & 0 \\
\hline KFW 24 & 0 & 12 & 0 \\
\hline KFW 25 & 0 & 12 & 0 \\
\hline Mitsubishi 23 & 0 & 11 & 1 \\
\hline Nordea 22 & 0 & 12 & 0 \\
\hline NRW 26 & 2 & 10 & 0 \\
\hline NRW 27 & 0 & 12 & 0 \\
\hline RATP 27 & - & - & - \\
\hline Tenne 29 & 0 & 12 & 0 \\
\hline Tenne 33 & 0 & 12 & 0 \\
\hline Toyota 21 & 0 & 12 & 0 \\
\hline Subtotal 2 & 6 & 208 & 2 \\
\hline Total 1 e 2 & 11 & 334 & 2 \\
\hline
\end{tabular}

Fonte: elaboração própria do autor (Maróstica, 2019), baseado em dados obtidos junto a Bloomberg.

A lista acima contém os Green Bonds que aparecem com mais frequência entre aqueles que apresentaram prêmio verde ou desconto, tanto em dólares como em Euros. Não foram incluídos, portanto, os Green Bonds que apresentaram prêmio ou desconto somente uma ou duas vezes durante o período de análise. 
Os resultados acima mostram que tanto os Green Bonds com desconto como os que apresentam prêmio verde tiveram volumes de negócios na maior parte dentro do intervalo apresentado pelos demais bonds das respectivas curvas de rendimentos ou dos bonds equivalentes com vencimentos próximos. Esse resultado mostra que pode ser correta a hipótese de que traders indiferentes podem estar arbitrando a diferença de taxas de rendimentos.

O resultado parece consistente em relação ao processo de seleção da amostra de Green Bonds e dos demais bonds comparáveis. Já foram selecionadas previamente as emissões de valores maiores (acima de USD 300 milhões) e nas moedas USD e EUR que representam a porção mais líquida do mercado.

A liquidez dentro da normalidade para os Green Bonds com prêmio também permite assumir que os demais Green Bonds sem prêmio verde também possuem liquidez normal. Desta forma, os traders indiferentes aos atributos ambientais podem estar arbitrando as eventuais diferenças de rendimentos entre os Green Bonds e os demais bonds no mercado secundário.

Esta análise tem uma importante limitação decorrente da impossibilidade de se comparar o número de negociações (ou frequência de negócios) dos Green Bonds e demais bonds que ocorreram no período analisado. Em consulta direta ao terminal Bloomberg, foi confirmado que não existe a função que mostra a média do número de negócios nos terminais da empresa.

Apesar de não ter sido possível analisar o número de negócios realizados, o resultado desta análise de liquidez é consistente quanto ao estudo realizado por Febi et al. (2018), que adotaram métodos indiretos de medida de liquidez, como a diferença de ofertas para compra e venda (bid/ask spread). O estudo concluiu que, contrariamente às expectativas iniciais dos autores, em média, a liquidez dos Green Bonds foi maior que a dos bonds tradicionais para o período analisado, de 2014 a 2016.

O estudo de Bachelet et al. (2019) também analisou as diferenças de liquidez e encontrou, a partir da comparação das diferenças entre as ofertas diárias de compra e venda (bid/ask spread) que a liquidez dos Green Bonds é maior que dos outros bonds comparáveis. 
O resultado do presente estudo também é sustentado pelo último estudo da Climate Bonds Initiative (2019), em que se constatou que nas novas emissões de Green Bonds ocorridas no segundo semestre de 2018 em EUR e USD, 53\% dos volumes foram vendidos a investidores que se declaram green ou socialmente responsáveis.

Portanto, $47 \%$ dos investidores que adquiriram Green Bonds no último período analisado não teriam motivações fiduciárias ou pecuniárias para manter tais títulos em suas carteiras até o vencimento. Isso corrobora a hipótese de que pode, sim, haver arbitragem do diferencial de taxas entre Green Bonds e outros bonds semelhantes.

\subsubsection{Resultados das Análises de Formação do Green Halo}

O total de bonds que fazem parte das curvas de emissores de 59 Green Bonds selecionados para esta análise somam 626 bonds.

Partiu-se de um total de 63 Green Bonds que atendiam aos critérios da seção 6.3.3.2 até a etapa 8, incluindo desta vez aqueles com menos de quatro outros bonds na curva do emissor que haviam sido excluídos para viabilizar a regressão das curvas polinomiais.

Desses 63 Green Bonds, foram excluídos um bond dos emissores Mexican Airport e Tennet, pois estes apresentavam curva de bonds em duplicidade em relação a outro de seus bonds. Um terceiro bond do emissor EDF (Electricité de France) e outro do emissor SNCF também foram excluído devido a problemas na coleta de dados. Restaram assim 59 Green Bonds para esta análise.

A distribuição das diferenças entre $S^{p}$ e $S^{b}$ das curvas analisadas segue representada na Figura 9. 
Figura 9. Alteração Spreads x Benchmark Bonds

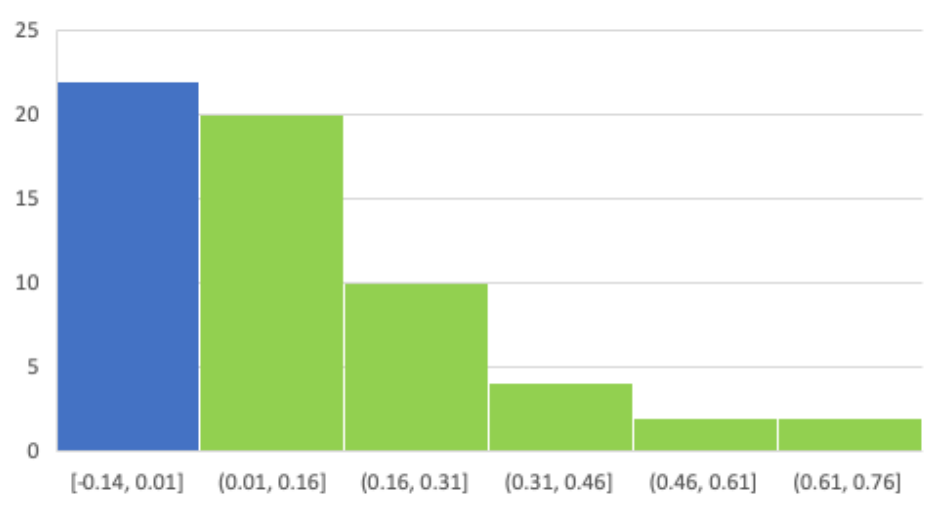

Fonte: elaboração própria do autor (Maróstica, 2019), baseado em dados obtidos junto a Bloomberg.

O Quadro 9 mostra os casos em que $S^{b}-S^{p}>0$ (em verde) contrariam a direção geral das diferenças de rendimento nos mercados de bonds soberanos e corporativos, para o período seis meses antes da precificação dos Green Bonds e para a data da última coleta de dados em março de 2019, portanto fortalecendo o argumento do aparecimento do fenômeno Green Halo em alguns casos. 
Quadro 9. Green Halo e Direção do Mercado (EUR)

\begin{tabular}{|c|c|c|c|c|c|c|}
\hline Bond & $\begin{array}{c}\text { Moed } \\
a\end{array}$ & $\begin{array}{c}\text { Sb - } \\
\mathrm{Sp}\end{array}$ & $\begin{array}{l}\text { Pre- } \\
\text { precificação }\end{array}$ & $\begin{array}{l}\text { Direção } \\
\text { Mercado }\end{array}$ & $\begin{array}{l}\text { Contra } \\
\text { Mercado }\end{array}$ & Rating \\
\hline ABN 22 & EUR & 0.09 & Nov. . 15 & BAIXA & NÃO & \\
\hline Adif 23 & EUR & 0.23 & Dez 16 & BAIXA & NÃO & Upgraded \\
\hline Ag France 24 & EUR & 0.08 & Mar. 14 & ALTA & SIM & $\begin{array}{l}\text { Downgra } \\
\text { ded }\end{array}$ \\
\hline $\begin{array}{l}\text { Berlin Hypo } \\
22\end{array}$ & EUR & 0.00 & Fev 14 & ALTA & SIM & $\begin{array}{l}\text { Downgra } \\
\text { ded }\end{array}$ \\
\hline $\begin{array}{l}\text { Berlin Hypo } \\
23\end{array}$ & EUR & 0.02 & Mai 17 & ALTA & SIM & $\begin{array}{l}\text { Downgra } \\
\text { ded }\end{array}$ \\
\hline BNP 22 & EUR & 0.27 & Mai 16 & BAIXA & NÃO & Upgraded \\
\hline BPCE 22 & EUR & 0.28 & Jun.15 & $=$ & SIM & Upgraded \\
\hline $\begin{array}{l}\text { City of Paris } \\
31\end{array}$ & EUR & 0.72 & Mai 15 & $=$ & SIM & \\
\hline $\begin{array}{l}\text { Deutsche } \\
\text { Hypo } 23\end{array}$ & EUR & -0.01 & Mar. 16 & & & Upgraded \\
\hline Engie 26 & EUR & 0.25 & Nov. 13 & ALTA & SIM & $\begin{array}{l}\text { Downgra } \\
\text { ded }\end{array}$ \\
\hline Engie 28 & EUR & -0.06 & Set 16 & & & \\
\hline Engie 29 & EUR & 0.09 & Mar. 17 & ALTA & SIM & \\
\hline France 39 & EUR & 0.51 & Dez 15 & BAIXA & NÃO & \\
\hline $\begin{array}{l}\text { Gas Natural } \\
25\end{array}$ & EUR & -0.09 & Ago 16 & & & \\
\hline Iberdrola 22 & EUR & 0.42 & Out 13 & ALTA & SIM & Upgraded \\
\hline Iberdrola 25 & EUR & 0.49 & Mar. 16 & BAIXA & NÃO & Upgraded \\
\hline Iberdrola 26 & EUR & 0.67 & Out 15 & BAIXA & NÃO & Upgraded \\
\hline Iberdrola 27 & EUR & 0.29 & Mar. 17 & ALTA & SIM & Upgraded \\
\hline $\begin{array}{l}\text { lle de France } \\
26\end{array}$ & EUR & 0.20 & Out 13 & ALTA & SIM & $\begin{array}{l}\text { Downgra } \\
\text { ded }\end{array}$ \\
\hline $\begin{array}{l}\text { lle de France } \\
27\end{array}$ & EUR & 0.04 & Out 14 & ALTA & SIM & $\begin{array}{l}\text { Downgra } \\
\text { ded }\end{array}$ \\
\hline Intesa 22 & EUR & 0.04 & Dez 16 & BAIXA & NÃO & \\
\hline KBN 28 & EUR & 0.00 & Out 14 & ALTA & SIM & \\
\hline KFW 24 & EUR & 0.04 & Nov. 15 & BAIXA & NÃO & \\
\hline KFW 25 & EUR & 0.02 & Nov. 16 & BAIXA & NÃO & \\
\hline NAB 22 & EUR & -0.09 & Ago 16 & & & \\
\hline Nordea 22 & EUR & -0.04 & Dez 16 & & & $\begin{array}{l}\text { Downgra } \\
\text { ded }\end{array}$ \\
\hline NRW 25 & EUR & 0.39 & Mai 14 & ALTA & SIM & \\
\hline NRW 26 & EUR & 0.29 & Mai 16 & BAIXA & NÃO & \\
\hline NRW 27 & EUR & 0.07 & Mar. 17 & ALTA & SIM & \\
\hline Poland 21 & EUR & 0.30 & Jun. 16 & BAIXA & NÃO & Upgraded \\
\hline Poland 26 & EUR & -0.10 & Jul. 17 & & & Upgraded \\
\hline Rabobank 21 & EUR & 0.18 & Abr 15 & BAIXA & NÃO & $\begin{array}{l}\text { Downgra } \\
\text { ded }\end{array}$ \\
\hline RATP 27 & EUR & -0.02 & Dez 16 & & & \\
\hline SNCF 34 & EUR & 0.19 & Set. 16 & BAIXA & NÃO & \\
\hline SNCF 47 & EUR & -0.14 & Jan. 17 & & & \\
\hline
\end{tabular}




\begin{tabular}{|l|c|c|l|l|l|l||}
\hline Sparebank 25 & EUR & -0.05 & Jul. 17 & & & \\
\hline Tenne 25 & EUR & -0.06 & Dez 16 & & & \\
\hline Tenne 27 & EUR & 0.00 & Dez 14 & & & \\
\hline Tenne 29 & EUR & -0.02 & Dez 16 & & & \\
\hline Tenne 33 & EUR & -0.10 & Abr 16 & & & \\
\hline Tenne 36 & EUR & 0.03 & Dez 15 & BAIXA & NÃO & \\
\hline Toyota 21 & EUR & 0.04 & Mai 17 & ALTA & SIM & Upgraded \\
\hline Unibail 24 & EUR & 0.14 & Ago 13 & ALTA & SIM & \\
\hline Unibail 25 & EUR & 0.03 & Out 14 & ALTA & SIM & \\
\hline Westpac 24 & EUR & -0.10 & Mai 17 & & & \\
\hline
\end{tabular}

Fonte: elaboração própria do autor (Maróstica, 2019), baseado em dados obtidos junto a Bloomberg. 
Quadro 10. Green Halo e Direção do Mercado (USD)

\begin{tabular}{|l|c|c|l|l|l|l|}
\hline Bond & $\begin{array}{c}\text { Moed } \\
\text { a }\end{array}$ & $\begin{array}{c}\text { Sb - } \\
\text { Sp }\end{array}$ & $\begin{array}{l}\text { Pre- } \\
\text { precificação }\end{array}$ & $\begin{array}{l}\text { Direção } \\
\text { Mercado }\end{array}$ & $\begin{array}{l}\text { Contra } \\
\text { Mercado }\end{array}$ & Rating \\
\hline ABD 27 & USD & 0.01 & Fev 17 & BAIXA & NÃO & \\
\hline Apple 23 & USD & 0.00 & Ago 15 & & & \\
\hline Apple 27 & USD & 0.07 & Jun. 16 & BAIXA & NÃO & \\
\hline Asia 25 & USD & 0.00 & Set 14 & & & NÃO \\
\hline Asia 26 & USD & 0.04 & Fev 16 & BAIXA & NÃO & $\begin{array}{l}\text { Downgra } \\
\text { ded }\end{array}$ \\
\hline $\begin{array}{l}\text { Bank of China } \\
21\end{array}$ & USD & 0.04 & Jan. 16 & BAIXA & & \\
\hline China 22 & USD & 0.00 & Mar. 17 & & & \\
\hline IBRD 25 & USD & -0.07 & Ago 14 & & NÃO & \\
\hline IFC 26 & USD & -0.09 & Out 15 & & NÃO & \\
\hline KFW 21 & USD & 0.31 & Mai 16 & BAIXA & & $\begin{array}{l}\text { Upg, } \\
\text { Downgr. }\end{array}$ \\
\hline KFW 22 & USD & 0.04 & Mar. 17 & BAIXA & $\begin{array}{l}\text { Downgra } \\
\text { ded }\end{array}$ \\
\hline $\begin{array}{l}\text { Mex. Airport } \\
26\end{array}$ & USD & 0.00 & Mar. 16 & & NÃO \\
\hline $\begin{array}{l}\text { Mid Am } \\
\text { Energy 48 }\end{array}$ & USD & 0.44 & Jun. 17 & BAIXA & NÃO & $\begin{array}{l}\text { Downgra } \\
\text { ded }\end{array}$ \\
\hline Mitsubishi 23 & USD & 0.09 & Mar. 16 & BAIXA & \\
\hline
\end{tabular}

Fonte: elaboração própria do autor (Maróstica, 2019), baseado em dados obtidos junto a Bloomberg.

Tem-se, portanto, doze casos de possível formação de Green Halo, onde a contração de spreads contraria a tendência do mercado geral de renda fixa no mesmo período, e contraria também o efeito esperado do rebaixamento (Donwgrading) do Rating dos Green Bonds.

Os Green Bonds que apresentaram contração de spreads contrariando a direção geral do mercado, mas que tiveram melhoria de seus Ratings (Upgrading) foram excluídos da lista de formação do Green Halo, para evitar um possível efeito do Upgranding na melhoria da percepção dos investidores.

Observa-se que no período analisado, ocorreram melhorias e rebaixamentos de Rating dos Green Bonds em quantidades iguais (11 cada). Portanto não se pode estabelecer uma correlação direta entre o fato de um bond ser Green e alterações de Rating que acontecem após a emissão.

Não foi observada a formação de Green Halo nas curvas de bonds emitidos em USD, porém não se pode concluir nada a respeito da influência da moeda de emissão na formação do Green Halo, pois a amostragem de Green Bonds em dólares é menor que a amostragem em euros. 
Além disso, existe uma proporção maior de emissores soberanos na amostragem de Green Bonds emitidos em dólares, o que reduziria as possibilidades de ocorrência do Green Halo, pois os emissores soberanos já desfrutam de alta reputação conforme já discutido anteriormente.

Um estudo de Hachenberg e Shiereck (2018) mostrou empiricamente que as diferenças de preço entre Green Bonds e outros bonds de referência são maiores quando o rating dos Green Bonds é mais baixo. A menor diferença foi encontrada para os Green Bonds com rating AAA, como a dos bonds soberanos que foram incluídos na amostra em USD do presente estudo.

Nota-se também que, entre as doze curvas que apresentaram o Green Halo, nove delas se referem a Green Bonds que constantemente não apresentam prêmio verde na análise de regressão polinomial feita anteriormente. Essas curvas são dos seguintes emissores:

- Ag. France 24;

- Berlin Hypo 22;

- City of Paris 31;

- Engie 26;

- Ile de France 26;

- Ile de France 27;

- NRW 25;

- Unibail 24;

- Unibail 25.

A formação do Green Halo pode influenciar na formação do prêmio verde nos Green Bonds no mercado secundário, e talvez por essa razão são encontrados poucos Green Bonds que mantêm os prêmios ao longo do tempo. Tais prêmios desapareceriam com 0 ganho reputacional de seus emissores e com 0 deslocamento das curvas de rendimentos para níveis mais baixos. 


\section{CONCLUSÕES E RECOMENDAÇÕES}

O estudo se propôs a analisar o papel dos Green Bonds como um novo instrumento de mercado para o financiamento de atividades de baixo impacto ambiental ou de impacto social positivo, além da contribuição destes para financiar a transição para atividades econômicas sustentáveis.

O objetivo geral da pesquisa foi alcançado por meio de análises qualitativas baseadas em revisão bibliográfica e análises quantitativas que complementam as que já foram realizadas por outros autores em trabalhos recentes, de 2018 e 2019, e descritos neste documento.

O estudo da performance dos Green Bonds com relação ao prêmio verde e ao comportamento geral do mercado de bonds permitiu concluir que o prêmio atribuído aos Green Bonds existe, mas ainda é pequeno. Também é possível concluir que o prêmio verde diminui no mercado secundário, sendo consistente em relação a outros estudos citados.

A presente pesquisa é a primeira que testa algumas hipóteses para justificar a queda do prêmio verde no mercado secundário e a sugerir medidas para manter tal prêmio como uma forma de diferenciação contínua dos Green Bonds.

Se por um lado podem existir motivações não pecuniárias e percepção de exposição menor ao risco de stakeholders (BACHELET et al., 2019) para justificar a demanda forte por Green Bonds que resultariam no prêmio verde, por outro lado existe o desconhecimento e temor do risco de fraudes (greenwashing).

Existem oportunidades para redução da assimetria de informações entre emissores e investidores para que as características positivas dos Green Bonds sejam mais amplamente exploradas.

Os resultados encontrados no presente estudo mostram que na maioria dos casos $(58,6 \%)$ os Green Bonds obtiveram um prêmio no preço de lançamento. A redução média foi de -22 pontos-base no YTM em relação ao rendimento teórico indicado pela curva polinomial de rendimentos dos demais bonds de cada emissor. 
O prêmio encontrado no lançamento da maioria dos Green Bonds mostra que a sociedade, por meio de seus investimentos, começa a reconhecer os atributos positivos dos Green Bonds, confirmando a Proposição 1, feita pelo autor deste estudo.

Observou-se também que, no decorrer do período analisado e com as negociações que ocorrem no mercado secundário de bonds, o prêmio verde que inicialmente era atribuído à maioria dos Green Bonds foi desaparecendo. Tal resultado é consistente em relação aos resultados encontrados por Gianfrate e Peri (2019).

Enquanto no lançamento dos Green Bonds 58,6\% deles apresentavam prêmio verde, ao final do período analisado o prêmio foi observado em apenas $25,7 \%$ destes.

O presente estudo foi o primeiro até então que buscou avaliar possibilidades que pudessem justificar o desaparecimento do prêmio verde dos Green Bonds no mercado secundário:

1. Arbitragem das diferenças de taxas de rendimento

Foi analisada a ação de negociadores indiferentes aos atributos ambientais dos Green Bonds, que arbitrariam o prêmio inicial destes com o dos bonds do mesmo emissor ou outros semelhantes. Tal arbitragem retomaria o equilíbrio de preços baseados no modelo CAPM, conforme estudado por Fama e French (2007).

A possibilidade de arbitragem foi avaliada a partir de um estudo de liquidez que mostrou que esta hipótese não pode ser descartada. Os volumes médios negociados de Green Bonds no mercado secundário estão próximos aos dos volumes médios negociados dos demais bonds.

2. A formação do Green Halo, ou efeito reputacional positivo

Esse fenômeno representaria o deslocamento para valores mais baixos de toda a curva de rendimentos dos emissores de Green Bonds por conta da percepção de mudanças positivas decorrente das emissões de Green Bonds. 
A análise foi feita a partir da comparação dos diferenciais de preço entre os bonds que compõem as curvas dos emissores de Green Bonds e seus respectivos bonds de referência (benchmark bonds).

As comparações foram feitas em dois momentos distintos. O primeiro ocorreu seis meses antes da precificação de cada Green Bond e o segundo no final do período de análise, março de 2019.

Os resultados obtidos levaram em consideração a tendência geral do mercado de bonds por meio da comparação do diferencial de preços entre bonds corporativos e soberanos no período que se iniciou seis meses antes da emissão de cada Green Bond e março de 2019, e também alterações nos Ratings dos Green Bonds desde seus lançamentos até a última coleta de dados.

O aparecimento do Green Halo só foi considerado quando a redução do diferencial de rendimentos entre os bonds analisados e os respectivos benchmark bonds não coincidiu com condições de alta generalizada de preços de bonds corporativos e soberanos no mesmo período, nem com melhorias dos Ratings dos Green Bonds.

Das doze curvas que apresentaram o Green Halo, nove são de Green Bonds que não apresentavam prêmio verde na comparação com a curva de rendimentos de seus emissores. Ou seja, o prêmio verde pode ter sido absorvido pelo deslocamento da curva de rendimentos dos emissores devido à formação do Green Halo.

A redução do prêmio verde pode desencorajar parte dos investidores, que não têm mandatos específicos para investir em Green Bonds, a aceitar rendimentos relativamente menores na emissão primária destes. Seria inviável justificá-los desde um ponto de vista de risco/retorno que seja consistente em relação a obrigações fiduciárias.

Os Green Bonds também poderiam ser adquiridos depois, no mercado secundário, quando o prêmio desaparecer, conforme ocorreu com a amostra analisada. Consequentemente, nesses casos a demanda no lançamento diminuiria ou os potenciais interessados em um Green Bond a ser lançado estariam menos dispostos a aceitar o prêmio. 
Enquanto o mercado não incorporar amplamente as externalidades ambientais nos preços dos ativos e ajustar o risco/retorno, investidores ainda podem ser encorajados a pagar um prêmio verde no lançamento dos Green Bonds por motivos não pecuniários (FAMA \& FRENCH, 2007).

Ainda segundo esses autores, os investidores que valorizam determinadas características não pecuniárias de determinado ativo não só estão dispostos a pagar um preço maior por tal ativo, mas também tendem a manter essa disposição com o tempo.

Os emissores podem continuar motivados a financiar projetos ambientais de forma mais atrativa por meio da emissão de Green Bonds se estes mantiverem sua diferenciação ao longo do tempo.

Portanto, parece importante que se promovam os atributos não pecuniários dos Green Bonds, para que uma classe de investidores fiéis e dispostos a pagar mais por estes se desenvolva.

Avaliando a correlação da performance de Green Bonds e demais bonds, Pham (2016) concluiu que esta aumentou no período analisado, além disso comenta que seria importante introduzir estratégias de diferenciação entre as duas categorias de bonds.

O presente estudo corrobora a sugestão de Pham, de que a certificação poderia ser um diferenciador, conforme os resultados encontrados também por Baker et al. (2018) e Bachelet et al. (2019), e acrescenta que os relatórios padronizados de performance pós-emissão seriam uma estratégia de diferenciação continuada no mercado secundário.

Se os Green Bonds consistentemente entregarem retornos superiores ajustados aos riscos, investidores poderiam atribuir valor a estes e o prêmio verde poderia ser justificado por fundamentos, e não somente por preferências não pecuniárias.

Do contrário, se não houver maior transparência e padronização de informações, os investidores podem temer exposição a fraudes (greenwashing) dos emissores de Green Bonds e evitar investimentos nesse tipo de ativo (HACHENBERG \& SHIERECK, 2018; BACHELET et al., 2019). 
As características de ativo de proteção ou defensivo dos Green Bonds ainda foram pouco estudadas. Comparando índices que acompanham a performance de Green Bonds com a dos outros bonds, Daszyńska-Żygadło et al. (2018) concluíram que existe uma correlação entre a performance dos dois tipos de índice, mas que os índices de Green Bonds são menos sensíveis a riscos sistêmicos do mercado, como no caso da votação do Brexit no Reino Unido.

Nesse estudo de 2016, durante alguns dias os índices de Green Bonds desenvolveram uma correlação negativa para com os índices dos outros bonds durante a votação para o Brexit, em 2016. Uma explicação para as características defensivas dos Green Bonds, segundo os autores, seria o fato de que muitos investidores em Green Bonds procuram mantê-los em carteira até o vencimento.

Segundo a análise dos relatórios pós-emissão de Green Bonds feitos pela Climate Bonds Initiative (2019), apenas 26\% dos Green Bonds emitidos reportam como os recursos provenientes da emissão foram alocados e quais os impactos ambientais positivos obtidos.

Além disso, apenas $15 \%$ dos relatórios são produzidos de acordo com alguma estrutura pré-estabelecida para reportar impactos, sendo que os demais são produzidos seguindo estruturas próprias, o que resulta em mais de duzentas métricas reportadas.

Ainda segundo o mesmo estudo, uma porcentagem maior de relatórios pósemissão é encontrada entre as maiores emissões, os que têm melhor rating, e entre os emissores do setor financeiro e soberanos e multilaterais. Uma menor porcentagem de relatórios pós-emissão é encontrada entre os emissores de mercados pequenos de Green Bonds.

Essa baixa prática de produção de relatórios somada ao possível rating mais baixo desses mercados menores podem ser barreiras à confiança de investidores e representa uma oportunidade de desenvolvimento de mercado.

Mesmo nos casos em que a performance pós-emissão é realizada, falta padronização, métricas comuns, consistência, revisão por terceira parte e fácil acesso às informações. 
Segundo o relatório da Climate Bonds Initiative (2019), a maior parte dos emissores reporta a performance no nível de programa e não do Green Bond ou do projeto. O resultado é o seguinte: em apenas metade dos casos, os investidores encontram as informações que procuram.

Em termos de Monitoramento, Relatórios e Verificação (MRV) de performance, os mercados de reduções de emissões de GEE, como o EU ETS ou o $M D L$, são muito mais maduros e sofisticados do que o mercado de Green Bonds. As experiências nesses mercados poderiam servir de referência para propostas de implementação de um sistema de MRV para Green Bonds.

Restaria ainda o desafio de desenvolver métricas padronizadas para projetos que não são relacionados à redução de GEE, como por exemplo os relacionados a gestão de água, adaptação às mudanças climáticas e economia circular.

O E. U. Technical Expert Group on Sustainable Finance (2019) tem trabalhado em uma proposta para um padrão europeu de Green Bonds, e algumas sugestões desse grupo dizem respeito a padronizar o sistema de MRV e auditorias, entretanto, sem detalhar ainda quais seriam as metodologias para medir os impactos.

$O$ argumento em favor da importância da manutenção dos prêmios verdes no mercado secundário, que hoje pode não ocorrer devido ao baixo acesso às informações padronizadas e auditadas sobre os Green Bonds, se alinha à Proposição 2 colocada inicialmente pelo autor do presente estudo.

Além dos progressos relacionados à disponibilidade de informação sobre a performance dos Green Bonds, uma outra forma de manter o prêmio verde no mercado secundário poderia ocorrer por meio da remuneração da performance ambiental. Como exemplo, pode-se pensar na isenção de impostos sobre os rendimentos dos Green Bonds, mediante comprovação de performance em cada período.

A isenção de impostos sobre os rendimentos dos Green Bonds mediante performance comprovada seria positiva nos seguintes aspectos: 
- A atração de uma contribuição dos governos, na forma de renúncia fiscal, ao financiamento de atividades que contribuiriam para a transição a atividades econômicas sustentáveis.

- O diferencial de preços dos Green Bonds se daria mediante performance comprovada ex post, como acontece nos mercados de créditos de carbono, e não apenas pela qualificação do Green Bond no lançamento.

- A percepção de risco e reputação ambiental dos emissores de Green Bonds seria constantemente atualizada segundo a performance das atividades ambientais financiadas.

- A incorporação das externalidades ambientais nos preços dos Green Bonds aconteceria conforme os serviços ambientais resultantes das atividades financiadas forem provisionados, conforme proposto por Wunder (2005) e Muradian et al. (2010).

A isenção de impostos mediante performance dos Green Bonds também poderia seguir o modelo proposto por Taghizadeh-Hesary e Yoshino (2019), em que a perda de arrecadação com a isenção dos impostos sobre os rendimentos dos Green Bonds poderia ser compensada com os impostos adicionais do incremento da atividade econômica local gerada pelos projetos (spillover effects), por exemplo como no caso de energia renovável gerada localmente.

Mihálovits e Tapaszti (2018), por sua vez, abordam a questão do default das obrigações ambientais dos emissores de Green Bonds. Os autores corretamente afirmam que não existem, com poucas exceções, cláusulas que penalizem o default ambiental dos Green Bonds, e que a grande maioria destes tem a obrigação legal de cumprir apenas as cláusulas tradicionais de um bond.

Os autores propõem regulamentar o default ambiental por meio de mecanismos como a recompra do Green Bond pelo emissor, a perda de benefícios tributários e a perda do selo ou certificação de Green Bond. Mihálovits e Tapaszti, entretanto, reconhecem que é necessário preservar um balanço delicado, ao mesmo tempo aumentando a segurança dos investidores e não amedrontando possíveis emissores de Green Bonds. 
Durante a execução do presente estudo, foi possível observar um caso real de default, ou suspensão temporária, das entregas ambientais de dois Green Bonds analisados do emissor Mexican Airports, com vencimentos em 2026 e 2046.

Os projetos de aeroportos sustentáveis que seriam financiados pelos Green Bonds emitidos foram cancelados depois que as obras já haviam sido iniciadas, tudo isso por meio um referendo popular e sob alegações de corrupção. Entretanto, os dois Green Bonds continuam a ser negociados no mercado secundário e com variações insignificantes da diferença de seus rendimentos para a curva de rendimentos dos demais bonds.

Uma alternativa proposta pelo presente estudo seria a criação de cláusulas de compensação ambiental em caso de default. Por exemplo, o emissor de Green Bonds em default ambiental poderia ser obrigado a comprar no mercado e a aposentar créditos de carbono de outros projetos em quantidade equivalente aos benefícios que o projeto geraria caso o default não tivesse ocorrido. Obviamente se faz necessário desenvolver outros instrumentos de compensação para os casos em que o benefício ambiental, que deveria ser promovido, não seja a redução de GEE.

A atratividade dos Green Bonds também poderia ser maior se suas emissões fossem mais convenientes aos emissores, por exemplo por meio de um processo mais rápido ou preferencial de aprovação das emissões de Green Bonds pelos agentes reguladores, ou da depreciação acelerada dos ativos investidos.

Atendendo ao segundo objetivo específico do presente estudo, seguem as recomendações decorrentes das análises qualitativas e quantitativas, e que poderiam ser implementadas por diversas partes interessadas em aumentar a viabilidade e atratividade dos Green Bonds e contribuir com o desenvolvimento do mercado.

\subsection{Recomendações às Partes Interessadas no Desenvolvimento do Mercado de Green Bonds}

\subsubsection{Emissores de Green Bonds}

Um estudo de Karpf e Mandel (2018) avaliou os rendimentos de Green Bonds municipais americanos e concluiu que quanto mais distante o vencimento do Green 
Bond, maior é a formação do prêmio verde, sendo que os Green Bonds de rating mais baixo se beneficiam mais após um vencimento maior que 23 anos. $O$ argumento usado pelos autores para explicar esse comportamento é que os investidores percebem os Green Bonds como alinhados aos objetivos de desenvolvimento sustentável e menos arriscados no longo prazo.

Portanto, dado que a pesquisa de Karpf e Mandel foi realizada num período em que a transparência ainda era baixa, pode-se concluir que, enquanto um sistema de MRV padronizado não foi amplamente adotado, os emissores de Green Bonds devem buscar emitir bonds de longo prazo, com vencimento acima de 23 anos. O mesmo raciocínio se aplica a emissores com rating mais baixo.

Da mesma forma, um sistema transparente e padronizado de MRV poderia contribuir para o surgimento e manutenção do prêmio verde dos Green Bonds de vencimento mais curto. Segundo os resultados obtidos por Karpf e Mandel, os Green Bonds com vencimentos entre dez e 23 anos seriam os mais beneficiados.

De acordo com Zerbib (2019), os emissores com baixo rating ou do setor financeiro são os que mais se beneficiariam da expansão da base dos investidores e de seus Green Bonds, pois são os que obtiveram maior prêmio, segundo o resultado de suas análises.

Portanto, a recomendação para esses dois tipos de emissores é de que aumentem a emissão de Green Bonds para atender uma demanda que está disposta a pagar mais pelo prêmio, ou que tem sido muito maior que a oferta, comparativamente a outros setores.

O setor financeiro poderia aproveitar de seu maior prêmio e centralizar a captação de recursos mais baratos que seriam depois repassados para financiar os outros setores em que o prêmio verde é menor.

Os emissores deveriam também publicar relatórios pós-emissão que estejam alinhados aos compromissos feitos na emissão. Para os Green Bonds cujos recursos serão alocados a diversos projetos, por exemplo no caso de emissões de instituições financeiras, estas deveriam fornecer informações no âmbito de projetos. Da mesma forma, para os emissores recorrentes de Green Bonds, como os que 
promovem programas, os relatórios deveriam conter informações de cada bond e projeto.

Disponibilizar informações no âmbito de projetos pode ser desafiador para instituições financeiras que repassam os recursos ou as instituições multilaterais que desenvolvem programas. Uma sugestão colocada pela Climate Bonds Initiative (2019), para lidar com esse desafio, seria incorporar em relatórios ex ante os impactos esperados e incluí-los no processo de diligência para seleção de projetos.

Os impactos poderiam também ser reportados por amostragem ex post, como é feito para os Programas de Atividades (Programme of Action, PoA) sob o âmbito do MDL/Kyoto. De qualquer forma, no caso de portfólios diversificados, os relatórios com conteúdo setorial seriam mais úteis.

Quanto à disponibilização de relatórios, segundo a Climate Bonds Initiative (2019), em muitos casos os relatórios pós-emissão são produzidos pelos emissores, porém eles não são facilmente encontrados. Os emissores de Green Bonds poderiam criar páginas na internet dedicadas a publicar esse tipo de relatório e reportar com frequência adequada.

Para portfólios dinâmicos ou refinanciamentos, a periodicidade dos relatórios deveria ser anual. Obviamente a harmonização das métricas também melhorariam muito os relatórios.

As verificações externas também seriam bastante benéficas aos emissores, adicionando transparência e credibilidade aos relatórios. Estudos de Bachelet et al. (2019) concluíram que o prêmio verde é maior para os Green Bonds que passaram pelo processo de verificação externa.

No âmbito da gestão das organizações emissoras de Green Bonds, novos indicadores de performance relacionados com criação de valores compartilhados poderiam ser desenvolvidos de adotados, incluindo metas ambientais, sociais e de governança (ESG), em complemento aos indicadores financeiros.

Para alinhar a tomada de decisões aos indicadores ESG, se poderia atrelar a remuneração dos gestores a tais indicadores, o que indiretamente contribuiria para a performance dos projetos financiados pelos Green Bonds. 


\subsubsection{Governos e Bancos Centrais}

Antes mesmo de se mencionar os incentivos ao crescimento do mercado de Green Bonds que governos e bancos centrais poderiam proporcionar, é válido lembrar que, segundo a OECD (2017), não são muitos os governos que desenvolveram planos de desenvolvimento e investimento em infraestrutura verde que reflitam seus comprometimentos com um crescimento mais sustentável e consistente em relação a seus compromissos perante acordos internacionais. Esses planos para infraestrutura verde poderiam ser importantes motivadores do crescimento do mercado de Green Bonds.

Além dos incentivos relacionados a isenções de impostos ou emissão mais rápida de Green Bonds já mencionados anteriormente, os governos também poderiam atuar reduzindo as barreiras à publicação de relatórios pós-emissão. Estes poderiam patrocinar os custos de coleta de dados e preparo dos relatórios, assim como das auditorias de terceiros, principalmente para os pequenos emissores.

Um outro incentivo que os governos poderiam oferecer aos emissores de Green Bonds seria a depreciação mais rápida dos ativos financiados por Green Bonds.

Conforme sugerido pelo EU TEG (2019), bancos centrais poderiam, sem prejudicar princípios de neutralidade, promover um sistema financeiro mais verde por meio de preferência dada à compra de Green Bonds.

Monnin (2018) sugere as seguintes medidas para que bancos centrais contribuam com a transição para uma econômica de baixo carbono e, como consequência, com o desenvolvimento do mercado de Green Bonds:

- Expandir a base de conhecimentos sobre riscos sistêmicos relacionados ao clima por meio do desenvolvimento de testes de estresse no sistema financeiro. Com esse tipo de informação, os mercados financeiros serão capazes de precificar adequadamente os riscos climáticos, o que reduziria as distorções atuais na alocação de capital.

- Implementar maiores exigências de capital para empréstimos a setores intensivos em carbono, além de prover incentivos aos bancos que 
mudarem seus portfólios de empréstimos para atividades de baixo carbono.

- Mitigar o atual desvio na compra de grande escala de ativos em setores intensos em carbono, refletindo os riscos climáticos em suas decisões de compra. Tal mudança seria possível contanto que não reduzam a habilidade dos bancos centrais para atingir seus objetivos em termos de estabilidade de preços e atividade econômica. Deveriam também introduzir análises relacionadas ao clima nos critérios de elegibilidade e limites de colaterais que aceitam.

\subsubsection{Instituições Financeiras Multilaterais}

As instituições financeiras multilaterais, como o Banco Mundial, podem ter um papel importante de catalizadores na expansão e desenvolvimento do mercado de Green Bonds, assim como na definição e implementação de políticas públicas.

Autores como Karpf e Mandel (2018) e Zerbib (2019) efetuaram análises sobre os prêmios de Green Bonds e concluíram que a qualidade média do risco de crédito dos emissores destes tem uma forte influência no aparecimento do prêmio verde.

Uma parte importante da necessidade de recursos financeiros para mitigação e adaptação às mudanças climáticas deve vir de países menos desenvolvidos e de projetos pequenos, e estes têm em geral uma qualidade pior de crédito. A expansão do mercado de Green Bonds para emissores com essas características pode, desta forma, enfraquecer a existência do prêmio verde para os Green Bonds.

Uma solução proposta por Karpf e Mandel (2018) seria a distribuição dos riscos (pooling) em um portfólio de projetos, que poderiam ser financiados por meio da emissão de Green Bonds por instituições multilaterais. Estas já vêm fazendo isso, e existem limites para a expansão de seus balanços, o que demandaria a participação de instituições financeiras privadas desempenhando tal papel.

As instituições privadas, entretanto, possuem menos credibilidade e capacidade para atestar o desempenho ambiental dos projetos. Por isso, o 
desenvolvimento de sistemas de rating verde seria importante, segundo Karpf e Mandel.

O presente estudo acrescentaria que a implementação de um sistema MRV padronizado também ajudaria a endereçar as limitações das instituições financeiras privadas no que se refere a reportar a alocação de recursos e performance dos projetos financiados por Green Bonds.

O EU TEG (2019) sugere que garantias de crédito sejam oferecidas a emissores de Green Bonds que não tenham grau de investimento. Tal sugestão também foi colocada por Taghizadeh-Hesary e Yoshino (2019), tendo como fonte de recursos os impostos adicionais que a atividade econômica local adicional geraria aos governos locais (spillover effects), como no caso de energia renovável gerada localmente.

O EU TEG também sugere que sejam criados fundos dedicados à aquisição de Green Bonds nos lançamentos, além de um esquema que patrocinaria os custos adicionais da verificação externa para emissores menores.

\subsubsection{Organizações e Programas de Padronização}

A International Organization for Standardization (ISO) tem discutido, no âmbito da ISO 14030 e por meio de seus diversos comitês nacionais, a criação de um padrão internacional para Green Bonds. O E. U. Technical Expert Group on Sustainable Finance (EU TEG, 2019) também tem trabalhado em um padrão europeu para Green Bonds, que inclui taxonomia e benchmarks para a Europa.

Embora as orientações para os relatórios de emissão de Green Bonds já venham sendo discutidas há algum tempo no âmbito dos GBP (Green Bonds Principles) e estejam relativamente desenvolvidas, o mesmo não acontece para os relatórios pós-emissão. Seria importante, pelas razões anteriormente discutidas, que orientações, modelos e protocolos sejam desenvolvidos e padronizados para os relatórios pós-emissão.

O EU TEG recomenda a criação de um regime centralizado para acreditação de verificadores externos de Green Bonds, assim como um comitê de acreditação voluntário para um período de transição. 
De acordo com a Climante Bonds Initiative (2019), 85\% dos emissores de Green Bonds usam suas próprias metodologias ou não reportam as metodologias usadas em seus relatórios de impacto pós-emissão.

O desenvolvimento das taxonomias para Green Bonds sob o sistema europeu e o ISO 14030 é importante para endereçar as incertezas relacionadas a riscos reputacionais. O EU TEG (2019) também recomenda incluir despesas operacionais e capital de giro necessários para a manutenção de ativos verdes na taxonomia de Green Bonds.

\subsubsection{Provedores de Informações Financeiras}

Empresas como a Bloomberg e outros agentes poderiam contribuir com o aumento da atratividade dos Green Bonds por meio da disponibilização de mais informações, tais como a facilitação da identificação de Green Bonds nos terminais.

Até o fim desta pesquisa não era possível, por exemplo, encontrar informações sobre Green Bonds nos terminais da Bloomberg utilizando como critério de busca palavras-chave como "Green Bond". Estes só puderam ser encontrados nos terminais da Bloomberg por meio da compilação de Green Bonds emitidos, obtida a partir de outras fontes, como o Climate Bonds Initiative. A única informação que identifica os bonds como Green está contida no menu "Additional Information" da página descritiva de bonds nos terminais da Bloomberg.

\subsubsection{ONGs Ambientalistas}

As organizações não governamentais ambientalistas poderiam alavancar sua posição de isenção de conflitos de interesse ao contribuir com o desenvolvimento do mercado de Green bonds por meio de trabalhos de esclarecimento e divulgação deste tipo de instrumento financeiro à população em geral.

Poderiam motivar comportamentos altruístas ou criar pressão social (BRODBACK et al., 2018; DELLAVIGNA et al., 2012), o que poderia gerar um aumento da demanda primária por esse tipo de ativo (HONG \& KACPERCZYK, 2009; RIEDL \& SMEETS, 2017). 
As ONGs ambientalistas também poderiam atuar no monitoramento da performance social e ambiental dos projetos financiados por Green Bonds, ou ratificar e participar dos sistemas MRV que estão sendo discutidos.

\subsubsection{Academia}

Além de desempenhar seu papel na pesquisa e divulgação de informações sobre os Green Bonds e seu mercado, as instituições de pesquisa também poderiam contribuir com o desenvolvimento de metodologias, proxies e protocolos para monitoramento da performance dos Green Bonds.

Os mercados de créditos de carbono deixaram um legado de metodologias para monitoramento de redução da emissão de GEE em vários setores econômicos ${ }^{5}$, porém, poucas foram desenvolvidas para o setor agrícola, em que se tem grandes oportunidades de intervenção.

Os projetos relacionados ao consumo, tratamento e geração de água também precisam de metodologias padronizadas, assim como os projetos relacionados à adaptação às mudanças climáticas e à economia circular.

\subsubsection{Agências Reguladoras e Supervisoras do Mercado Financeiro}

O pequeno prêmio dos Green Bonds encontrado neste estudo é consistente em relação aos demais estudos sobre o tema e endereça preocupações sobre o aparecimento de uma bolha de ativos verdes, conforme levantadas pelo Banco Central Holandês (ZERBIB, 2019).

Agentes reguladores e supervisores podem desempenhar um papel crucial estabelecendo estruturas regulatórias que destravem o potencial do mercado de Green Bonds. Por exemplo, a Comissão Europeia trabalha para criar uma taxonomia para finanças sustentáveis, além de rótulos verdes para produtos financeiros baseados em tal classificação. Essas ações vão ajudar a estabelecer requerimentos precisos e, assim, simplificar o processo de aprovação de Green Bonds e desenvolver o mercado.

\footnotetext{
${ }^{5} \mathrm{Cf}$. https://cdm.unfccc.int/methodologies/index.html.
} 
Daszyńska-Żygadło et al. (2018) analisaram a volatilidade dos Green Bonds e concluíram que parece ser mais arriscado investir nesse tipo de ativo devido à alocação dos recursos em tecnologias que são ainda imaturas e possuem regulamentações incompletas.

Talvez tal percepção de maior risco seja um obstáculo para que o prêmio verde seja maior. Portanto, caberia às agências reguladoras em diversos países o papel de desenvolver novas regulamentações para setores ou atividades relativamente novas, que são consistentes em relação à taxonomia de Green Bonds e que contribuem com a transição para economias sustentáveis.

O EU TEG (2019) recomenda um regime de abertura de informações para investidores institucionais, como gestores de ativos, fundos de pensão e seguradoras. O regime proposto para a Europa é chamado comply or explain, ou cumpra ou explique, como o Artigo 173 (VI) do Decreto de Transição para o Crescimento Verde implementado na França.

O sistema financeiro europeu atualmente é um dos mais avançados do mundo no que se refere à sustentabilidade, e as propostas para esse sistema não podem ser igualmente implementadas em outros mercados.

A todos os agentes acima mencionados, também caberia a recomendação de promoverem os atributos não pecuniários dos Green Bonds de forma mais ampla e intensa, para que seja desenvolvida uma nova classe de investidores que tenha apreço e fidelidade a esse tipo de ativo, fazendo com que a demanda e o prêmio aumentem (FAMA \& FRENCH, 2007). 


\section{LIMITAÇÕES E SUGESTÕES PARA ESTUDOS FUTUROS}

Algumas análises quantitativas realizadas neste estudo, como por exemplo a formação do Green Halo, não têm ainda precedentes na literatura acadêmica, e assim podem conter imperfeições que ainda não foram amplamente discutidas e que podem ser aperfeiçoadas em estudos futuros.

Outra limitação do estudo é que o período utilizado para a coleta de dados pode ser considerado relativamente curto. De qualquer forma, as análises quantitativas aqui apresentadas podem ser consideradas como indicativas para que, no futuro, realizem-se estudos contendo um tempo de análise maior.

A amostragem de Green Bonds que se qualificam para a análise também pode ser considerada pequena em relação ao universo dos Green Bonds emitidos ou mesmo de bonds em geral. Pesquisas quantitativas mais rigorosas poderão ser feitas no futuro, quando mais Green Bonds forem emitidos e mais dados estiverem disponíveis.

Embora este documento liste os vários instrumentos de dívida que podem se qualificar como Green Bonds, o presente estudo não inclui todos os instrumentos de dívida listados.

A pesquisa tão pouco inclui Green Bonds municipais, por não existirem funções disponíveis nos terminais da Bloomberg que permitam a listagem dos bonds comparáveis do mesmo emissor. Existem também diferenças de tributação de ganhos segundo o município emissor e que dificultam a comparação em relação aos demais Green Bonds. Um estudo específico sobre Green Bonds municipais foi feito por Karpf e Mandel (2018).

Também não foram incluídos nesta análise títulos baseados em ativos (assetbacked securities), por serem na maioria dos casos emitidos em várias parcelas (tranches) e, portanto, não são comparáveis aos bonds analisados neste trabalho.

Não fazia parte do escopo deste estudo análises para avaliar o impacto de alguns fatores como rating no lançamento, setor, país, vencimento, certificações ou outros na performance dos Green Bonds. Os outros sete estudos que analisaram a 
performance de Green Bonds e que foram mencionados na discussão de resultados deste documento fizeram esse tipo de análise.

As limitações das análises realizadas suportam a escolha do método do estudo de caso para este trabalho, o qual possui caráter exploratório e indica alguns parâmetros e análises que podem ser realizadas com mais precisão no futuro, quando mais dados estiverem disponíveis.

\subsection{Sugestões para Estudos Futuros}

As sugestões para estudos futuros mencionados a seguir são decorrentes principalmente das limitações encontradas no presente estudo.

Seria interessante avaliar o comportamento dos Green Bonds vis-à-vis às respectivas curvas de rendimentos de seus emissores em períodos mais longos, de aumento de juros pelos bancos centrais e aumento dos spreads entre bonds corporativos e soberanos.

Nos cenários de aumento juros e caso as curvas de rendimentos se distanciem dos rendimentos dos Green Bonds, estes poderiam se consolidar como uma categoria de ativos defensivos e de proteção de rendimentos.

A União Europeia e os comitês nacionais para o desenvolvimento e gestão de normas ISO (14030) estão atualmente discutindo a taxonomia para qualificação e caracterização de Green Bonds, assim como os mecanismos de MRV padronizados para a performance desses.

Quando os procedimentos e padronizações forem mais amplamente adotadas pelos emissores de Green Bonds, possivelmente estarão disponíveis mais dados que permitirão análises mais detalhadas e sofisticadas do que as feitas no presente estudo.

Se os procedimentos padronizados para se reportar a performance dos projetos forem amplamente adotados, será possível observar com mais precisão se o mercado está disposto a manter o prêmio verde no mercado secundário por conta da diferenciação continuada dos Green Bonds. 
Seria também importante pesquisar a reação da performance dos Green Bonds mediante situações de estresse nos mercados financeiros para checar a hipótese de que os Green Bonds se comportam como ativos de proteção. 


\section{GLOSSÁRIO}

Acordo de Paris (2015): é atualmente o acordo internacional mais importante para que o aquecimento global e as mudanças climáticas sejam minimizados ou mitigados. O acordo foi negociado durante a Conferência das Partes (COP21) das Nações Unidas, realizada em Paris em 2015. Os países signatários do Acordo de Paris se comprometeram voluntariamente com a redução de emissões em diversos setores da economia.

CER (Certified Emission Reduction) ou RCE (Redução Certificada de Emissões): uma unidade emitida para redução de GEE de projetos ou programas do MDL, de acordo com as regras e requerimentos do $\mathrm{MDL}$, que equivale a uma tonelada métrica de dióxido de carbono, calculada usando o potencial de aquecimento global definida pela decisão 2/CP.3 ou as revisões subsequentes de acordo com o Artigo 5 do Protocolo de Kyoto (UNFCCC, 2018d e 2018b).

Climate Bonds: certificação para Green Bonds (CBI, 2008).

CND (Contribuições Nacionalmente Determinadas): o Acordo de Paris requer que todas as Partes signatárias se comprometam com seus melhores esforços para a redução da emissão de GEE e a adaptação às mudanças climáticas por meio de Contribuições Nacionalmente Determinadas (CNDs) e que fortaleçam esses esforços nos anos a seguir. Isso inclui requerimentos de que todas as Partes reportem regularmente suas emissões e esforços implementados para reduzi-las (UN, 2015b).

Colaterais ou Garantias (bond): regras que especificam os direitos do investidor e as obrigações do emissor (do bond). São identificados alguns tipos de colaterais: de ativos, de dividendos e financeiros. Nem todos os tipos são incluídos em cada bond (GRINBLATT \& TITMAN, 1998).

Crédito de Carbono: é um tipo de commodity criada na forma de redução ou remoção de emissões de GEE. Uma vez que o dióxido de carbono $\left(\mathrm{CO}_{2}\right)$ é o principal gás de efeito estufa, usa-se apenas carbono para se referir a GEE. A 
negociação de emissões de GEE permite que países, empresas ou outras entidades que possuem excedente de redução de emissões de GEE vendam este excesso a outros que precisam deste para compensar suas emissões. As negociações de redução de GEE ou de carbono formam o que se chama de mercado de carbono (UNFCCC, 2018a).

Duration (bond): também chamada de Macaulay duration, é a média ponderada de tempo até que os fluxos fixos de caixa de um ativo financeiro, como um bond, sejam recebidos. Quando o preço de um ativo é função do rendimento, o termo também pode ser interpretado como a sensibilidade do preço em relação a variações no rendimento (GRINBLATT \& TITMAN, 1998).

Duration Modificada (bond): é o nome dado à sensitividade do preço, trata-se da porcentagem da mudança no preço por unidade de mudança no rendimento (yield). Pode ser aplicada a instrumentos cujos fluxos de caixa não são fixos, enquanto a duration de Macaulay pode ser aplicada apenas a instrumentos com fluxos de caixa fixos. É definida como a derivada logarítmica do preço em relação ao rendimento, e pode ser aplicada a instrumentos cujos preços dependam do rendimento, tenham eles fluxos de caixa fixos ou não (BREALEY, MYERS \& ALLEN, 2011).

EU ETS (European Union Emissions Trading System): a União Europeia se comprometeu a reduzir as emissões de GEE de setores relevantes e criou um mercado regulado para alocações de carbono (ou emissões de GEE), as EUAs, e chamou o sistema de Sistema da União Europeia de Negociação de Emissões (EU, 2018).

GEE (Gases de [ou que causam] Efeito Estufa): gases integrantes da atmosfera, de origem natural ou antrópicos (produzidos pelo homem), que absorvem e reemitem radiação infravermelha para a superfície da Terra e para a atmosfera, causando o efeito estufa. $\mathrm{O}$ vapor de água $\left(\mathrm{H}_{2} \mathrm{O}\right)$, o dióxido de carbono ou gás carbônico $\left(\mathrm{CO}_{2}\right)$, o óxido nitroso $\left(\mathrm{N}_{2} \mathrm{O}\right)$, o metano $\left(\mathrm{CH}_{4}\right)$ e o ozônio $\left(\mathrm{O}_{3}\right)$ são os principais GEE na atmosfera. Existem também GEE totalmente produzidos por atividades humanas, como os halo carbonetos e outras substâncias com cloro e bromo, objetos do Protocolo de Montreal. O Protocolo de Kyoto também aborda o hexafluoreto de enxofre $\left(\mathrm{SF}_{6}\right)$, além de duas famílias de gases: os hidrofluorocarbonetos (HFC) e os 
perfluorcarbonetos (PFC). Entre os gases do efeito estufa que estão aumentando em concentração, o dióxido de carbono, o metano e o óxido nitroso são os mais importantes. $\mathrm{O} \mathrm{CO}_{2}$ contribui mais para o aquecimento, uma vez que representa $55 \%$ do total das emissões mundiais de gases do efeito estufa. O tempo de sua permanência na atmosfera é, no mínimo, de cem anos, com impactos no clima ao longo de séculos. Já a quantidade de metano emitida é bem menor, mas seu potencial de aquecimento é 21 vezes superior ao do $\mathrm{CO}_{2}$. No caso do óxido nitroso e dos clorofluorcarbonetos (CFC), suas concentrações são ainda menores, mas o poder de estufa é, respectivamente, de 310 e 6.200-7.100 vezes maior do que o do CO2 (UN, 1998).

Green Bonds: são quaisquer tipos de títulos de dívida cujos recursos serão exclusivamente aplicados para financiar ou refinanciar em parte ou a totalidade de projetos verdes elegíveis, novos ou existentes (CBI, 2008).

MDL (Mecanismo do Desenvolvimento Limpo): é um mecanismo sob o Protocolo de Kyoto cujo propósito é, de acordo com o Artigo 12, ajudar as Partes que não fazem parte do Anexo I a atingir o desenvolvimento sustentável e contribuir para o objetivo final da convenção, bem como auxiliar as Partes Anexo I a atingir suas metas mandatórias de limitação e redução de emissões de GEE sob o Artigo 3 do Protocolo de Kyoto (UNFCCC, 2018b; TOL, 2018).

\section{Objetivos do Desenvolvimento Sustentável da ONU ou Sustainable}

Development Goals: definidos no âmbito da ONU e de adesão voluntária por todos os países membros dela, visam obter um futuro melhor e mais sustentável para todos. Endereçam os desafios que a humanidade atualmente enfrenta, incluindo aqueles relacionados a pobreza, desigualdade, clima, degradação ambiental, prosperidade, paz e justiça. Os objetivos estão interconectados e, para que nenhum fique para trás, é importante que se atinja cada um deles até 2030 . No total foram estabelecidos dezessete objetivos.

Partes Anexo I do Protocolo de Quioto: as Partes incluídas no Anexo I do Protocolo de Kyoto se referem a países desenvolvidos que devem possuir limitações ou reduções de GEE não controlados pelo Protocolo de Montreal ou emitidos pela aviação civil internacional ou pela navegação marítima internacional (UN, 1998). 
Rating (bond): uma sequência de letras e números que especificam o risco de crédito de um bond e/ou do emissor de bonds no mercado de capitais, levando em consideração garantias e colaterais. Normalmente é atribuído por agências como Fitch, Moody's e Standard \& Poor's. O sistema de rating permite identificar os bonds que são considerados especulativos. Por exemplo, para a Standard \& Poor's e Fitch, o rating abaixo de BBB- denomina bonds de grau especulativo, com maiores riscos de inadimplência. Acima desse rating, os bonds são considerados como de grau de investimento, com menor risco (GRINBLATT \& TITMAN, 1998).

Spread: na área de finanças, refere-se às diferenças entre preços ou rendimentos (yields) de dois investimentos ou ativos diferentes, normalmente de maturidade semelhante. Normalmente indicam o prêmio de risco de um ativo em relação ao outro (GRINBLATT \& TITMAN, 1998).

Vanilla Bonds: neste documento, o termo é utilizado para se referir a bonds tradicionais, não green, cuja aplicação dos recursos financeiros obtidos com a emissão não se destinam exclusivamente a projetos ambientais (GRINBLATT \& TITMAN, 1998).

YMT (Yield to Maturity) (bond): é a taxa de desconto que faz o valor descontado dos futuros pagamentos de um bond se igualar ao preço de mercado de tal bond (GRINBLATT \& TITMAN, 1998). 


\section{REFERÊNCIAS BIBLIOGRÁFICAS}

AKHIGBE, Aigbe; EASTERWOOD, John C.; PETTIT, R. Richardson. (1997). "Wealth Effects of Corporate Debt Issues: The Impact of Issuer Motivations". In: Financial Management, vol. 26, no. 1, Spring 1997, pp. 32-47.

ANDERSON, David R.; SWEENEY, Dennis J.; WILLIAMS, Thomas A. (2013). Estatística Aplicada à Administração e Economia. São Paulo, Cengage Learning, 2013.

ANDERSON, Terry L.; PARKER, Dominic P. (2013). "Transaction Costs and Environmental Markets: the Role of Entrepreneurs". In: Review of Environmental Economics and Policy, vol. 7, no. 2, Summer 2013, pp. 259275.

BACHELET, Maria J.; BECCHETTI, Leonardo; MANFREDONIA, Stefano. (2019). "The Green Bonds Premium Puzzle: the Role of Issuer Characteristics and Third-Party Verification". In: Sustainability, vol. 11, no. 4, 1098, fev. 2019, pp. $1-22$.

BAKER, Malcolm; BERGSTRESSER, Daniel; SERAFEIM, George; WURGLER, Jeffrey. (2018). "Financing the Response to Climate Chage: the Pricing and Ownership of U.S. Green Bonds". In: The National Bureau of Economic Research, working paper no. 25194, out. 2018. Disponível em: http://www.nber.org/papers/w25194. Acesso em: 24 jun. 2019.

BARDIN, Laurence. (2011). Análise de Conteúdo. Lisboa, Edições 70, 2011.

BEDEIAN, Arthur G. (2013). "More than Meets the Eye': a Guide to Interpreting the Descriptive Statistics and Correlation Matrices Reported in Management Research". In: The Academy of Management Learning and Education, vol. 13, no. 1 , ago. 2013 , pp. 121-135.

BNDES (Banco Nacional de Desenvolvimento Econômico e Social). (2018). Green Bond: Relatório Anual 2018. Rio de Janeiro, BNDES, 2018. Disponível em: https://www.bndes.gov.br/wps/wcm/connect/site/fcf2cc93-21fa-41cd-9882-fbff be68ebe6/relatorio-anual-green-bond-2018.pdf?MOD=AJPERES\&CVID=mco pFPt. Acesso em: 24 jun. 2019.

BREALEY, Richard A.; MYERS, Stewart C.; ALLEN, Franklin. (2011). Principles of Corporate Finance. 10a. ed. Nova York: McGraw-Hill Irwin, 2011, pp. 50-53.

BROADSTOCK, David C.; CHENG, Louis T. W. (2019). "Time-varying Relation Between Black and Green Bond Price Benchmarks: Macroeconomic Determinants for the First Decade". In: Finance Research Letters, vol. 29, jun. 2019, pp. 17-22. 
BRODBACK, Daniel; GUENSTER, Nadja; MEZGER, David. (2018). "Altruism and Egoism in Investment Decisions". In: Working Paper, 4 jun. 2018. Disponível em: https://papers.ssrn.com/sol3/papers.cfm?abstract id=2978660. Acesso em: 8 jul. 2019.

BUCHANAN, James M.; STUBBLEBINE, Wm. Craig. (1962). "Externality". In: Economica, vol. 29, no. 116, nov. 1962, pp. 371-384.

BUSHNELL, James; PETERMAN, Carla; WOLFRAM, Catherine. (2008). "Local Solutions to Global Problems: Climate Change Policies and Regulatory Jurisdiction". In: Review of Environmental Economics and Policy, vol. 2, no. 2, Summer 2008, pp. 175-193.

CBI (Climate Bonds Initiative). (2008). "Climate Bonds Standard \& Certification Scheme". Ver. 2.1, mar. 2008. Disponível em https://www.climatebonds.net/ files/files/Climate $\% 20$ Bonds $\% 20$ Standards $\% 20$ and $\% 20$ Certification $\% 20$ Sche me\%20Brochure\%202018.pdf. Acesso em: 1 abr. 2018.

. (2017). "Post-issuance Reporting in the Green Bond Market". 28 jun. 2017. Disponível em: https://www.climatebonds.net/files/files/UoP FINAL 120717. pdf. Acesso em: 16 mar. 2019.

. (2018). "Bonds and Climate Change: The State of the Market 2018". Set. 2018. Disponível em: https://www.climatebonds.net/system/tdf/reports/cbi sot m 2018 final 01k-web.pdf?file=1\&type=node\&id=34941\&force=1. Acesso em: 1 abr. 2018.

. (2019). "Green Bond Pricing in the Primary Market: July - December 2018". H1 (Q1-Q2) 2018, maio 2019. Disponível em https://www.climatebon ds.net/files/reports/cbi gb_pricing 2h2018 08052019.pdf. Acesso em: 1 abr. 2018.

CHERNEV, Alexander; BLAIR, Sean. (2015). "Doing Well by Doing Good: the Benevolent Halo of Corporate Social Responsibility". In: Journal of Consumer Research, vol. 41, no. 6, abr. 2015, pp. 1412-1425.

COASE, Ronald H. (1937). "The Nature of the Firm". In: Economica, vol. 4, no. 16, nov. 1937, pp. 386-405. Disponível em: https://onlinelibrary.wiley.com/doi/ epdf/10.1111/j.1468-0335.1937.tb00002.x. Acesso em: 9 jul. 2019.

. (1960). "The Problem of Social Cost". In: The Journal of Law and Economics, vol. 3, out. 1960, pp. 1-44. Disponível em: https://www.law.uchica go.edu/files/file/coase-problem.pdf. Acesso em: 9 jul. 2019.

COOPER, Donald R.; SCHINDLER, Pamela S. (2015). Métodos de pesquisa em Administração. São Paulo, Editora McGraw-Hill, 2015.

CUI, Lianbiao; HUANG, Yuran. (2018). "Exploring the Schemes for Green Climate Fund Financing: International Lessons". In: World Development, vol. 101, jan. 2018, pp. 173-187. 
DASZYŃSKA-ŻYGADŁO, Karolina; MARSZAŁEK, Jakub; PIONTEK, Krzysztof. (2018). "Sustainable Finance Instruments' Risk: Green Bond Market Analysis". In: European Financial Systems 2018 - Proceedings of the 15th International Scientific Conference. Brno, Masaryk University, 2018. Disponível em: https:// www.researchgate.net/publication/327552216 SUSTAINABLE FINANCE IN STRUMENTS' RISK - GREEN BOND MARKET ANALYSIS/link/5b9647ab 299bf14739391c6d/download. Acesso em: 9 jul. 2019.

DELLAVIGNA, Stefano; LIST, John A.; MALMENDIER, Ulrike. (2012). "Testing for Altruism and Social Pressure in Charitable Giving". In: The Quarterly Journal of Economics, vol. 127, no. 1, fev. 2012, pp. 1-56.

DUFFEE, Gregory R. (1998). "The Relation Between Treasury Yields and Corporate Bond Yield Spreads". In: The Journal of Finance, vol. 53, no. 6, dez. 1998, pp. 2225-2241.

EHLERS, Torsten; PACKER Frank. (2017). "Green Bond Finance and Certification". In: Bank for International Settlement Quarterly Review, set. 2017, pp. 89-104. Disponível em: https://www.bis.org/publ/qtrpdf/r qt1709h.pdf. Acesso em: 10 jul. 2019.

EISENHARDT, Kathleen M. (1989). "Building Theories from Case Study Research". In: The Academy of Management Review, vol. 14, no. 4, out. 1989, pp. 532550. Disponível em: https://www.jstor.org/stable/pdf/258557.pdf?refreqid=exc elsior\%3A41a242e167130f591e831af46f18e449. Acesso em: 9 jul. 2019.

; GRAEBNER, Melissa E. (2007). "Theory Building from Cases, Opportunities and Challenges". In: Academy of Management Journal, vol. 50, no. 1 , fev. 2007, pp. 25-32.

EUROPEAN COMMISSION. (“2018”). “EU Action”. Disponível em: https://ec.eu ropa.eu/clima/policies/ets/pre2013 en. Acesso em: 11 maio 2018.

EU TEG (European Union Technical Expert Group on Sustainable Finance). (2019). "Report of the Technical Expert Group (TEG) Subgroup on Green Bond Standard: Proposal for an EU Green Bond Standard". Green Bond Standard Subgroup, 6 mar. 2019. Disponível em: https://ec.europa.eu/info/sites/info/ files/business economy euro/banking and finance/documents/190306-sustai nable-finance-teg-int erim-report-green-bond-standard en 0.pdf. Acesso em: 10 jun. 2019.

FAMA, Eugene F.; FRENCH, Kenneth R. (2007). "Disagreement, Tastes, and Asset Prices". In: Journal of Financial Economics, vol. 83, no. 3, mar. 2007, pp. 667689.

FEBI Wulandari; SCHÄEFER, Dorothea; STEPHAN, Andreas; SUN, Chen. (2018). "The Impact of Liquidity Risk on the Yield Spread of Green Bonds". In: Finance Research Letters, vol. 27, dez. 2018, pp. 53-59.

FLAHERTY, Michael; GEVORKYAN, Arkady; RADPOUR, Siavash; SEMMLER, Willi. (2017). "Financing Climate Policies Through Climate Bonds: a Three Stage 
Model and Empirics". In: Research in International Business and Finance, vol. 42, dez. 2017, pp. 468-479.

FRIEWALD, Nils; JANKOWITSCH, Rainer; SUBRAHMANYAM Marti G. (2012). "Illiquidity or Credit Deterioration: a Study of Liquidity in the U.S. Corporate Bond Market During Financial Crises". In: Journal of Financial Economics, vol. 105, no. 1, jul. 2012, pp. 18-36.

GABRIEL, Marcelo Luiz D. (2014). "Métodos Quantitativos em Ciências Sociais: Sugestões para Elaboração do Relatório de Pesquisa". In: Desenvolvimento em Questão, ano 12, no. 28, Unijuí, out.-dez. 2014, pp. 348-369.

GE, Wenxia; LIU, Mingzhi. (2015). "Corporate Social Responsibility and the Cost of Corporate Bonds". In: Journal of Accounting and Public Policy, vol. 34, no. 6, nov.-dez. 2015, pp. 597-624.

GEPHART, Robert P. (2004). "Qualitative Research and the Academy of Management Journal". In: The Academy of Management Journal, vol. 47, no. 4, ago. 2004, pp. 454-462.

GIANFRATE, Gianfranco; PERI, Mattia. (2019). "The Green Advantage: Exploring the Convenience of Issuing Green Bonds". In: Journal of Cleaner Production, vol. 219, maio 2019, pp. 127-135.

GOULDER, Lawrence H.; PARRY, lan W. H. (2008). "Instrument Choice in Environmental Policy". In: Review of Environmental Economics and Policy, vol. 2, no. 2, Summer 2008, pp. 152-174.

GRINBLATT, Mark; TITMAN, Sheridan. (1998). Financial Markets and Corporate Strategy. Nova York, McGraw-Hill Irwin, 1998.

HACHENBERG, Britta; SHIERECK, Dirk. (2018). "Are Green Bonds Priced Differently from Conventional Bonds?". In: Journal of Asset Management, vol. 19, no. 6, Palgrave Macmillan, out. 2018, pp. 371-383.

HONG, Harrison; KACPERCZYK, Marcin. (2009). "The Price of Sin: the Effects of Social Norms on Markets". In: Journal of Financial Economics, vol. 93, no. 1, jul. 2009, pp. 15-36.

HORSCH, Andreas; RICHTER, Sylvia. (2017). "Climate Change Driving Financial Innovation: the Case of Green Bonds". In: The Journal of Structured Finance, vol. 23, no. 1, Spring 2017, pp. 79-90.

ICMA (International Capital Markets Association). (2018). Green Bond Principles: Voluntary Process Guidelines for Issuing Green Bonds, June 2018. Paris, ICMA, 2018. Disponível em: https://www.icmagroup.org/assets/documents/Reg ulatory/Green-Bonds/June-2018/Green-Bond-Principles---June-2018-140618WEB.pdf. Acesso em: 24 jun. 2019. 
KARPF, Andreas; MANDEL, Antoine. (2018). "The Changing Value of the 'Green' Label on the U. S. Municipal Bond Market". In: Nature Climate Change, vol. 8, fev. 2018, pp. 161-165.

KEOHANE, Nathaniel O. (2009). "Cap and Trade, Rehabilitated: Using Tradable Permits to Control U. S. Greenhouse Gases". In: Review of Environmental Economics and Policy, vol. 3, no. 1, Winter 2009, pp. 42-62.

LINDENBERG, Nannette. (2014). "Definition of Green Finance". In: German Development Institute, abr. 2014. Disponível em: https://www.cbd.int/financial/ gcf/definition-greenfinance.pdf. Acesso em: 10 maio 2018.

MARÓSTICA, Sandro Teixeira. (2019). "Dados sobre bonds e Green Bonds coletados no terminal Bloomberg, de 31 de maio de 2018 a 31 do março de 2019", ago. 2019. Disponível em: https://sites.google.com/usp.br/planilhasmarostica-2019. Acesso em: 9 de agosto de 2019.

MATHEWS, John Alwyn; KIDNEY, Sean. (2012). "Financing Climate-friendly Energy Development Through Bonds". In: Development Southern Africa, vol. 29, no. 2, pp. 337-349.

McINERNEY, Celine; JOHANNSDOTTIR, Lara. (2016). "Lima Paris Action Agenda: Focus on Private Finance - Note from COP21". In: Journal of Cleaner Production, vol. 126, jul 2016, pp. 707-710.

MIHÁLOVITS, Zsolt; TAPASZTI, Attila. (2018). "Green Bond, the Financial Instrument that Supports Sustainable Development: Opportunities and Barriers". In: Public Finance Quarterly, vol. 63, no. 3, State Audit Office of Hungary, 2018, pp. 303-318.

MILLENNIUM ECOSYSTEM ASSESSMENT. (2005). Ecosystems and Human wellbeing. Washington, Island Press, 2005. Disponível em: https://www.millennium assessment.org/documents/document.356.aspx.pdf. Acesso em: 6 abr. 2017.

MONASTEROLO, Irene; RABERTO, Marco. (2018). "The EIRIN Flow-of-funds Behavioral Model of Green Fiscal Policies and Green Sovereign Bonds". In: Ecological Economics, vol. 144, fev. 2018, pp. 228-243.

MONNIN, Pierre. (2018). Central Banks and the Transition to a Low Carbon Economy. Zurique, Council on Economic Policy, 2018. Disponível em: https://www.cepweb.org/wp-content/uploads/2018/03/CEP-DN-Central-Banksand-the-Transition-to-a-Low-Carbon-Economy.pdf. Acesso em: 10 jun. 2019.

MURADIAN, Roldan; CORBERA, Esteve; PASCUAL Unai; KOSOY, Nicolás; MAY, Peter H. (2010). "Reconciling Theory and Practice: an Alternative Conceptual Framework for Understanding Payments for Environmental Services". In: Ecological Economics, vol. 69, no. 6, abr. 2010, pp. 1202-1208.

NG, Thiam Hee; TAO, Jacqueline Yujia. (2016). "Bond Financing for Renewable Energy in Asia”. In: Energy Policy, vol. 95, ago. 2016, pp. 509-517. 
OECD (Organisation for Economic Co-operation and Development). (2017). Investing in Climate, Investing in Growth. Paris, OECD Publishing, 2017. Disponível em: http://www.oecd.org/env/investing-in-climate-investing-in-growth-97892642735 28-en.htm. Acesso em: 9 jul. 2019.

OIKONOMOU, Ioannis; BROOKS, Chris; PAVELIN, Stephen. (2014). "The Effects of Corporate Social Performance on the Cost of Corporate Debt and Credit Ratings". In: The Financial Review, vol. 49, no. 1, fev. 2014, pp. 49-75.

PAGE, Douglas. (2008). "Systematic Literature Searching and the Bibliographic Database Haystack". In: The Electronic Journal of Business Research Methods, vol. 6, no. 2, jan. 2008, pp. 171-180. Disponível em: http://www. ejbrm.com/issue/download.html?idArticle=195. Acesso em: 9 jul. 2019.

PATTANAYAK, Subhrendu K.; WUNDER, Sven; FERRARO, Paul J. (2010). "Show Me the Money: Do Payments Supply Environmental Services in Developing Countries?" In: Review of Environmental Economics and Policy, vol. 4, no. 2, Summer 2010, pp. 254-274.

PETTICREW, Mark; ROBERTS, Helen. (2006). Systematic Reviews in the Social Sciences: a Practical Guide. Nova Jersey, Wiley-Blackwell, 2006.

PHAM, Linh. (2016). "Is It Risky to Go Green?: a Volatility Analysis of the Green Bond Market". In: Journal of Sustainable Finance \& Investment, vol. 6, no. 4, maio 20166, pp. 263-291.

PIGOU, Arthur C. (1932). The Economics of Welfare. Londres, Palgrave Macmillan, 1932.

RIEDL, Arno; SMEETS, Paul. (2017). "Why do Investors Hold Socially Responsible Mutual Funds?". In: The Journal of the American Finance Association, vol. 72, no. 6 , pp. $2505-2550$.

SACHS, Jeffrey D. (2015). "Climate Change and Intergenerational Well-being". In: BERNARD, Lucas; SEMMLER, Willi (eds.). The Oxford Handbook of the Macroeconomics of Global Warming. Oxford, Oxford University Press, 2015, pp. 248-259.

SCHMALENSEE, Richard; STAVINS, Robert N. (2017). "Lessons Learned from Three Decades of Experience with Cap and Trade". In: Review of Environmental Economics and Policy, vol. 11, no. 1, Winter 2017, pp. 59-79.

SERRA, Fernando A. Ribeiro; COSTA, Lenise S. Vasconcelos; FERREIRA, Manuel Portugal. (2007). "Estudo de Caso em Pesquisa de Estratégia: Aspectos Fundamentais de Projeto de Investigação". In: Revista Angrad, vol. 8, no. 2, abr.-jun. 2007, pp. 169-182.

TAGHIZADEH-HESARY, Farhad; YOSHINO, Naoyuki. (2019). "The Way to Induce Private Participation in Green Finance and Investment". In: Finance Research Letters, vol. 31, dez. 2019, pp. 98-103. 
TEEB (The Economics of Ecosystems and Biodiversity). (2010). Mainstreaming the Economics of Nature: a Synthesis of the Approach, Conclusions and Recommendations of TEEB. Nairobi, Unep, 2010. Disponível em: http://doc. teebweb.org/wp-content/uploads/Study\%20and\%20Reports/Reports/Synthesi s\%20report/TEEB\%20Synthesis\%20Report\%202010.pdf. Acesso em: 6 abr. 2017.

TOL, Richard S. J. (2018). "The Economic Impacts of Climate Change". In: Review of Environmental Economics and Policy, vol. 12, no. 1, Winter 2018, pp. 4-25.

TRANFIELD, David; DENYER, David; SMART, Palminder. (2003). “Towards a Methodology for Developing Evidence-informed Management Knowledge by Means of Systematic Review". In: British Journal of Management, vol. 14, no. 3, pp. 207-222.

UN (United Nations). (1998). "Kyoto Protocol to the United Nations Framework Convention on Climate Change", 1998. Disponível em: https://unfccc.int/reso urce/docs/convkp/kpeng.pdf\#page:12. Acesso em: 15 abr. 2018.

. (2015a). "About the Sustainable Development Goals", 2015. Disponível em: $\quad$ https://www.un.org/sustainabledevelopment/sustainable-developmentgoals/. Acesso em: 29 maio 2019.

. (2015b). "Paris Agreement", 2015. Disponível em: https://unfccc.int/sites/ default/files/english paris agreement.pdf. Acesso em: 15 abr. 2017.

UNFCCC (The United Nations Framework Convention on Climate Change). (“2018"a). "CDM Registry". Disponível em: http://cdm.unfccc.int/Registry/index. html. Acesso em: 4 jan. 2018.

. ("2018"b). "What is the CDM". Disponível em: https://cdm.unfccc.int/about/ index.html. Acesso em: 15 abr. 2018.

. (“2018"c). "Emissions Trading". Disponível em: https://unfccc.int/process/ the-kyoto-protocol/mechanisms/emissions-trading. Acesso em: 15 abr. 2018.

. ("2018"d). "Glossary: CDM Terms". Ver 09.1. Disponível em: https://cdm. unfccc.int/Reference/Guidclarif/glos CDM.pdf. Acesso em: 15 abr. 2018.

VATN, Arild. (2010). "An Institutional Analysis of Payments for Environmental Services". In: Ecological Economics, vol. 69, no. 6, abr. 2010, pp. 1245-1252.

WARGA, Arthur D. (1991). "Corporate Bond Price Discrepancies in the Dealer and Exchange Markets". In: The Journal of Fixed Income, vol. 1, no. 3, Winter 1991, pp. 7-16.

WORLD BANK GROUP (2017). State and Trends of Carbon Pricing 2017. Washington, World Bank Group, 2017. Disponível em: http://documents. worldbank.org/curated/en/468881509601753549/State-and-trends-of-carbon-p ricing-2017. Acesso em: 1 abr. 2018. 
WUNDER, Sven. (2005). Payments for Environmental Services: Some Nuts and Bolts. CIFOR Occasional Paper no. 42. Jakarta, Center for International Forestry Research, 2005. Disponível em: https://www.cifor.org/publications/ pdf files/OccPapers/OP-42.pdf. Acesso em: 9 jul. 2019.

; ENGEL, Stefanie; PAGIOLA, Stefano. (2008). "Taking Stock: a Comparative Analysis of Payment for Environmental Services Programs in Developed and Developing Countries". In: Ecological Economics, vol. 65, no. 4, maio 2008, pp. 834-852.

YIN, Robert K. (2003). Estudo de Caso: Planejamento e Métodos. Tradução de Daniel Grassi. Porto Alegre, Bookman, 2003.

ZERBIB, Olivier David. (2019). "The Effect of Pro-environmental Preferences on Bond Prices: Evidence from Green Bonds". In: Journal of Banking and Finance, vol. 98, jan. 2019, pp. 39-60. 